\title{
Taxonomic studies of the tribe Potentilleae (Rosaceae) in Korea
}

\author{
Kyeong-In HEO, Sangryong LEE ${ }^{1}$, Yongsung KIM, Jongsun PARK* and Sangtae LEE * \\ InfoBoss Co., Ltd., and InfoBoss Research Center, Seoul 06088, Korea \\ ${ }^{1}$ Botanical Gardens, Tohoku University, Aoba, Sendai 980-0682, Japan \\ ${ }^{2}$ Department of Biological Sciences, Sungkyunkwan University, Suwon 16419, Korea \\ (Received 8 January 2019; Revised 25 March 2019; Accepted 28 March 2019)
}

\begin{abstract}
We conducted taxonomical investigations based on morphological characteristics, fruit morphology, and literature research on the tribe Potentilleae (Rosaceae) in Korea covering seven genera and 24 species. The style position on the ovary and the shape of style were useful characteristics for the classification of subtribal and generic levels in the tribe Potentilleae. The subtribe Fragariinae is characterized by subbasal or lateral style on the ovary and anthers with one theca. The subtribe Potentillinae has a subterminal style on the ovary, except for Argentina, which presents a subterminal and lateral style and anthers with two thecae. These results support the recent taxonomic recognition that i) the tribe Potentilleae consists of two subtribes, and ii) genera such as Dasiphora, Comarum, and Sibbaldianthe sometimes included in Potentilla s.l. are treated as independent genus. In the subtribe Potentillinae, Argentina, which has been treated as Potentilla, is supported as a distinct genus according to the characteristics of the subterminal and lateral style position and the ventral stipular auricles. In Fragaria, F. nipponica subsp. chejuensis, which has generally small leaves and a limited distribution only on Hallasan Mt., is supported by treatment as an endemic species. Duchesnea chrysantha is distinguished from $D$. indica by the characteristics of light green or yellowish green leaves, thin and somewhat membranous leaflets, and broad ovate or obovate leaflets. Each complex of $P$. dickinsii and $P$. chinensis remains unresolved with regard to controversy over the taxonomic circumscription due to their external morphological variations. Additional taxonomical research and molecular population studies are required for a more in-depth understanding of the tribe Potentilleae in Korea.
\end{abstract}

Keywords: tribe Potentilleae, subtribe Potentillinae, subtribe Fragariinae, morphological characters, fruit sculpture

장미과(Rosaceae Juss.)의 양지꽃족(tribe Potentilleae Sweet)은 전 세계에 약 19속 1,000-1,700여종 알려져 있으 며, 주로 북반구 온대와 한대 지역에 분포하고, 남반구에 는 소수의 종만이 분포한다(Ohwi, 1965; Shah and Wilcock, 1993; Morgan et al. 1994; Eriksen, 1996; Leht, 1996, 1997; Eriksson et al., 1998; Li et al., 2003; Naruhashi, 2003; Soják, 2004, 2008a). 분자분류학적 연구결과 장미아 과 내에서 양지꽃족의 단계통은 잘 지지되었으며(Potter et al., 2007), 형태적으로 5개의 악편과 부악편이 서로 호 생하고, 다수의 수술과 암술을 갖으며, 정단이 둥근 수과 등의 특징이 장미아과 내의 다른 족들과 차이가 있다 (Shishkin and Yuzepchuk, 1985).

양지꽃족의 족내 분류는 학자들 간에 논란이 있어왔다. 검은낭아초속(Comarum L.), 뱀딸기속(Duchesnea Smith), 물싸리속(Dasiphora Raf), 눈양지꽃속(Argentina Hill) 등
의 속들을 양지꽃속에 포함시키는 광의의 양지꽃속 (Potentilla s.1.)이 인정되거나(Wolf, 1908; Robertson, 1974; Kalkman, 1988) 또는 독립된 속으로서 이들 각각을 처리 하고 협의의 양지꽃속(Potentilla s.s.; Rydberg, 1898)을 인 정하기도 하였다(Hutchinson, 1964; Schulze-Menz, 1964; Shishkin and Yuzepchuk, 1985; Li et al., 2003; Naruhashi, 2003). Mabberley (2002)는 형태학적, 유전학적, 분자학적 연구를 바탕으로 한 양지꽃속과 딸기속(Fragaria L.)의 재검토에서, 딸기속을 포함하는 광의의 양지꽃속을 주장 하기도 하였다. 그러나 최근 다수의 분자계통학적 연구 결과 양지꽃족은 딸기아족(Fragariinae Torr. \& A. Gray)과 양지꽃아족(Potentillinae J. Presl)으로 분지되었으며, 다수 의 속들은 독립된 계통을 이루는 것으로 밝혀졌다 (Eriksson et al., 2003; Dobeš and Paule, 2010; Töpel et al., 2011; Feng et al., 2017) (Table 1). 또한 두 아족 간에는 전

\footnotetext{
*Author for correspondence: starflr@infoboss.co.kr, stlee1944@hanmail.net
} 
Table 1. Classification and history at the level of genera in tribe Potentilleae referencing the survey of Feng et al. (2017).

\begin{tabular}{|c|c|c|c|c|c|}
\hline $\begin{array}{c}\text { Rydberg } \\
(1898)\end{array}$ & $\begin{array}{l}\text { Wolf } \\
(1908)\end{array}$ & $\begin{array}{l}\text { Li et al. } \\
\text { (2003) }\end{array}$ & $\begin{array}{l}\text { Naruhashi } \\
(2003)\end{array}$ & $\begin{array}{l}\text { Sojak } \\
(2008)\end{array}$ & $\begin{array}{c}\text { Heo et al. (2019) } \\
\text { in Korea plant }\end{array}$ \\
\hline \multirow[t]{2}{*}{ Potentilleae } & \multirow[t]{2}{*}{ Potentilleae } & \multirow[t]{2}{*}{ Potentilleae } & \multirow[t]{2}{*}{ Potentilleae } & Potentilleae & Potentilleae \\
\hline & & & & Fragariinae & Fragariinae \\
\hline Comarum & [Comarum] & Comarum & Comarum & Comarum & Comarum \\
\hline Fragaria & Fragaria & Fragaria & Fragaria & Fragaria & Fragaria \\
\hline Sibbaldia & Sibbaldia & Sibbaldia & Sibbaldia & Sibbaldia & Sibbaldia \\
\hline Dasiphora & [Dasiphora $]$ & [Dasiphora] & Pentaphylloides & Dasiphora & Dasiphora \\
\hline$?$ & [Sibbaldianthe] & [Sibbaldianthe] & $?$ & Sibbaldianthe & - \\
\hline- & - & [Sibbaldianthe] & - & Schistophyllidium & Sibbaldianthe \\
\hline- & - & - & - & Farinopsis & - \\
\hline Drymocallis & [Drymocallis] & - & - & Drymocallis & - \\
\hline Sibbaldiopsis & [Sibbaldiopsis] & - & - & Sibbaldiopsis & - \\
\hline- & - & - & - & Potaninia & - \\
\hline & & & & Chamaerhodotinae & \\
\hline Chamaerhodos & Chamaerhodos & Chamaerhodos & - & Chamaerhodos & Chamaerhodos \\
\hline & & & & Alchemillinae & \\
\hline- & - & - & - & Alchemilla & - \\
\hline- & - & - & - & Aphanes & - \\
\hline- & - & - & - & Lachemilla & - \\
\hline & & & & Potentillinae & Potentillinae \\
\hline Potentilla & Potentilla & Potentilla & Potentilla & Potentilla & Potentilla \\
\hline Argentina & [Argentina] & [Argentina] & [Argentina] & [Argentina $]$ & Argentina \\
\hline Duchesnea & [Duchesnea] & Duchesnea & Duchesena & [Duchesnea] & Duchesena \\
\hline Horkelia & Horkelia & - & - & Horkelia & - \\
\hline- & - & - & & [Horkeliella] & \\
\hline Horkelia & - & - & - & Ivesia & - \\
\hline Comarella & Comarella & - & - & (Comarella) & - \\
\hline- & - & - & - & (Purpusia) & - \\
\hline Stellariopsis & Stellariopsis & - & - & Stellariopsis & - \\
\hline- & - & - & - & Tylosperma & - \\
\hline- & - & - & - & Piletophyllum & - \\
\hline
\end{tabular}

Square brackets present the genera treated as synonyms of Potentilla. Bar (-) means genus missed in study. The question mark indicates that data were not confirmed.

통적으로 주요한 특성으로 알려진 암술의 특징뿐 아니라 수술의 화분낭 특성에서도 차이가 있었다(Soják, 2008a).

지금까지 국내에서는 한국산 양지꽃족 식물들에 대한 분류학적 연구가 거의 이루어지지 않았으며, 족내의 속 분류에 대하여 학자들마다 이견이 있어왔다. 검은낭아초 속은 Nakai (1952), Chung (1957), Ahn and Park (1974)에
의해 독립된 속으로 인정되었으며, Nakai (1952)는 물싸 리속을 독립된 속으로 인정하기도 했다. 그러나 도감 등 에서는 검은낭아초, 물싸리, 물싸리풀, 눈양지꽃을 양지 꽃속에 포함시키기도 하였다(Lee, 1996; Lee, 1999; Lee, 2003). 이러한 양지꽃족 분류의 혼란은 한국산 분류군에 대한 계통학적 정보가 반영된 연구가 이루어지지 않았기 
때문이라 추정되며, 따라서 한국산 양지꽃족내 식물들에 대한 분류학적인 재정리가 필요하다.

한편 한국산 양지꽃족 식물들 중에는 형태적인 연속 변이로 인하여 학자들 간에 분류군 인식에 다른 견해를 보이기도 했으며 학명과 국명 사용에 오용도 있어왔다. 양지꽃속의 당양지꽃(P. ancistirolia Bunge)은 우리나라에 분포한다고 기록되기도 했으나(Chung et al., 1949; Nakai, 1952; Ahn and Park, 1974; Lee, 1996; Li et al., 2003), Lee (1999)와 Lee (2003) 등의 도감 등에는 언급되지 않았다. 좀양지꽃 $(P$. matsumurae Th. Wolf)의 경우 제주도 한라산 에 분포한다고 국내 도감 등에 기록되어 왔으나(Lee, 1996; Lee, 1999; Lee, 2003), Naruhashi (2003)는 좀양지꽃 이 일본과 러시아에만 제한적으로 분포한다고 기록하였 다. 제주양지꽃(P. stolonifera var. quelpaertensis Nakai)은 Nakai (1914)에 의해 신변종으로 기재되었으나, $P$. stolonifera Lehm. ex Ledeb.는 이미 P. fragarioides L.의 이 명으로 처리되기도 하였으며, P. fragarioides은 종내 변이
폭이 매우 넓다고 알려져 있다(Naruhashi, 2003). 제주양 지꽃 학명의 재검토가 이루어져야 한다. 섬양지꽃 $(P$. dickinsii var. glabrata Nakai)은 소엽이 넓고, 잎 끝부분에 작은 돌기가 있으며, 앞면의 맥 위에 산재하는 털과 뒷면 이 분백색이 아닌 특징으로 신변종으로 기재되었으나 (Nakai, 1918), 후에 Naruhashi (2003)는 돌양지꽃( $P$. dickinsii Franch. et Sav. var. dickinsii)의 이명으로 인식하기 도 하였으므로, 섬양지꽃의 한계 규명을 위한 분류학적 인 연구가 필요하다.

본 연구에서는 Rydberg (1898), Wolf (1908), Li et al. (2003), Soják (2008a)과 분자분류학적 연구를 수행한 Dobeš and Paul (2010)의 분류체계를 바탕으로 하여 외부 형태학적 특징, 과실 미세구조 연구 및 문헌 조사를 통한 한국산 양지꽃족의 분류를 재검토하고, 근연속들의 유연 관계를 살펴보고자 하였다. 또한 학명의 혼용 및 종의 폭 넓은 변이로 인하여 논란이 되어왔던 종들의 한계를 규 명하자 하였다.

Table 2. The list of specimen used for fruit morphology in this study.

\begin{tabular}{|c|c|c|}
\hline Taxon & Voucher specimens & $\begin{array}{l}\text { Collection } \\
\text { Date }\end{array}$ \\
\hline Dasiphora fruticosa & Jangbaeksan, Lee et al. (SKK) & 2007.7 .30 \\
\hline Fragaria $\times$ ananassa & Soul-si, Gwanaksan, Hoyoung Lee B200507062051 (SKK) & 2007. 7.27 \\
\hline Comarum plaustre & Hamgyeongbuk-do, ?. 7030 (KYO) & $? .8 .9$ \\
\hline Comarum plaustre & Yeongil, Lee et al. HKI00871 (SKK) & 2007. 7.27 \\
\hline Argentina egedii & Gangwon-do, Songgiho, Heo, K.I. HKI00186 (SKK) & 2005.6 .4 \\
\hline Duchesnea indica & Gyeongsangbuk-do, Hyangrobong, Choi, H.G. (SNU) & 1972. 5.31 \\
\hline Duchesnea chrysantha & Jeollabuk-do, Seonwoonsan, Heo, K. I., Kim, Y. S. HKI00948 (SKK) & 2008.5 .25 \\
\hline Potentilla dickinsii & Gyeonggi-do, Yongmunsan, Chung, T. H. (SKK B-8811) & 1959. 10.10 \\
\hline Potentilla dickinsii & Gyeongsangbuk-do, Ulleungdo, Kim, J. H., Kim, J. O. HKI00212 (SKK) & 2005.7 .20 \\
\hline Potentilla chinensis & Gangwon-do, Mureungdowon, Heo, K. I. et al. B200508192269 (SKK) & 2003.8. 15 \\
\hline Potentilla chinensis & Gangwon-do, Chongseokjeong, Do, B. S., Sim, H. J. (SKK) & 1933.8 .3 \\
\hline Potentilla chinensis & Gangwon-do, Goseong-gun, Songjiho, Heo, K. I. et al. A200508121081 (SKK) & 2003. 8. 15 \\
\hline Potentilla discolor & Gangwon-do, Myeongjugun, Okgaemyeon, Lee, W. T. 0008060 (GW) & 1977. 7.20 \\
\hline Potentilla nivea & Hamgyeongbukdo, T. Ishidoya (KYO) & 1931.7. ? \\
\hline Potentilla cryptotaeniea & Gangwon-do, Daeryongsan, Lee, W. T. 0008005 (KWU) & 1975. 8.10 \\
\hline Potentilla centigrana & Gangwon-do, Jeongbongsan, Lee et al. HKI183 (SKK) & 2006. 6.21 \\
\hline Potentilla anemonifolia & Gyeonggi-do, Suwonsi, Hagwangkyo, Heo, K. I., et al. B200508192268 (SKK) & 2004. 6. 13 \\
\hline Potentilla supina subsp. paradoxa & Gangwon-do, Gyeongpodae, Heo, K. I., Go, J. E. B200508192149 (SKK) & 2004. 6.15 \\
\hline Potentilla amurensis & Gyeonggi-do, Yangpyeonggun, Jeong, E. S. (KH) & 2002.5. 15 \\
\hline Potentilla fragarioides var. major & Jeju-do, Hallasan, Arimok, Chen, W.L., et al. (SKK) & 2003. 6.20 \\
\hline Potentilla squamosa & Gangwon-do, Myeonsan, Lee, S.T., et al. (SKK) & 2006. 6.20 \\
\hline Potentilla freyniana & Jangbaeksan, Lee, C. S. (SKK) & 2006.6 .4 \\
\hline Potentilla yokusaiana & Gangwon-do, Jeombongsan, Lee, S.T., et al. (SKK) & 2006. 6. 21 \\
\hline
\end{tabular}




\section{재료 및 방법}

본 연구에는 한반도 북부지방에 분포하는 것으로 알려진 너도양지꽃(Sibbaldia procumbens L.), 좀낭아초(Chamaerhodos erecta (L.) Bunge), 흰물싸리(Dasiphora fruticosa L. var. madshurica (Maxim.) Rehder), 만주딱지꽃(P. multifida L.), 끈근이딱지(P. viscosa J.) 및 $P$. coreana Soják 등을 제외한
양지꽃족 7 속 24 분류군이 사용되었다.

연구에 사용된 재료는 2002년 4월부터 2012년 5월까지 국내 각지와 백두산(중국)에서 채칩하여 제작한 석엽표 본을 사용하거나 생체를 직접 이용하였으며, 일부 분류 군은 성균관대학교에 이식하여 관찰하고 실험에 이용하 였다. 또한 성균관대학교표본관(SKK), 강원대학교표본 관(KWNU), 경북대학교표본관(KNU), 국립수목원표본

Table 3. Comparison table of morphological characters in tribe Potentilleae. Bar (-) means species missed in study.

\begin{tabular}{|c|c|c|c|c|c|}
\hline & Style insertion & Style shape & Hair on the ovary & $\begin{array}{l}\text { Surface of the } \\
\text { achene }\end{array}$ & $\begin{array}{c}\text { Developed epicuticular waxes } \\
\text { on the leaf surface } \\
\text { (Heo et al., 2013) }\end{array}$ \\
\hline \multicolumn{6}{|l|}{ Subtribe Fragariinae } \\
\hline Dasiphora fruticosa & subbasal & claviform & densely pubescent & psilate & abaxial side \\
\hline \multicolumn{6}{|l|}{ Fragaria } \\
\hline F. x ananassa & lateral & claviform & glabrous & - & abaxial side \\
\hline F. mandshurica & lateral & claviform & glabrous & - & abaxial side \\
\hline F. nipponica subsp. chejuensis & lateral & claviform & glabrous & - & abaxial side \\
\hline Sibbaldianthe semiglabra & subbasal, basal & claviform & $\begin{array}{l}\text { sparsely } \\
\text { pubescent }\end{array}$ & - & abaxial side \\
\hline Comarum plaustre & subbasal & filiform & glabrous & psilate & both surface \\
\hline \multicolumn{6}{|l|}{ Subtribe Potentillinae } \\
\hline Argentina egedii & lateral, subterminal & cylindrical & glabrous & psilate & none \\
\hline \multicolumn{6}{|l|}{ Duchesnea } \\
\hline D. indica & subterminal & filiform & glabrous & ridged/aculeate & none \\
\hline D. chrysantha & subterminal & filiform & glabrous & ridged/aculeate & none \\
\hline \multicolumn{6}{|l|}{ Potentilla } \\
\hline \multicolumn{6}{|l|}{ 1. Sect. Nematostylae } \\
\hline P. dickinsii & subterminal & filiform & $\begin{array}{c}\text { pubescent } \\
\text { on the upper part }\end{array}$ & ridged & both surface \\
\hline \multicolumn{6}{|l|}{ 2. Sect. Potentilla } \\
\hline P. fragarioides var. major & subterminal & claviform & glabrous & ridged & none \\
\hline P. stolonifera var. quelpaertensis & subterminal & claviform & glabrous & ridged & none \\
\hline P. freyniana & subterminal & claviform & glabrous & ridged & none \\
\hline P. yokusaiana & subterminal & filiform & glabrous & ridged & none \\
\hline P. squamosa & subterminal & claviform & glabrous & ridged & none \\
\hline \multicolumn{6}{|l|}{ 3. Sect. Conostylae } \\
\hline P. centigrana & subterminal & coniform & glabrous & ridged/aculeate & both surface \\
\hline P. nivea & subterminal & coniform & glabrous & ridged & none \\
\hline P. chinensis & subterminal & coniform & $\begin{array}{c}\text { pubescent } \\
\text { on the lower part }\end{array}$ & ridged & none \\
\hline P. discolor & subterminal & coniform & glabrous & psilate & none \\
\hline P. cryptotaeniae & subterminal & coniform & glabrous & ridged & none \\
\hline P. anemonifolia & subterminal & coniform & glabrous & ridged/aculeate & none \\
\hline P. supina subsp. paradoxa & subterminal & coniform & glabrous & ridged & none \\
\hline P. amurensis & subterminal & coniform & glabrous & ridged & none \\
\hline
\end{tabular}


관(KH), 서울대학교표본관(SNU), 서울대학교수우표본 관(SNUA), 전남대학교표본관, 인포보스표본관(IN)과 일 본 교토대학교표본관(KYO), 동경대학교표본관(TI), 중 국 북경식물원표본관(PE)에 소장된 약 3000 여점의 석엽 표본을 대여하여 사용하였다. 본 실험에 사용된 생체 재 료는 성균관대학교 식물표본관(SKK)에 확증표본으로 보관하였다. 연구에 사용된 석엽표본 목록은 Appendix 1 에 기록하였으며, 수과 관찰에 사용된 재료는 Table 2에 정리하였다.

외부형태학적 형질의 관찰은 석엽표본과 완전히 성장 한 생체를 이용하였으며, 식물의 습성, 높이, 줄기의 변화 된 특성, 소엽의 수, 소엽의 길이와 너비, 소엽 거치, 탁엽 의 길이와 너비 등의 영양형질과, 화서의 종류, 화주가 자 방에 부착한 위치, 꽃잎, 꽃받침, 부꽃받침의 길이와 너비 등의 생식형질을 관찰하고, 약 10-20개체를 이용하여 측 정하였다. 분류학적으로 중요하다고 판단되는 몇몇 형질 에 대하여 그 특징을 Table 3에 정리하였다. 형태 형질에 관한 용어는 Lawrence (1970)과 Lee (2004)에 따랐다. 암술, 수술 및 수과 등의 형질들을 해부현미경(Leica Wild M8, Germany)으로 관찰하였다. 또한 암술과 수과의 주름 및 표면의 미세형질 관찰을 위해서 건조된 시료를 $\mathrm{Au}$ 로 이 온 증착(JEOL JFC-1100 ion sputter) 시킨 후에 주사전자 현미경(Jeol JSM 5600, Japan)을 이용하여 관찰하였다. 본 연구에서는 한국산 양지꽃족의 검색표 작성을 위해서 외 부형태 형질과 수과 미세형질 특징 뿐 아니라 표피 미세 형질 연구결과(Heo et al., 2013) 또한 이용하였다. 자세한 분류학적 기재는 Heo (2009)에 수록되어 있다.

\section{결 과}

\section{외부형태학적 형질}

1. 영양형질

1) 습성

소관목인 물싸리(Dasiphora fruticose (L.) Rydb.)를 제외
한 한국산 양지꽃족의 23 분류군은 모두 초본이다.

2) 뿌리

섬유형의 뿌리(Fig. 1A, B)가 대부분의 분류군에서 나 타나며, 주근형(Fig. 1C)은 딱지꽃(P. chinensis Ser.), 개소 시랑개비(P. supina subsp. paradoxa (Nutt. ex Torr. \& A. Gray) Soják), 좀개소시랑개비(P. amurensis Maxim.)에서 관찰되고, 방추형(Fig. 1D)의 괴근은 솜양지꽃(P. discolor Bunge)에서 발달한다.

3) 줄기

(1) 근경의 발달(Fig. 1B): 물싸리(D. fruticose (L.) Rydb.), 물싸리풀(Sibbaldianthe semiglabra (Soják) Mosyakin \& Shiyan), 검은낭아초(Comarum palustris L.), 은양지꽃 $(P$. nivea L.), 돌양지꽃 (P. dickinsii Franch. et Sav.), 섬양지꽃 (P. dickinsii var. glabrata Nakai)은 지하부에 단단한 근경 이 발달한다. 이 외의 나머지 분류군에서는 근경이 발달 하지 않거나 미약하게 존재한다.

(2) 포복경(stolon): 딸기(Fragaria $\times$ ananassa (Weston) Duchesne ex Rozier), 땃딸기(F. mandshurica Staudt), 흰땃 딸기(F. nipponica subsp. Chejuensis Staudt \& Olbricht), 눈 양지꽃(Argentina egedii (Wormsk. ex Hornem.) Rydb.), 뱀 딸기(Duchesnea indica (Andrews) Teschem.), 산뱀딸기 (Duchesnea chrysantha (Zoll. \& Moritzi) Miq.), 좀딸기(P. centigrana Maxim.), 물양지꽃(P. cryptotaeniae Maxim.), 가 락지나물(P. anemonifolia Lehm.), 제주양지꽃(P. stolonifera var. quelpaertensis Nakai), 털양지꽃(P. squamosa Soják), 민 눈양지꽃(P. yokusaiana Makino)은 개화기에 지상에서 수 평으로 기는 포복경이 확연하게 발달하며, 줄기의 마디 에서 부정근이 발달한다. 이들 외의 나머지 12 분류군은 포복경이 발달하지 않는다. 외부 형태적으로 매우 유사 한 우상복엽을 갖는 양지꽃(P. fragarioides var. major Maxim.)과 제주양지꽃(P. stolonifera var. quelpaertensis Nakai) 그리고 삼출엽의 세잎양지꽃(P. freyniana Bornm.) 과 털양지꽃( $P$. squamosa Soják)은 포복경의 발달 여부가 종간 구분의 중요한 형질이다. 양지꽃과 세잎양지꽃은

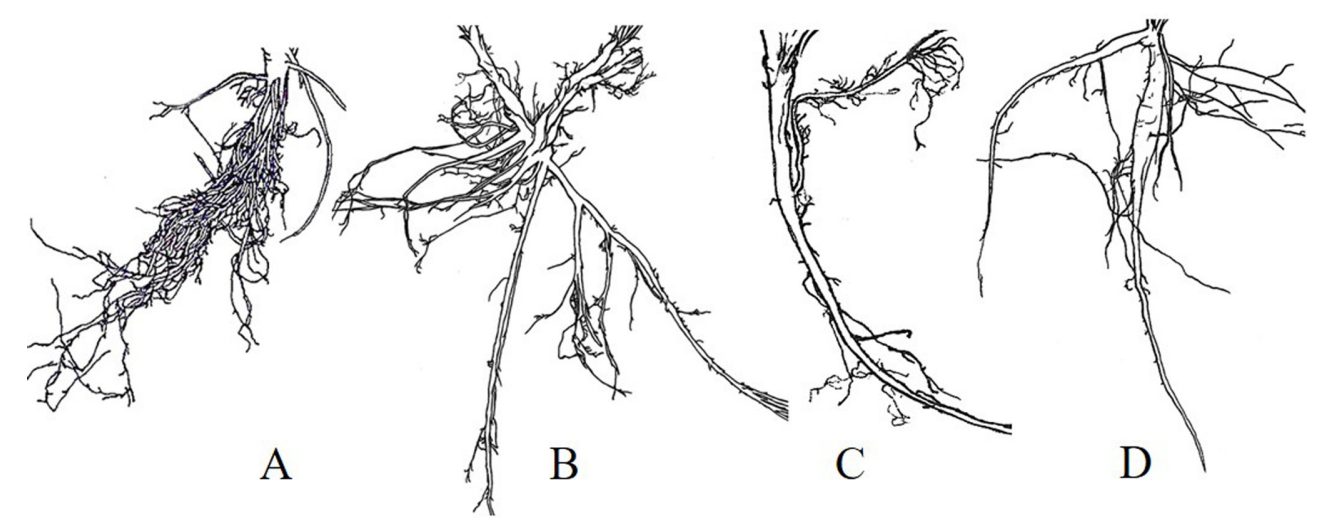

Fig. 1. Root types of tribe Potentilleae in Korea. A. Fibrous. B. Woody rhizome. C. Tap. D. Fusiform. 


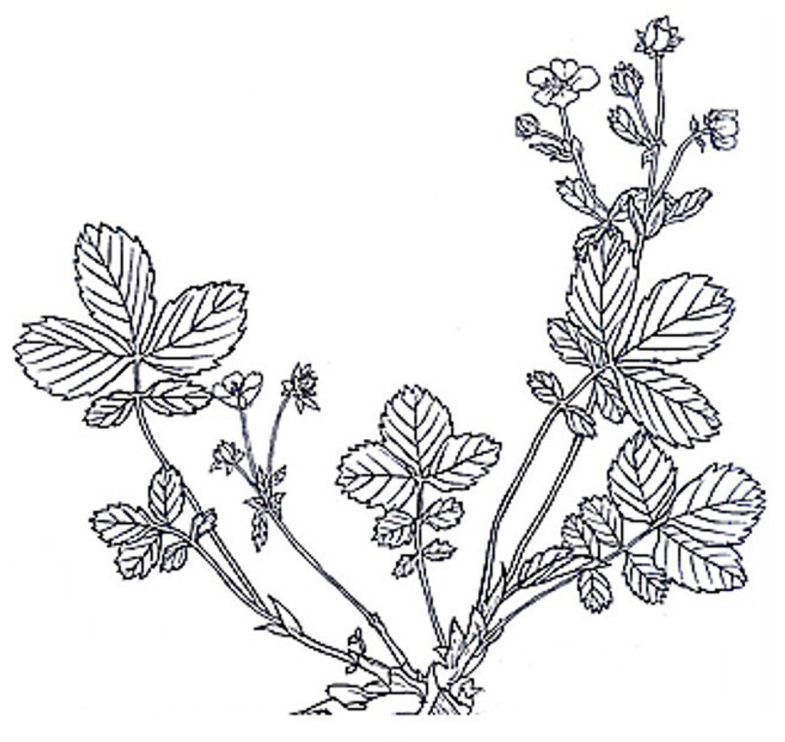

A

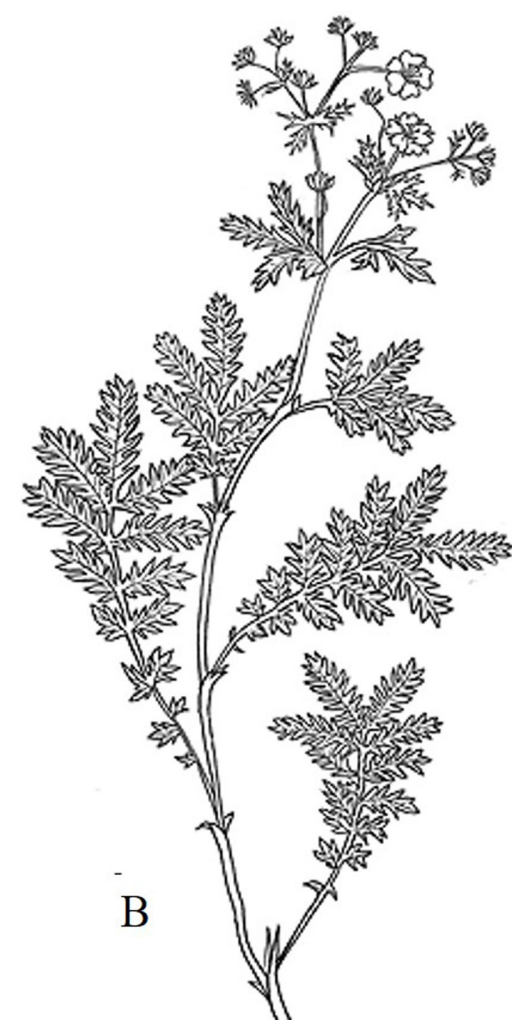

Fig. 2. Stem types of tribe Potentilleae in Korea. A. Decumbent. B. Erect.

포복경이 거의 발달하지 않으나, 제주양지꽃과 털양지꽃 은 포복경이 발달하는 특징으로 각각 구분된다.

(3) 줄기의 성장: 딸기, 땃딸기, 흰땃딸기, 눈양지꽃, 뱀 딸기, 산뱀딸기, 가락지나물, 양지꽃절(sect. Potentilla (Syme) Yü et Li.)에서는 줄기가 옆으로 퍼지다가 위로 향 하여 성장하는 복와형 줄기가 발달하며, 줄기는 단단하 지 않다(Fig. 2A). 이에 반하여 줄기가 목질화되거나 또는 단단한 직립형의 줄기가 관찰되는 식물은 물싸리, 물싸 리풀, 검은낭아초와 딱지꽃절(sect. Conostylae (Th. Wolf) $\mathrm{Yü}$ et Li.; 가락지나물 제외), 돌양지꽃절(sect. Nematostylae Gusuleac)에서 나타난다. 직립형 식물 중에 고산지대에 분포하는 물싸리, 물싸리풀, 검은낭아초는 줄기 전체가 목질화되거나 또는 기부만 목질화된다(Fig. 2B). 딱지꽃절과 돌양지꽃절의 줄기는 단단하여 직립 성 장하지만, 목질화되지는 않는다.

4) 잎

잎의 모양, 엽연 거치의 모양과 수, 잎 표면의 털의 형질 및 유무 등은 양지꽃족 식물의 주요 식별형질이다. 양지 꽃족 식물들은 경생엽의 형태가 근생엽과 거의 유사하며, 경생엽은 근생엽에 비하여 위로 갈수록 크기가 작아지고 소엽의 수가 적어진다. 따라서 본 연구의 양지꽃족 잎의 관찰은 근생엽에 한하여 이루어졌다.

(1) 근생엽의 종류: 딸기, 땃딸기, 흰땃딸기, 뱀딸기, 산
뱀딸기, 섬양지꽃, 좀딸기, 물양지꽃, 은양지꽃, 좀개소시 랑개비, 세잎양지꽃, 민눈양지꽃, 털양지꽃은 삼출엽이 관찰되며, 드물게 돌양지꽃에서도 삼출엽이 나타난다 (Fig. 3A). 가락지나물은 장상엽을 갖는다(Fig. 3B). 물싸 리, 물싸리풀, 검은낭아초, 솜양지꽃, 개소시랑개비, 양지 꽃, 제주양지꽃, 돌양지꽃에서는 우상복엽 이 나타난다 (Fig. $3 \mathrm{C}$ ). 눈양지꽃과 딱지꽃은 부소엽이 있는 우상복엽 이 관찰된다(Fig. 3D).

(2) 근생엽의 숙존: 딸기, 땃딸기, 흰땃딸기, 눈양지꽃, 뱀딸기, 산뱀딸기, 돌양지꽃, 딱지꽃, 은양지꽃, 솜양지꽃, 양지꽃절은 근생엽이 숙존한다. 물싸리풀, 검은낭아초, 좀딸기, 물양지꽃, 가락지나물, 개소시랑개비, 좀개소시 랑개비는 근생엽이 조락한다.

(3) 엽형: 1) 타원상 피침형 또는 피침형: 물싸리, 물싸리 풀; 2) 난상피침형: 물양지꽃; 3) 도란상타원형 또는 타원 형: 검은낭아초, 돌양지꽃, 가락지나물; 4) 타원형: 눈양 지꽃, 딱지꽃, 솜양지꽃, 개소시랑개비; 5) 도란형: 딸기, 산뱀딸기, 좀딸기, 개소시랑개비, 양지꽃, 제주양지꽃, 세 잎양지꽃, 털양지꽃, 민눈양지꽃; 6) 난형: 뱀딸기, 좀개소 시랑개비; 7) 난상원형 또는 도란상원형: 딸기, 땃딸기, 흰 땃딸기, 좀딸기, 은양지꽃, 세잎양지꽃, 털양지꽃; 8) 능형 또는 능상도란형: 민눈양지꽃으로 구분된다.

(4) 엽선: 물싸리, 물싸리풀, 검은낭아초, 눈양지꽃, 뱀딸 


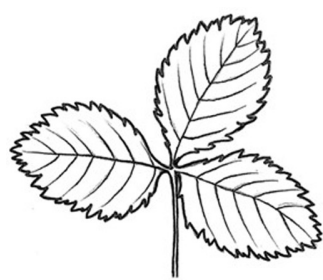

A

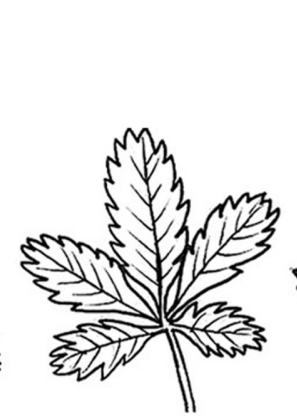

$\mathrm{B}$
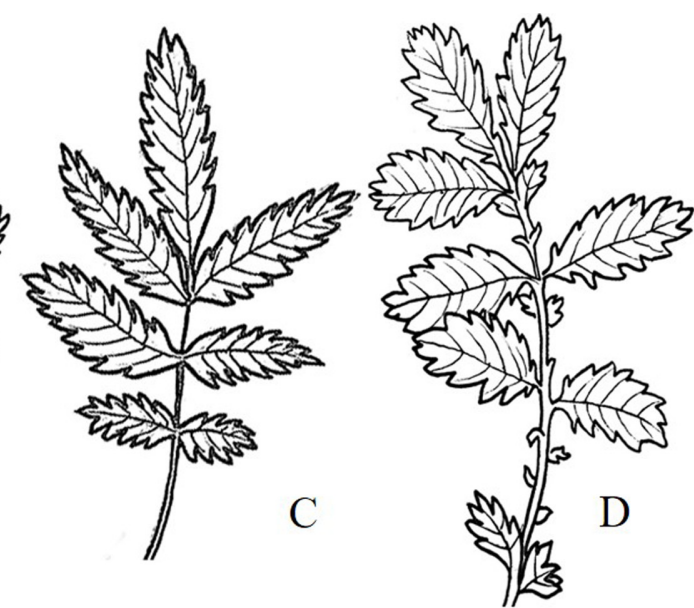

Fig. 3. Leaf types of tribe Potentilleae in Korea. A. Trifoliolate. B. Palmately compound. C. Pinnately compound. D. Pinnately compound with accessory leaflets.

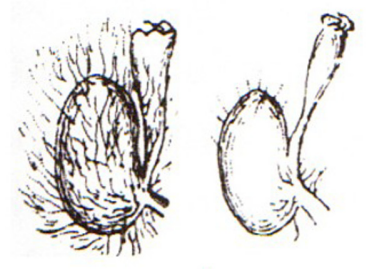

A

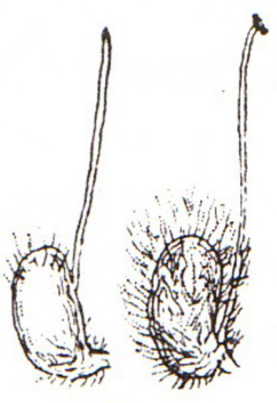

$\mathrm{B}$

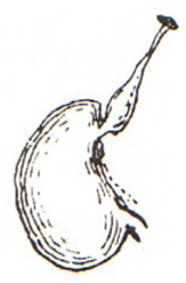

$\mathrm{C}$

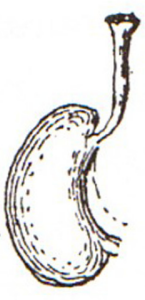

$\mathrm{D}$

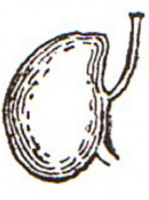

E

Fig. 4. Style types of tribe Potentilleae cited from Wolf (1908). A. Style position: left side is basal and right side is subbasal/style shape: claviform. B. Style position: left side is subterminal and right side is basal/style shape: filiform. C. Subterminal/coniform. D. Subterminal/ claviform. E. Lateral/cylindrical.

기, 돌양지꽃, 딱지꽃, 은양지꽃, 솜양지꽃, 가락지나물, 개소시랑개비, 좀개소시랑개비, 세잎양지꽃, 민눈양지꽃, 털양지꽃은 예두가 관찰되며, 물양지꽃은 예두와 피침형 이 관찰된다. 딸기, 땃딸기, 흰땃딸기, 눈양지꽃, 딱지꽃, 은양지꽃, 가락지나물, 개소시랑개비, 양지꽃, 제주양지 꽃, 세잎양지꽃, 털양지꽃에서는 원두가 나타나며, 흰땃 딸기, 산뱀딸기, 좀딸기, 개소시랑개비, 양지꽃은 둔두가 확인된다. 몇몇 분류군에서는 예두와 원두, 둔두와 원두, 또는 예두, 둔두, 원두가 같이 관찰된다.

(5) 엽연: 물싸리와 물싸리풀은 전연이다. 검은낭아초, 딸기, 땃딸기, 흰땃딸기, 뱀딸기, 돌양지꽃, 섬양지꽃, 좀 딸기, 은양지꽃, 솜양지꽃, 가락지나물, 개소시랑개비, 좀 개소시랑개비, 양지꽃, 제주양지꽃, 세잎양지꽃, 털양지 꽃, 민눈양지꽃은 예거치가 나타나며, 산뱀딸기와 물양 지꽃은 예거치와 복예거치가 함께 나타나며, 눈양지꽃은 예거치와 둔예거치가 확인된다. 눈양지꽃, 딱지꽃, 개소
시랑개비는 엽연이 우상으로 깊게 갈라지는 우상심열형 이 관찰된다. 좀개소시랑개비는 정소엽이 세 개로 심열 하여 장상엽처럼 보이며, 측소엽이 두 개로 심열하기도 하여 다른 분류군과 구분된다.

\section{2. 생식형질}

꽃잎, 꽃받침, 그리고 부악편의 크기와 모양 등은 분류 군 간에 매우 유사하여 종간 구분에 유용한 형질이 아니 며, 분류군 내에서도 변이가 나타난다.

1) 화서

기본적으로 취산화서가 나타난다. 1-5(-7)개의 꽃으로 이루어진 취산화서를 갖는 식물은 물싸리, 물싸리풀, 딸 기, 땃딸기, 흰땃딸기, 은양지꽃, 털양지꽃이다. 5 개 이상 의 꽃으로 된 취산화서 또는 원추상 취산화서는 검은낭아 초, 돌양지꽃, 딱지꽃, 솜양지꽃, 물양지꽃, 가락지나물, 양지꽃, 제주양지꽃, 세잎양지꽃, 민눈양지꽃에서 관찰 

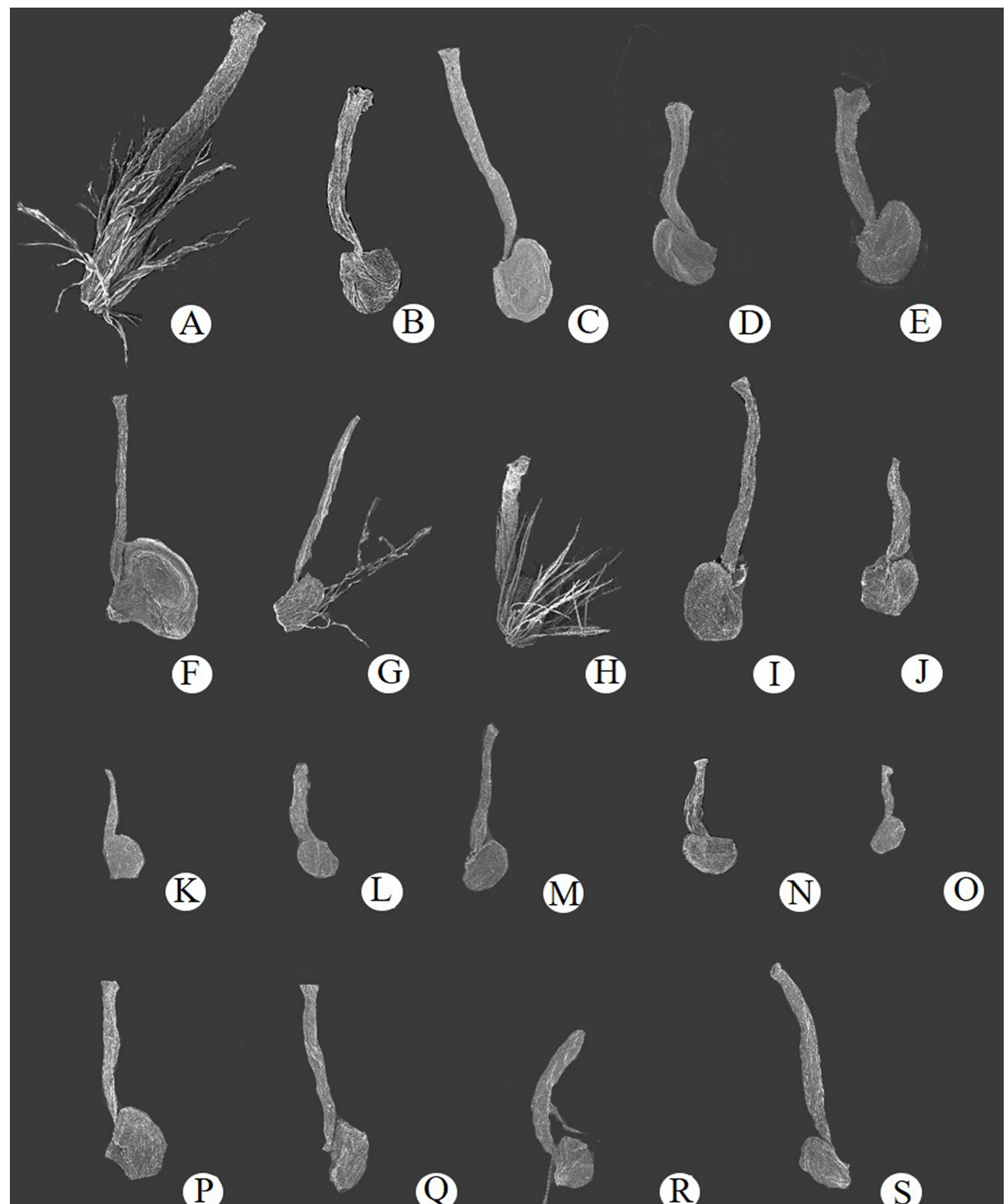

Q
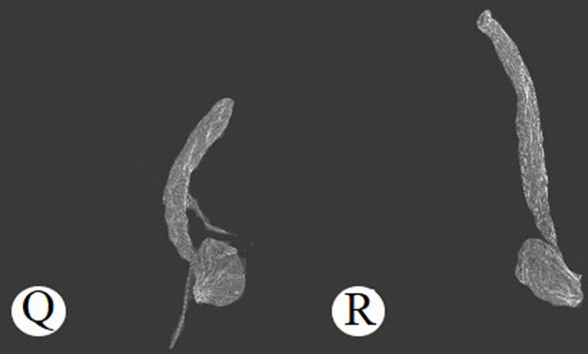

S
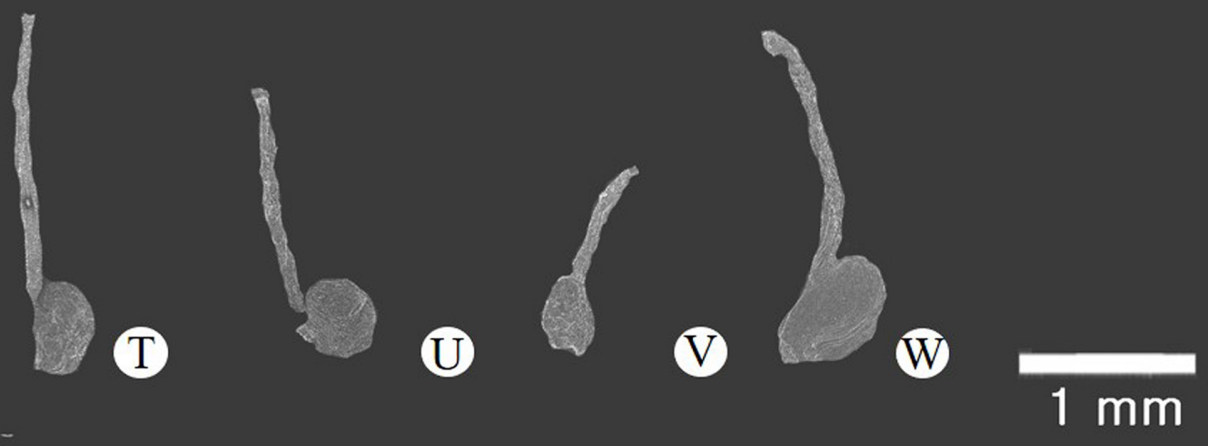

Fig. 5. Style shapes of tribe Potentilleae in Korea. A. Dasiphora fruticose. B. Sibbaldianthe semiglabra. C. Fragaria x ananassa. D. F. nipponica subsp. Chejuensis. E. F. mandshurica. F. Comarum palustre. G. Potentilla dickinsii. H. P. chinensis. I. P. discolor. J. P. nivea. K. P. centigrana. L. P. anemonifolia. M. P. cryptotaeniae. N. P. supina subsp. Paradoxa. O. P. amurensis. P. P. fragarioides var. major. Q. P. stolonifera var. quelpaertensis. R. P. freyniana. S. P. squamosal. T. P. yokusaiana. U. Duchesnea indica. V. D. chrysantha. W. Argentina egedii. 
된다. 취산화서 이외에 단정화서가 관찰되기도 한다. 눈 양지꽃, 뱀딸기, 산뱀딸기는 포복경의 엽액에서 1 개의 꽃 이 나오며, 좀딸기, 개소시랑개비, 좀개소시랑개비는 줄 기의 엽액에서 1 개의 꽃이 나오는 단정화서를 갖는다.

2) 수술

수술은 20개(13-22개)이다. 3열로 배열되고, 바깥부터 안쪽으로 10 개, 5 개, 5 개 순으로 환상으로 배열한다. 가장 안쪽 열의 수술이 제일 길고, 중간 열은 가장 짧으며, 바
깥쪽 열의 수술이 안쪽 열의 수술보다 다소 짧다.

3) 화주

화주가 자방에 붙는 위치와 화주의 모양은 족내 속간 분류에 중요한 형질이다(Figs. 4, 5).

(1) 화주가 자방에 붙는 위치에 따라 3가지 유형으로 구 분된다. 1) 기저생과 아기저생(Fig. $4 \mathrm{~A})$ : 화주가 자방의 기 부 또는 중간 아래쪽에 위치하는 것으로 물싸리(Fig. 5A) 와 검은낭아초(Fig. $5 \mathrm{~F}$ )에서는 아기저생 화주가, 물싸리
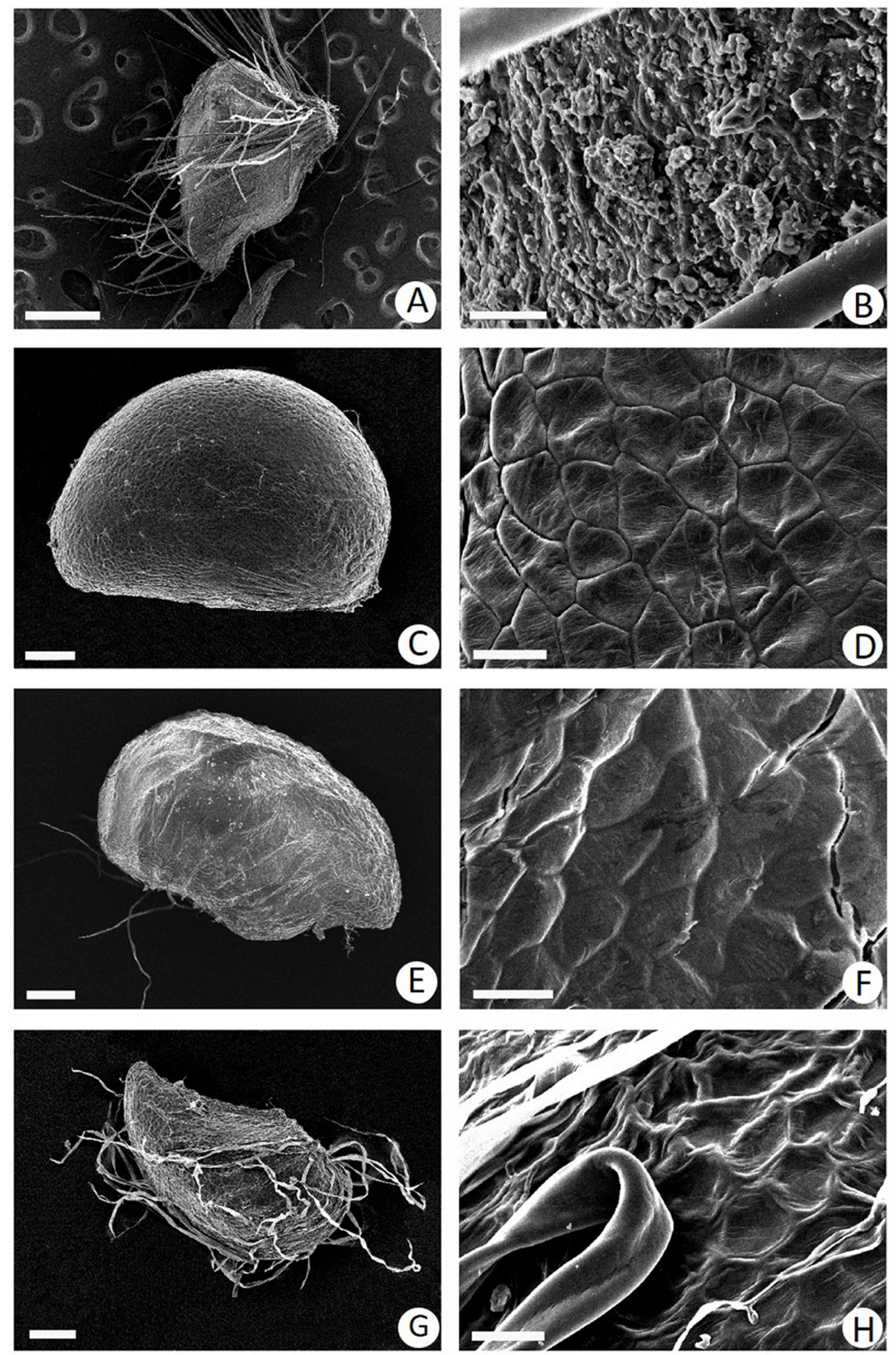

Fig. 6. SEM photographs of fruits. Fruit shape (left, scale bar $=200 \mu \mathrm{m}$ ) and fruit surface (right, scale bar $=25 \mu \mathrm{m}$ ). A, B. Dasiphora fruticosa. C, D. Comarum palustre. E, F. Potentilla dickinsii. G, H. P. dickinsii var. glabrata. 
풀(Fig. 5B)에서는 기저생과 아기저생 화주가 관찰된다. 2) 측생(Fig. $4 \mathrm{E})$ : 화주가 자방의 중간에 위치하는 것으로 딸기(Fig. 5C), 흰땃딸기(Fig. 5D), 땃딸기(Fig. 5E), 눈양지 꽃(Fig. $5 \mathrm{~W}$ )에서 관찰된다. 이들 중에서 딸기는 아기저생 도 관찰되며, 눈양지꽃은 아정생도 나타난다. 3) 아정생 (Fig. $4 \mathrm{C}, \mathrm{D})$ : 화주가 자방의 위쪽에 붙으며, 눈양지꽃을 제 외한 양지꽃아족 17 분류군들에서 나타난다(Fig. $5 \mathrm{~F}-\mathrm{V}$ ).

(2) 화주의 모양: 1) 원뿔형(Fig. 4C): 화주의 기부가 두
터운 형태로 딱지꽃절(sect. Conostylae)에서 관찰된다 (Fig. 5H-O). 2) 사상형(Fig. 4B): 화주 전체가 고른 사상형 이다. 때로 다소 비후하기도 한다. 검은낭아초(Fig. $5 \mathrm{~F}$ ), 뱀딸기(Fig. $5 \mathrm{U}$ ), 산뱀딸기(Fig. $5 \mathrm{~V}$ ), 돌양지꽃(Fig. 5G), 민 눈양지꽃(Fig. 5T)에서 관찰된다. 3) 원통형(Fig. 4E): 눈양 지꽃은 나머지 분류군에 비해서 전체적으로 화주가 다소 비후하여 원통형이며(Fig. $5 \mathrm{~W}$ ), 간혹 기부가 약간 비후하 기도 한다. 4) 곤봉형(Fig. $4 \mathrm{D})$ : 화주의 정단이 비후한 형
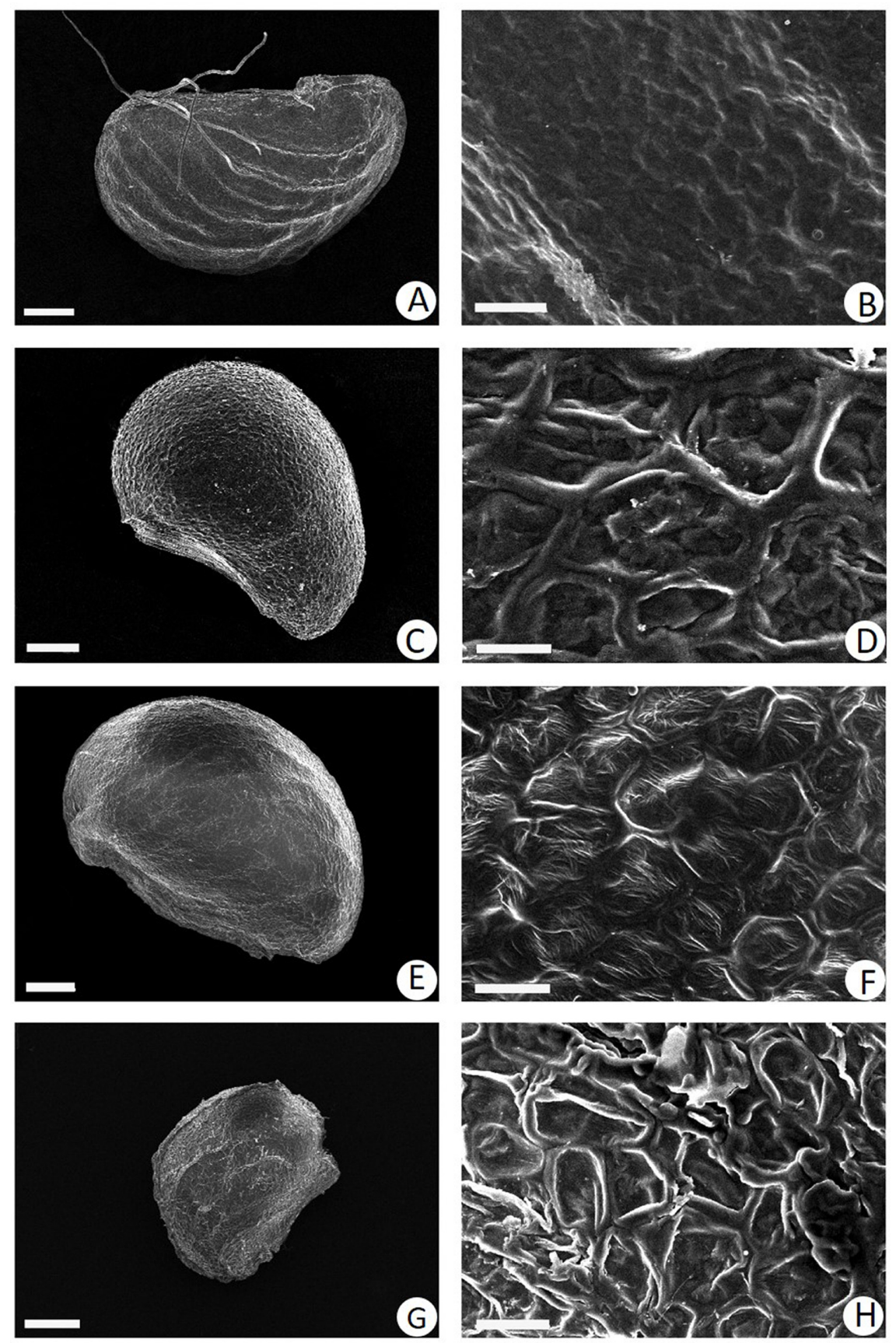

Fig. 7. SEM photographs of fruits. Fruit shape (left, scale bar $=200 \mu \mathrm{m}$ ) and fruit surface (right, scale bar $=25 \mu \mathrm{m})$. A, B. Potentilla chinensis. C, D. P. discolor. E, F. P. nivea. G, H. P. centigrana. 
태로, 물싸리와 물싸리풀은 눈에 띄게 팽창하며, 양지꽃 절은 다소 팽창한다. 물싸리(Fig. 5A), 물싸리풀(Fig. 5B), 딸기(Fig. 5C), 흰땃딸기(Fig. 5D), 땃딸기(Fig. 5E), 양지꽃 (Fig. 5P), 제주양지꽃(Fig. 5Q), 세잎양지꽃(Fig. 5R), 털양 지꽃(Fig. $5 \mathrm{~S}$ )에서 관찰된다.

4) 자방

암술은 흰털이 밀생한 화탁통 위에 위치한다. 자방에 는 털이 있는 것처럼 보이나, 실제로 많은 분류군에는 자
방에 털이 없다. 물싸리에서는 자방 위에 많은 털이 밀생 하고, 돌양지꽃에서는 자방 위에 털이 골고루 분포하며, 물싸리풀에서는 산재하는 드문 털이 관찰된다. 딱지꽃은 자방의 기부에 털이 있다. 나머지 20 분류군들은 자방위 에 털이 없다.

5) 수과(Figs. 6-10)

수과의 털은 소수의 분류군에서만 관찰된다. 딱지꽃 (Fig. 7A, B)은 제(hilum) 주변에 털이 분포하고, 물싸리
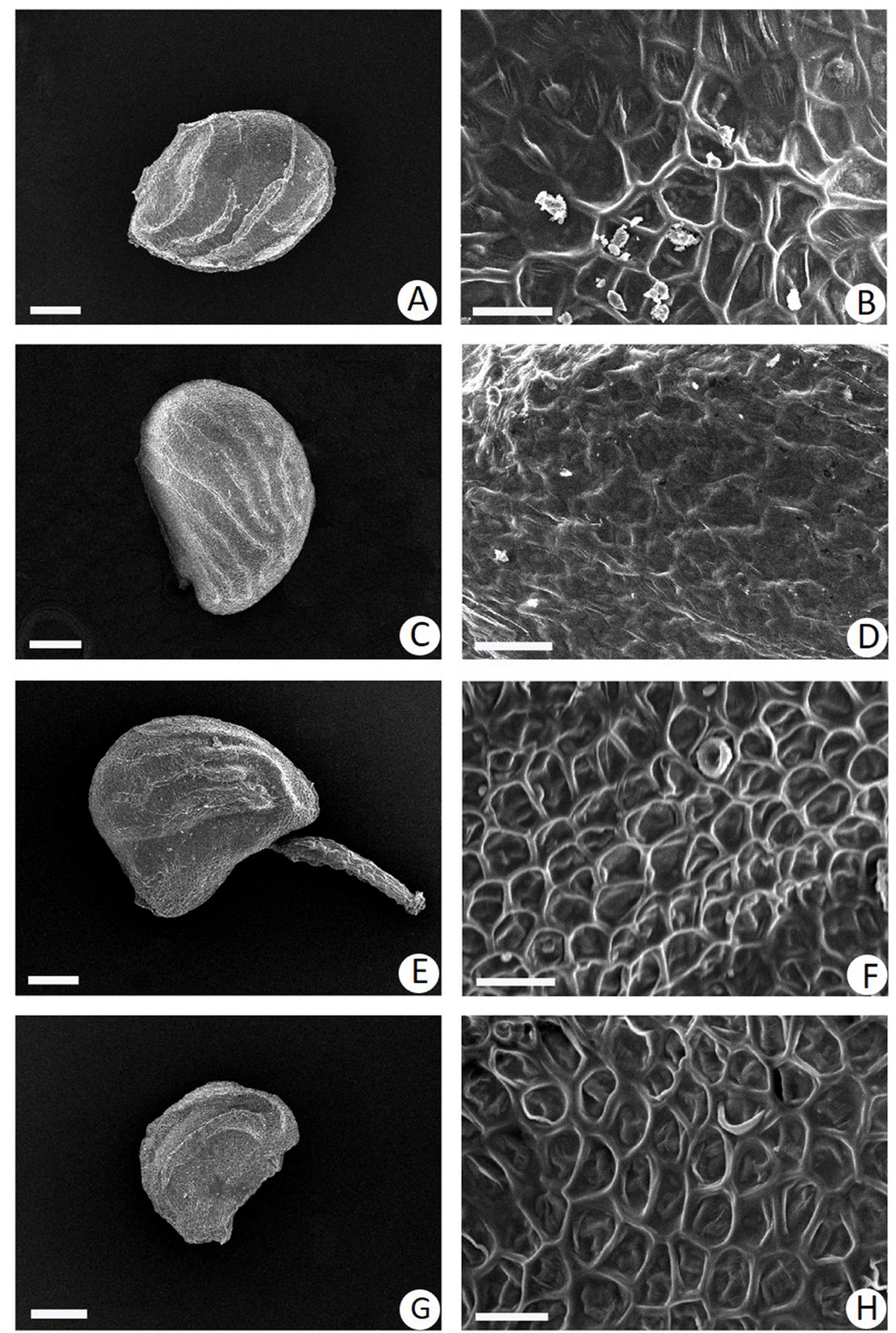

Fig. 8. SEM photographs of fruits. Fruit shape (left, scale bar $=200 \mu \mathrm{m}$ ) and fruit surface (right, scale bar $=25 \mu \mathrm{m}$ ). A, B. Potentilla anemonifolia. C, D. P. cryptotaeniae. E, F. P. supina subsp. paradoxa. G, H. P. amurensis. 
(Fig. 6A, B), 돌양지꽃(Fig. 6E, F)과 섬양지꽃(Fig. 6G, H) 은 산재하거나 또는 밀모한다. 물싸리풀은 암술에 털이 존재하지만, 수과에서는 조락한다. 나머지 한국산 양지 꽃속 20 분류군은 수과에 털이 없다. 수과의 과피 표면에 는 5-6각형의 다각형 세포가 관찰되며(예: Fig. 6D), 세포 의 크기는 과실의 크기에 비례하여 크기가 다양하나 분 류학적으로는 유용하지 않았다.
수과 표면에 주름의 존재와 돌기 여부가 분류군마다 차이가 있다.

(1) 평활형(psilate): 주름이 없거나 또는 미약하게 나타 난다(물싸리: Fig. 6A, B; 검은낭아초: Fig. 6C, D; 눈양지 꽃: Fig. 10G, H; 솜양지꽃: Fig. 7C, D).

(2) 주름형(ridged): 표면에 주름 구조가 관찰된다. 이들 은 다시 돌기 특징으로 구분된다. 첫째, 뱀딸기(Fig. 10C,
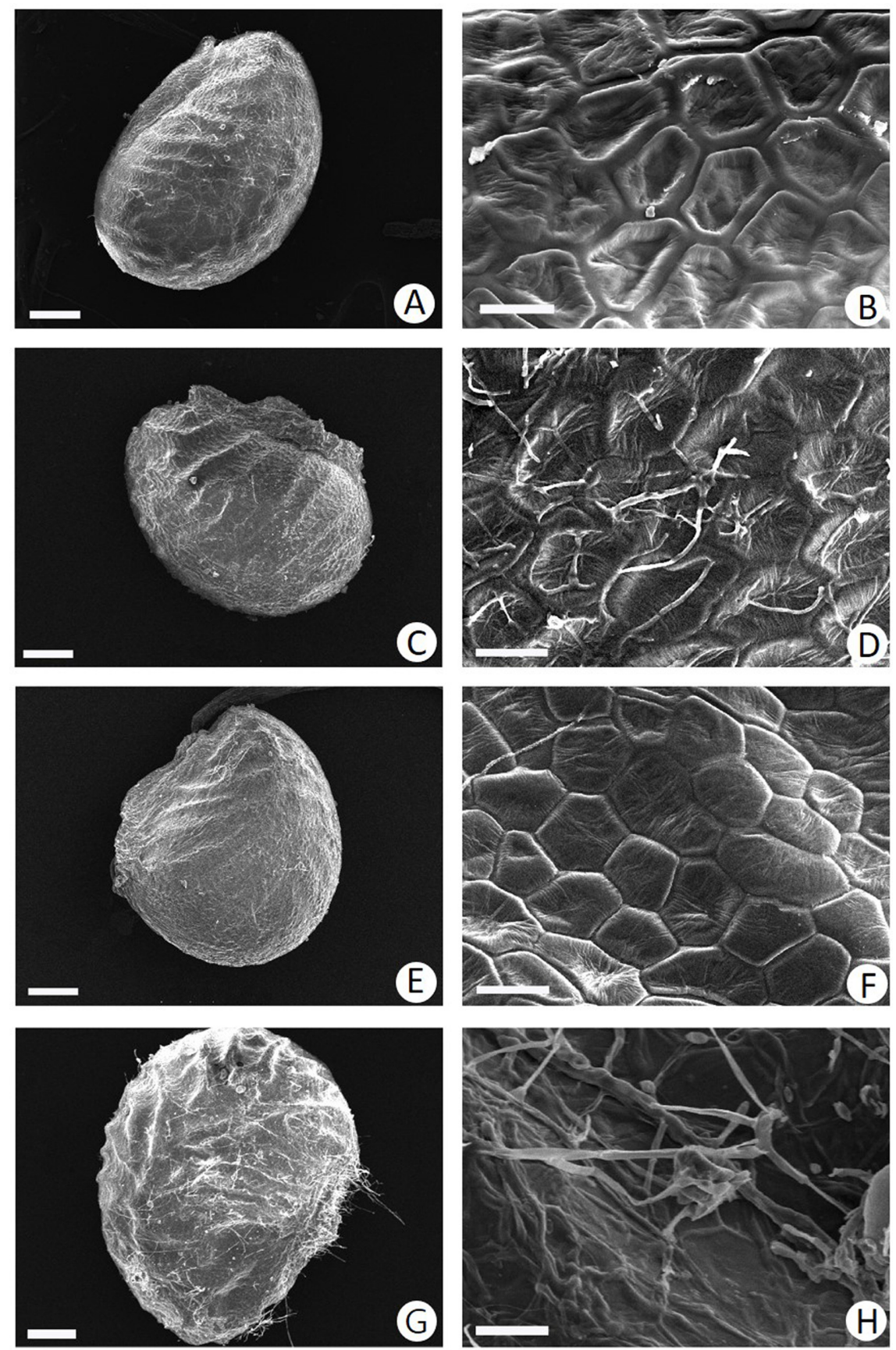

Fig. 9. SEM photographs of fruits. Fruit shape (left, scale bar $=200 \mu \mathrm{m}$ ) and fruit surface (right, scale bar: $25 \mu \mathrm{m}$ ). A, B. Potentilla fragarioides var. major. C, D. P. stolonifera var. quelpaertensis. E, F. P. freyniana. G, H. P. squamosa. 
D), 산뱀딸기(Fig. 10E, F), 좀딸기(Fig. 7G, H), 가락지나물 (Fig. 8A, B)에서는 돌기(aculeate)가 나타난다. 뱀딸기는 돌기가 많거나 또는 거의 없는 개체들이 다양하게 나타 나는 반면, 산뱀딸기는 뚜렷한 돌기들이 관찰된다. 가락 지나물과 좀딸기에서는 돌기가 드물게 관찰되지만, 주름 이 매우 뚜렷하여 날개 같은 형태를 띤다. 둘째, 주름은 존재하나 돌기는 없다(돌양지꽃: Fig. $6 \mathrm{E}, \mathrm{F}$; 섬양지꽃:
Fig. 6G, H; 딱지꽃: Fig. 7A, B; 은양지꽃: Fig. 7E, F; 물양 지꽃: Fig. $8 \mathrm{C}, \mathrm{D}$; 개소시랑개비: Fig. $8 \mathrm{E}, \mathrm{F}$; 좀개소시랑개 비: Fig. 8G, H; 양지꽃: Fig. 9A, B; 제주양지꽃: Fig. 9C, D; 세잎양지꽃: Fig. 9E, F; 털양지꽃: Fig. 9G, H; 민눈양지꽃: Fig. $10 \mathrm{~A}, \mathrm{~B})$. 특히 개소시랑개비와 좀개소시랑개비는 날 개 같은 뚜렷한 주름이 관찰되어 다른 분류군들과 구분 된다.
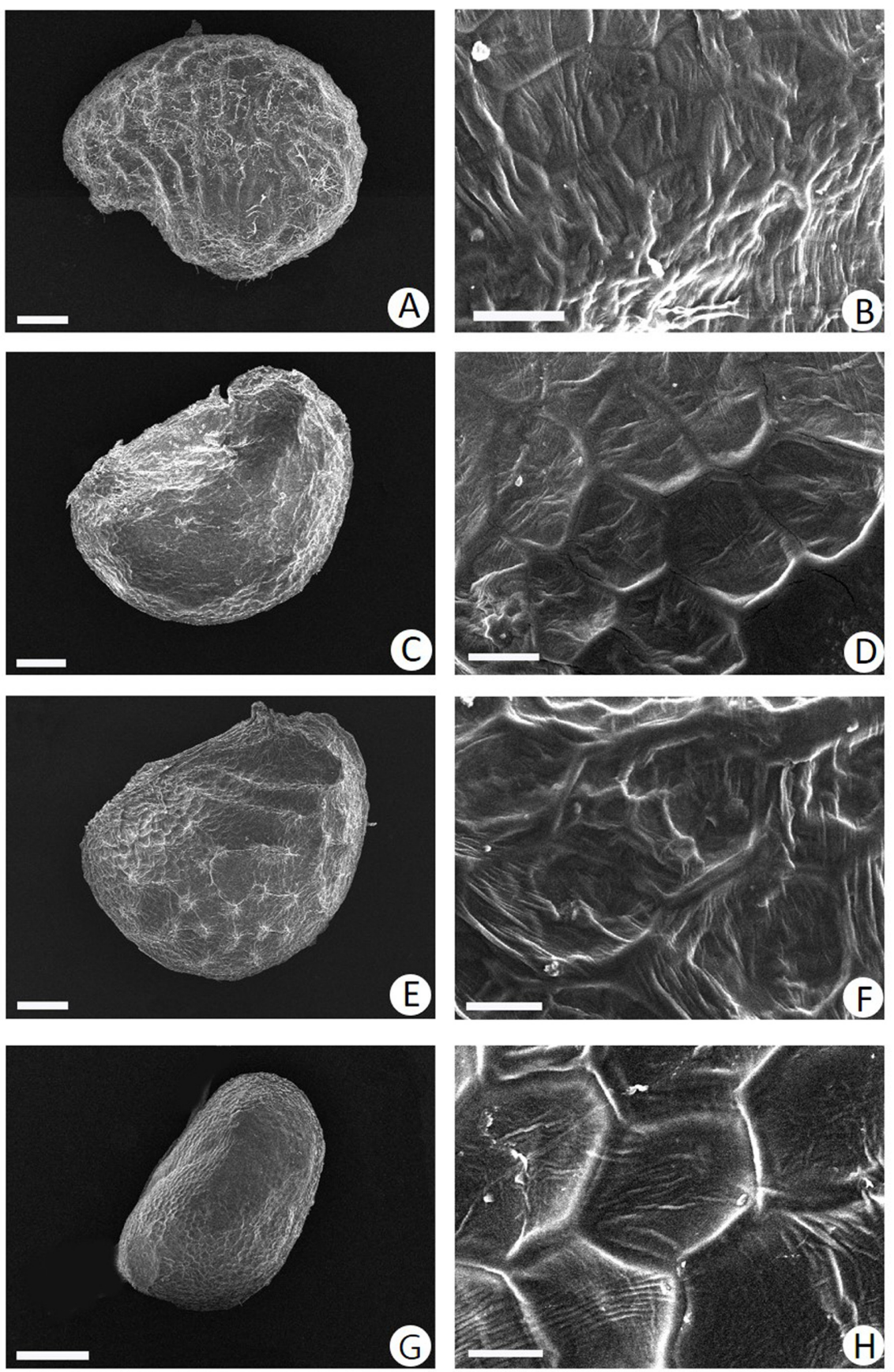

Fig. 10. SEM photographs of fruits. Fruit shape (left, scale bar $=200 \mu \mathrm{m}$ ) and fruit surface (right, scale bar $=25 \mu \mathrm{m}$ ). A, B. Potentilla yokusaiana. C, D. Duchesnea indica. E, F. D. chrysantha. G, H. Argentina egedii. 


\section{한국산 양지꽃족의 검색표}

1. 잎 표피 상납질이 발달하거나 미약하게 발달한다. 수 술은 한 개의 화분낭이 존재하며, 화주는 기저생, 아 기저생 또는 측생이다. (subtribe Fragariinae)

2. 관목이다. 자방에 털이 밀생한다

물싸리 (Dasiphora fruticosa)

2. 초본 또는 아관목이다. 자방에 털이 없거나 산재한다.

3. 줄기는 복와형이며, 포복경이 발달한다. 화주 는 측생한다. 화탁이 육질화된다.

4. 꽃은 직경 $2 \mathrm{~cm}$ 이상이고, 위과는 직경 $1.5 \mathrm{~cm}$ 이상이다 ………….... 딸기 (Fragaria $\times$ ananassa)

4. 꽃은 직경 $2 \mathrm{~cm}$ 이하이고, 위과는 직경 $1.5 \mathrm{~cm}$ 이하이다.

5. 식물의 높이는 $10 \mathrm{~cm}$ 이하이며, 소엽의 길이가 짧다 $(1.7 \mathrm{~cm}$ 이하) $\cdots . . . . . .$. 흰땃딸기 (Fragaria nipponica subsp. chejuensis)

5. 식물의 높이는 $10 \mathrm{~cm}$ 이상이며, 소엽의 길이가 길다 $(1.7 \mathrm{~cm}$ 이상 $)$

땃딸기 (Fragaria mandshurica)

3. 줄기는 직립형이며, 포복경이 발달하지 않는 다. 화주는 아기저생 또는 기저생한다. 화탁은 육질화되지 않는다.

6. 꽃잎은 노란색이다. 화주의 모양은 곤봉형 이다 ... 물싸리풀 (Sibbaldianthe semiglabra)

6. 꽃잎은 보라색이다. 화주의 모양은 사상형 이다

검은낭아초 (Comarum palustre)

1. 잎 표피 상납질이 없거나 또는 드물게 발달한다. 수 술은 두 개의 화분낭을 갖으며, 화주는 아정생한다(눈 양지꽃 제외). (subtribe Potentillinae)

7. 근생엽의 탁엽은 엽병의 앞면에 부착한다. 화주 는 측생 또는 아정생하고, 화주의 모양은 원통형 이다 눈양지꽃 (Argentina egedii)

7. 근생엽의 탁엽은 엽병의 측면에 부착한다. 화주는 아정생하고, 화주의 모양은 원뿔형, 곤봉형 또는 사상형이다.

8. 포복경에서 꽃이 하나씩 나오는 단정화서이 다. 화탁은 육질이며 매우 부푼다.

9. 잎은 녹색-진녹색이고, 다소 두껍고, 능형장타원형이며, 예두이다

뱀딸기 (Duchesnea indica)

9. 잎은 연한 녹색 또는 황녹색이며, 얇고, 넓 은 난형 또는 도란형이고, 둔두이다 산뱀딸기 (Duchesnea chrysantha)

8. 대부분 취산화이며, 드물게 줄기의 엽액에서 단정화서가 발달한다. 화탁은 육질이 아니다.

10. 잎 양면에 표피 상납질 결정체가 발달한다. 화 주는 사상형이다. 수과는 전체면이 유모이다.
11. 전국 산지 돌 틈에 서식한다. 주로 우상복엽이다. 잎 양면과 엽병에 털이 많거나 산재한다

.............. 돌양지꽃 (Potentilla dickinsii var. dickinsii)

11. 울릉도에 제한 분포한다. 삼출엽을 갖는다. 잎 양 면과 엽병에 털이 없으며, 드물게 산재한다

양지꽃 (P otentilla dickinsii var. glabrata)

10. 대부분은 잎에 표피 상납질 결정체가 발달하지 않 는다(예외: 좀딸기). 화주는 원뿔형 또는 곤봉형이 며, 드물게 사상형이다. 수과는 무모이거나 제 주위 에만 털이 있다.

12. 화주의 모양은 원뿔형이다.

13. 근생엽은 숙존한다. 소엽 뒷면에는 융모가 나타난다.

14. 바닷가 또는 저지대 양지에 분포한다. 근 경이 발달하지 않는다. 잎은 타원형이다.

15. 뿌리는 주근 1 개가 매우 발달한다 $\cdots$ 딱지꽃 (Potentilla chinensis)

15. 1-4개의 다소 비후한 방추형의 괴근 이 발달한다

솜양지꽃 (Potentilla discolor)

14. 고산지대에 분포한다. 근경이 발달한다. 잎은 난상원형 혹은 도란상원형이다 …….. 은양지꽃 (Potentilla nivea)

13. 근생엽은 조락한다. 소엽 뒷면에는 짧거나 긴 미세강모를 가진다.

16. 근생엽은 장상복엽으로 대부분 5 개의 소엽을 갖는다

... 가락지나물 (Potentilla anemonifolia)

16. 근생엽은 삼출엽 또는 우상복엽이다.

17. 소엽에는 복예거치와 예거치가 함 께 나타난다. 취산화서가 발달한다 ....

...... 물양지꽃 (Potentilla cryptotaeniae)

17. 소엽은 예거치를 갖는다. 줄기 엽액 에서 1 개의 꽃이 단생한다.

18. 포복경이 발달한다. 뿌리는 섬유 형이다. 과피에 돌기가 발달한다 ...

.... 좀딸기 (Potentilla centigrana)

18. 포복경이 발달하지 않는다. 뿌 리는 주근형이다. 과피에 돌기 가 없다.

19. 근생엽은 삼출엽이며, 정 소엽이 3 개로 심열하여 장 상엽처럼 보인다 좀개소시랑개비

(Potentilla amurensis)

19. 근생엽은 우상복엽이다 ........

... 개소시랑개비 (Potentilla supina subsp. paradoxa) 
12. 화주의 모양은 사상형 또는 곤봉형이다.

20. 근생엽은 우상복엽이다.

21. 포복경이 발달하지 않는다

양지꽃 (Potentilla fragarioides var. major)

21. 포복경이 매우 발달한다 …... 제주양지꽃

(Potentilla stolonifera var. quelpaertensis)

20. 근생엽은 삼출엽이다.

22. 소엽은 난형 또는 타원상 난형이다.

23. 포복경이 발달하지 않는다. 엽병은 무모이거나 털이 산재하며, 잎 뒷 면은 다소 짧은 미세강모가 드물 거나 산재한다

.... 세잎양지꽃 (Potentilla freyniana)

23. 포복경이 발달한다. 엽병에는 퍼진 털이 밀생하며, 잎 뒷면에는 미세 강모가 많거나 산재한다

... 털양지꽃 (Potentilla squamosa)

22. 소엽은 능형 또는 능상 난형이다

.............. 민눈양지꽃 (Potentilla yokusaiana)

\section{한국산 양지꽃족(tribe Potentilleae Sweet)의 분류 학적 처리}

1. Subtribe Fragariinae (딸기아족)

1) Dasiphora Raf. Autik. Bot. 167-168, 1840; Potentilla subg. Dasiphora (Raf,) Panigr. et Dikshit, Bull. Bot. Surv. Ind. 27: 179, 1985.

Pentaphylloides Duh., Traité Arbres Arbust. 2: 99, 1755. nomen illeg. (Potentilla L. pro syn.)

Potentilla sect. Trichocarpae subsect. Rhopalostylae grex Fruticosae T. Wolf, Biblioth. Bot. 16: 54, 1908; P. ser. Fruticosae (T. Wolf) Yü et Li., Fl. Reupublicae Popularis Sinicae. 37: 244, 1985.

\section{국명: 물싸리속}

분류학적 검토: 물싸리속은 Pentaphylloides로 기록되 거나(Naruhashi, 2003) 또는 Potentilla에 포함되기도 하였 다(Wolf, 1908; Lee, 2003; Li et al., 2003). 관목이며, 잎은 전연이고, 화주는 아기저생하는 형태적인 특징으로 다른 속들과 잘 구분된다. 분자분류학적 연구 결과에서도 물 싸리속은 딸기아족 분계조에 포함되어 양지꽃아족의 양 지꽃속과는 확연한 차이가 있다(Eriksson et al., 1998; Dobeš and Paule 2010). 한편 물싸리속은 Pentaphylloides Duh.으로 기록되기도 하였으나, Duhamel (1755)이 Pentaphylloides를 기재할 때 이명으로 Potentilla s.s.를 명 시하였기 때문에, 후에 Pentaphylloides Duh.은 비합법명 으로 처리되었다(Eriksson et al., 1998; Kurtto and Eriksson, 2003).
(1) Dasiphora fruticosa (L.) Rydb., Monogr. N. Amer. 188, 1898; Potentilla fruticosa L., Sp. Pl. 1: 495, 1753; Pentaphylloides fruticosa (L.) O. Schwarz, Mitt. Thüring. Bot. Ges. 1: 105, 1949.

Dasiphora riparia Raf., Autik. Bot. 167, 1840.

Potentilla rigida Wall. ex Lehm., Revis. Potentill. 19, pl. 1, 1856; Potentilla fruticosa var. rigida (Wall. ex Lehm.) Th. Wolf, Biblioth. Bot. 16: 57, 1908.

국명: 물싸리

개화기: 6-8월.

서식처: 고산지대.

분포: 아시아, 유럽, 북미.

분류학적 검토: 물싸리(D. fruticosa (L.) Rydb.)는 전 세 계의 다양한 생태 환경에 널리 분포하며, 형태적인 변이 가 심하다(Klackenberg, 1983). 한반도에 분포하는 물싸리 에 대하여 Lee (1996)는 P. fruticosa var. rigida (Wall. ex Lehm.) Th. Wolf로 인식하였다. 확인 결과 P. fruticosa var. rigida는 잎 양면이 거의 무모이거나 또는 앞면에만 짧은 털이 산재하는 특징이 있다(Wolf, 1908). Li et al. (2003)는 물싸리 $(=P$. fruticosa var. fruticosa)의 잎 앞면에는 털이 산 재하거나 또는 다소 밀모하며, 뒷면에는 밀모하는 털이 있거나 없는 특징을 기록하였다. Heo et al. (2013)의 잎 표 피의 털 형질 연구 결과에 따르면 백두산 및 함북 지역에 분포하는 개체들은 잎 앞면에는 털이 밀모하거나, 산재 하거나, 또는 무모며, 뒷면에는 털이 없거나 드물게 관찰 됨에 따라서 물싸리의 잎의 털 변이는 매우 심한 것으로 나타났다. 따라서 P. fruticosa var. rigida의 잎의 털 특징은 D. fruticosa의 변이폭에 포함되므로 두 식물은 동일종으 로 판단된다. Naruhashi (2003)는 이미 P. fruticosa var. rigida를 D. fruticosa의 이명으로 처리한 바 있다. 물싸리 중에서 꽃잎이 흰색인 개체가 흰물싸리(P. fruticosa var. mandschurica Maxim., Bull. Acad. Imp. Sci. St. Petersbourg 19: 164, 1873)로 발표되었으나, 물싸리의 꽃잎 색은 노란 색, 황백색, 또는 백색으로 다양한 생태 변이가 나타난다 고 지적되었다(Klackenberg, 1983). 본 연구에서는 흰물싸 리를 직접 관찰하지 못하였으므로 추후 분류학적 처리를 시도하고자 한다.

2) Sibbaldianthe Juz., Fl. URSS 10: 615, 1941.

Potentilla sect. Trichocarpae subsect. Rhopalostylae grex Bifurcae Th. Wolf, Biblioth. Bot. 16: 62, 1908; Potentilla ser. Bifurcae (Wolf) Yü et Li, Fl. Reupublicae Popularis Sinicae. 37: 250, 1985.

Potentilla subg. Schistophyllidium Juz. ex Fed. Fl. Armen.3: 87, 1958; Schistophyllidium (Juz. ex Fed.) Ikonn. Opred. Vyssh. Rast. Badakhshana 210, 1979; Sibbaldianthe subg. Schistophyllidium (Juz. ex Fed.) Mosyakin \& Shiyan, 
Phytotaxa. 296: 101-117, 2017.

국명: 물싸리풀속

분류학적 검토: 물싸리풀속은 광의의 양지꽃속 (Potentilla s.l.)에 포함되어 Potentilla subgenus Schistophyllidium Juz. ex Fed. (1958)으로 인정되기도 하였 으며, 후에 독립된 속인 Schistophyllidium (Juz. ex Fed.) Ikonn. (1979)로 처리되었다. 최근 분자계통분류학적 연 구 결과에 의하면 Sibbaldianthe type 종인 S. adpressa (Bunge) Juzepczuk는 Schistophyllidium bifurcum (L.) Ikonnikov (=Potentiilla bifurca L.)와 동일 분계조에 포함되 어 유연관계가 매우 가까운 것으로 나타났으며(Kurtto and Eriksson et al., 2003; Eriksson et al., 2015), 이미 형태 학적으로도 두 종은 매우 유사하다고 기록되었다(Wolf, 1908). 이러한 두 속의 밀접한 유연관계의 이유로 학명의 선취권에 따라서 본 속은 Sibbaldianthe로 인정되고 있다 (Paule and Soják, 2009; Eriksson et al., 2015; Mosyakin and Shiyan, 2017).

(1) Sibbaldianthe semiglabra (Soják) Mosyakin \& Shiyan, Phytotaxa. 296: 101-117, 2017.

Potentilla bifurca var. major Ledeb. Fl. Ross. 2: 43, 1843.

Potentilla. bifurca var. glabrata Lehmann, Rev. Potent. 33, 1851.

Potentilla semiglabra Juzepczuk, Weeds URSS 3: 124, 1934. nom. inval. descr. ross.

Schistophyllidium bifurcum subsp. semiglabrum Soják. Notes on Potentilla XXI. 357, 2008.

국명: 물싸리풀

개화기: 6월.

서식처: 고산지대.

분포: 아시아, 유럽 중부-동부.

분류학적 검토: Sibbaldianthe bifurca 그룹에는 세 분류 군이 있다고 알려져 왔다(S. bifurca (L.) Kurtto \& T. Eriksson, S. orientalis (Soják) Mosyakin \& Shiyan, $S$. semiglabra (Soják) Mosyakin \& Shiyan (Soják, 2008a; Mosyakin and Shiya, 2017). Mosyakin and Shiya (2017)는 물싸리풀속에 대한 심도 깊은 분류학적인 연구를 수행하 였다. 이에 따르면 S. bifurca은 주로 시베리아, 카자흐스 탄 북부, 중국 서부, 몽고, 유럽 극동부에 분포하며 줄기 가 직립하고 줄기와 엽병에 옆으로 퍼진 털(patent pubescence)이 존재하는 특징을 가지며, S. orientalis는 중 국과 유럽 남동부에서 중앙아시아까지 분포하며, 줄기, 엽병, 화경에 눌러진 털(appressed pubescence)이 관찰되 고, 특히 줄기 아랫부분에 털이 있다고 기록하였다. 이러 한 두 종과 달리 S. semiglabra은 극동지방, 몽고, 중국 북 동부에만 제한 분포하며 줄기 아랫부분이 무모이고, 줄
기의 윗부분과 엽병에는 눌러진 털(apressed trichomes)이 있는 특징으로 정리하였다. 백두산에 분포하는 물싸리풀 은 잎 앞면은 무모이고 뒷면과 엽병에는 누운털이 있으며 (Fig. 2M-O in Heo et al., 2013), 분포 특징 및 줄기에 누운 털이 있거나 줄기가 무모인 특징을 갖고 있으므로 물싸리 풀을 S. semiglabra로 인식함이 타당하다고 판단된다. 추가 적인 S. bifurca 그룹의 분류군 간의 비교 연구를 수행하여 보다 확실한 종간 한계 규명이 필요하다고 판단된다.

3) Fragaria L., Sp. Pl. 1: 494, 1753.

국명: 딸기속

분류학적 검토: Wolf (1908)는 딸기속을 독립된 속으로 인정했으나, 딸기속의 한 종인 Fragaria sterilis L.을 Potentilla sterilis (L.) Garcke로 처리하였다. Panigrahi and Dikshit (1985)와 Shah and Wilcock (1993) 또한 P. sterilis을 인정하기도 하였다. Mabberley (2002)는 단지 화탁이 부 풀고 먹을 수 있는 특징만으로 딸기속을 독립된 속으로 처리하는 것은 무리가 있으며, 양지꽃속에 통합 처리하 는 것이 타당하다고 주장하기도 하였다. 그러나 딸기속 은 확탁이 육질화 되는 특징뿐만 아니라, 화주가 자방에 측생하는 특징(Fig. $5 \mathrm{C}-\mathrm{E}$ ), 다수의 분자분류학적 연구 결 과에서 양지꽃족의 자매군인 딸기아족에 포함되고 있으 므로(Soják, 2008a; Dobeš and Paule, 2010; Feng et al., 2017), 양지꽃아족의 양지꽃속과는 확연히 구분된다.

(1) Fragaria $\times$ ananassa (Weston) Duchesne ex Rozier, Cours Compl. Agric. 5: 52, t. 5, f. 1, 1785; Fragaria chiloensis var. ananassa Weston, Bot. Univ. 2: 329, 1771. P. × ananassa (Rozier) Mabb., Telopea 9: 796, 2002.

국명: 딸기

개화기: 4-7월.

서식처: 식재.

분포: 전 세계에 널리 식재.

분류학적 검토: 딸기 $(F . \times$ ananassa $)$ 는 전 세계에 널리 재배되는 종으로 F. virginiana Mill.와 F. chiloensis (L.) Mill. 의 잡종으로 알려져 있다(Hancock et al., 2010). 딸기는 꽃 의 직경이 $2 \mathrm{~cm}$ 이상이고, 과실의 크기가 $1.5 \mathrm{~cm}$ 이상으로, 꽃의 직경이 약 $1.5 \mathrm{~cm}$ 이고 과실의 크기가 약 $1 \mathrm{~cm}$ 정도인 고산지대에 분포하는 땃딸기와 잘 구분된다.

(2) Fragaria nipponica subsp. chejuensis Staudt \& Olbricht, Bot. Jahrb. Syst. 127: 330-332, 2008.

국명: 흰땃딸기

개화기: $5-6$ 월.

서식처: 고산지대.

분포: 한국(한라산). 
분류학적 검토: 흰땃딸기는 우리나라 여러 도감 등에 서 F. nipponica Makino (Lee, 1996; Lee, 1999; Lee, 2003) 로 사용되어 왔다. Fragaria nipponica 식물 그룹에 대한 형태학적, 세포학적, 화분학적인 연구를 수행한 Staudt and Olbricht (2008)에 따르면 F. nipponica subsp. nipponica 는 식물체, 잎, 꽃, 과실 등의 크기가 전반적으로 $F$. nipponica subsp. yakusimensis (Masamune) Staudt \& Olbricht와 F. nipponica subsp. chejuensis Staudt \& Olbricht 보다 크므로 잘 구분되며, subsp. nipponica는 Honshu, Hokkaido, Kuril 지방에 널게 분포한다고 지적하였다. 이 에 반하여 제주도 한라산에 분포하는 흰땃딸기는 지리적 으로 독립되어 있으며, 식물체가 작고, 간혹 엽병에 부소 엽이 존재하는 특징으로 인해서 독립된 아종으로 기재하 였다(Staudt and Olbricht, 2008). 본 연구에서는 Staudt and Olbricht (2008)의 견해에 따라서 흰땃딸기를 F. nipponica subsp. chejuensis으로 정리하였으며, 추가적인 $F$. nipponica 식물 그룹의 종간 유연관계 및 진화 경향성에 대한 심도 있는 연구가 필요하다고 판단된다. 한편 한라 산에 분포하는 흰땃딸기는 식물 높이가 $10 \mathrm{~cm}$ 이하이고 소엽은 도난상 원형 또는 도란형이며 소엽 길이가 $1.7 \mathrm{~cm}$ 이하인 특징을 가졌으며, 백두산에 분포하는 땃딸기는 높이가 14.5-20.5 cm 정도이고 소엽이 도란형이며 소엽 길이가 $1.7-3.1 \mathrm{~cm}$ 정도의 특징을 가져 형태적으로 구분 된다.

(3) Fragaria mandshurica Staudt, Bot. Jahrb. Syst. 124: 397-419, 2003.

Fragaria yezoensis Hara, J. Jap. Bot. 20: 118, 1944; Fragaria nipponica var. yezoensis (H. Hara) Kitam., Acta Phytotax. Geobot. 20: 199, 1962.

국명: 땃딸기

개화기: 6-7월.

서식처: 고산지대.

분포: 한국(백두산), 중국 동북부, 몽고, 러시아.

분류학적 검토: 땃딸기의 학명은 F. nipponica var. yezoensis (Hara) Kitam. (Lee, 2003), F. nipponica subsp. mandsurica (Staudt) Y. Lee (Lee, 1999) 등으로 기록되어 왔 다. 조사결과 F. mandchurica는 자웅동주이며, 이배체인 특징을 가지며, 중국 북동부 분포지역에 위치한다. 이에 반하여 형태가 가장 유사한 F. orientalis Losinsk.는 식물체 가 자웅이주이고 사배체인 특징이 보고되었다(Staudt, 2003; Lei et al., 2016). 그러므로 자웅동주의 특징을 가지 는 백두산에 분포하는 땃딸기는 F. mandchurica로 판단된 다. 백두산에 분포하는 땃딸기에 대한 실체 파악을 위해 서 중국 북동부 지역 및 백두산에 분포하는 딸기속 종들 에 대한 보다 심도 깊은 세포학적인 연구 및 분자 계통학 적인 연구가 필요하다.
4) Comarum L., Sp. Pl. 1: 502. 1753; Potentilla sect. Comarum (L.) Tausch, Hort. Canal., 1823; Potentilla subg. Comarum (L.) Jepson. Man. Fl. Pl. Calif. 483, 1925.

국명: 검은낭아초속

(1) Comarum palustre L., Sp. P1.: 502, 1753; Fragaria palustris (L.) Crantz, Stirp. Austr. Fasc. 2: 11, 1763; Potentilla palustris (L.) Scop., Fl. Carniol. ed. 2, 1: 359, 1772. Potentilla comarum Nestl., Monogr. Potent. 36, 1816.

국명: 검은낭아초

개화기: 6-8월.

서식처: 습지.

분포: 북반구.

분류학적 검토: 검은낭아초는 화피가 어두운 보라색이 고, 화탁이 다소 부풀며, 해면질인 특징을 가진다 (Rydberg, 1898). 본 분류군은 잎 양면 표피에 섬유질이 발 달하며(Heo et al., 2013), 화분학적 연구결과 양지꽃족에 서 유일하게 유선상 망상의 표면무늬가 관찰되고 $(\mathrm{Heo}$, 2009), 형태적으로 사상형의 화주, 화주가 자방에 측생하 는 특징(Fig. $5 \mathrm{~F}$ )으로 다른 분류군들과 잘 구별된다.

2. Subtribe Potentillinae (양지꽃아족)

1) Argentina Hill., Brit. Herb., 1756; Potentilla subgen. Argentina (Hill) Jeps., Fl. Calif. 2: 175, 1936.

국명: 눈양지꽃속

분류학적 검토: 눈양지꽃속(Argentina)은 학자에 따라 서 독립된 속으로 처리되거나 광의의 양지꽃속(Potentilla s.l.)에 포함되어 왔다(Rydberg, 1898; Wolf, 1908). 최근의 엽록체 DNA 분석에 근거한 분자분류학적 연구결과에 따 르면 양지꽃아족 분계조에서 눈양지꽃속은 단계통을 형 성하며 아족내 다른 속들의 자매군을 이루고 있으며, 핵 DNA 분석에서는 딸기아족 분계조에 포함되는 결과를 나 타냈다(Töpel et al., 2011; Dobeš et al., 2015; Eriksson et al., 2015; Feng et al., 2017). 또한 눈양지꽃속은 아정생 화주도 관찰되지만 양지꽃아족에서 유일하게 자방에 측생하는 화주 특징을 갖는다(Wolf, 1908). Soják (2010)은 눈양지꽃 속의 경우 근생엽의 탁엽이 엽병의 앞면(ventral)에 위치하 는 공통파생형질을 갖는 반면에, 양지꽃속의 근생엽의 탁 엽은 엽병의 측면(lateral)에 위치하는 확연한 차이를 발견 하였으며, 이에 따라서 독립된 속으로서 눈양지꽃속을 처 리하였다. 이러한 분자형질 및 형태형질에 근거하여 눈양 지꽃속은 독립된 속으로 인정된다.

(1) Argentina egedii (Wormsk. ex Hornem.) Rydb., Monogr. N. Amer. Potent. 158, 1898; Potentilla egedii Wormsk. ex Hornem., Fl. Dan. 9: 5, pl. 1578, 1818; P. 
anserina var. egedii (Wormsk. ex Hornem.) Torr. et A. Gray. Fl. N. Amer. 1: 444, 1840; P. anserina subsp. egedii (Wormsk. ex Hornem.) Hitt., Suom. Kasvio: 449, 1933; Argentina anserina subsp. egedii (Wormsk. ex Hornem.) Á. Löve \& Ritchie, Canad. J. Bot. 44: 435, 1966.

Potentilla anserina var. groenlandica Tratt., Rosac. Monogr. 4: 13, 1824; P. egedii var. groenlandica (Tratt.) Polunin, Rhodora 41: 40, 1939; Argentina anserina subsp. groenlandica (Tratt.) Á. Löve, Taxon 19: 300, 1970.

국명: 눈양지꽃

개화기: 6-8월.

서식처: 바닷가 근처 습지.

분포: 유라시아_아메리카에 널게 분포.

분류학적 검토: 국내에서 눈양지꽃은 학자에 따라 $P$. anserina L. (Nakai, 1911; Chung et al., 1937; Park, 1949), P. pacifica Howell (Nakai, 1952; Chung, 1957; Ahn and Park, 1974), 또는 P. egedei var. groenlandica (Tratt.) Polunin (Lee, 1996; Lee, 1999; Lee, 2003)로 기록되어 학명 사용에 혼란 이 있어 왔다.

눈양지꽃이 포함된 식물 그룹을 독립된 속인 Argentina 으로 인정한 Rydberg (1898)는 잎의 형태와 털 특징으로 A. anserina 복합체를 A. anserina (L.) Rydb. var. anserina, A. anserina var. grandis (Torr. \& A. Gray) Rydb. (= P. pacifica), A. egedii (Wormsk. ex Hornem.) Rydb.로 정리하 였다. 후에 A. anserina 복합체에 대한 심도 깊은 생분류학 적(biosystematic) 연구를 수행한 Rousi (1965)는 $P$. anserina subsp. anserina는 잎 뒷면에 견모(silverysericeous)가 존재하는 반면에 subsp. egedii (Wormsk. ex Hornem.) Hiitonen와 subsp. pacifica (Howell) Rousi는 연모 (pubescence)가 존재하거나 드물게 무모이며, 엽맥을 제 외하고 곱슬거리는 털의 특징을 가져 구분됨을 확인하였 다. 그리고 두 아종간의 차이로는 subsp. egedii의 경우 측 소엽이 3-7쌍, 거치는 4-9쌍을 가지고 심피는 20-50개를 갖는 반면에, subsp. pacifica는 측소엽이 대개 7쌍 이상이 고, 거치는 9쌍 이상이며, 심피는 100 개 이거나 그 이상을 갖는 특징을 보고하였다. 이와 같이 A. egedii가 $A$. anserina의 아종으로 처리되기도 하였으나, 후에 A. egedii 는 A. anserina보다는 작은 식물체 크기 특징뿐 아니라 포 복경이 무모이며 소엽에 견모가 없는 특징으로 독립된 종으로 지지되었다(Trelawny, 1983; Soják, 2004). 우리나 라에 분포하는 눈양지꽃의 잎과 엽병의 털 형질 관찰 결 과 잎 뒷면에는 곱슬한 융모가 밀모하고 미세강모가 나 타나므로 A. anserina와는 구분되었다(Heo et al., 2013). 또 한 형태형질 관찰 결과 눈양지꽃은 측소엽이 5-7쌍, 소엽 의 길이가 $1.5-3.2 \mathrm{~cm}$, 화경 길이는 6-21 cm, 거치는 7-9쌍 이었고, 심피는 50 여개의 특징으로 A. anserina subsp. pacifica와도 차이가 있다. 따라서 이러한 확연한 잎의 특
징과 잎 뒷면의 털 특징으로 눈양지꽃은 $A$. egedii으로 인 식함이 타당하다고 판단된다.

2) Duchesnea Sm., Trans. Linn. Soc. London, 10: 372 374, 1811; Potentilla sect. Duchesnea (Sm.) Panigr. et Dikshit, Bull. Bot. Surv. Ind. 27: 181, 1985; Potentilla subgen. Duchesnea (Sm.) Shah et Wilcock, Edinb. J. Bot. 50: 176, 1993.

국명: 뱀딸기속

(1) Duchesnea indica (Andrews) Teschem., Hort. Reg. \& Gard. Mag. 1: 460, 1835; Fragaria indica Andrews, Bot. Repos. VII. t. 479, 1807; P. indica (Andrews) Th. Wolf, Asch. \& Graebn. Syn. Mitteleur. Fl. 6: 661, 1904.

Potentilla denticulosa Ser., DC., Prodr. 2: 573, 1825.

P. indica var. serrulata Th. Wolf, Biblioth. Bot. 16 (Ht. 71): 666, 1908.

Duchesnea indica var. major Makino, Bot. Mag. (Tokyo) 28: 184, 1914; D. major (Makino) Makino, J. Jap. Bot. 2: 19, 1921.

국명: 뱀딸기

개화기: 4-5월.

서식처: 양지바른 곳, 풀밭.

분포: 아시아, 북미, 인도, 유럽.

분류학적 검토: Nakai (1909)와 Chung et al.(1937)은 $D$. indica (Andrews) Teschem.를 배암딸기("Hebiichigo"), Chung et al. (1949)은 D. wallichiana (Ser.) Nakai ex H. Hara 를 뱀딸기(“Hebiichigo")로 기록하였다. Park (1949)은 $D$. indica를 배암딸기("Yabuhibiichigo")로 정리했으며, $D$. wallichiana를 큰배암딸기("Hebiichigo")로 언급하였다. 후에 Nakai (1952)는 D. wallichiana 만이 우리나라에 분포 한다고 기록하였으며, Chung $(1957,1974)$ 은 전국에 야생 하는 뱀딸기를 D. wallichiana (Ser.) Nakai로 인식하였고, $D$. indica는 이명으로 보았다. 그러나 Ahn and Park (1974)의 경 우 D. indica는 홍실뱀딸기, D. wallichiana는 뱀딸기로 언급 하였고, 다시 Lee (1976)는 우리나라 전국에 분포하는 분류 군을 D. indica (뱀딸기, "Hebiichigo")로 기록하였다. 후에 도감 등에서 전국에 분포하는 분류군을 D. chrysantha (Zoll. \& Moritzi) Miq. (뱀딸기)로 기록하였으며(Lee, 1996; Lee, 1999; Lee, 2003), Lee (1996)는 D. indica를 민뱀딸기로 언급하기도 하였다. 이렇듯 지금까지 본 분류군에 대한 국 명 및 학명에 대한 혼란이 있어왔으며, 이는 Nakai (1909)가 전국에 분포하는 분류군인 D. indica을 일본의 "Hebiichigo" 로 기록하면서 분류학적인 혼란이 발생한 것으로 여겨진 다. 확인 결과 일본에서는 "Hebiichigo"를 D. chrysantha로 인정하고 있으며, "Yabuhibiichigo"를 D. indica로 기록하고 있다(Ohwi, 1965; Naruhashi, 2003). 따라서 우리나라 전국 
에 분포하는 식물은 원기재문, 문헌조사, 표본관찰 등의 결과 잎의 색깔이 녹색-진녹색이며, 소엽 형태는 능형장타원형이고 예두이며, 꽃잎은 도란형 또는 좁은 도란 형 등의 특징으로 D. indica (뱀딸기)임이 분명하다. 현재 국가생물종목록에서는 D. indica의 국명을 민뱀딸기로 하고, D. chyrsantha의 국명을 뱀딸기로 표기하고 있어, 국 명에 혼선이 있으므로 검토가 필요하다.

(2) Duchesnea chrysantha (Zoll. \& Moritzi) Miq., Fl. Ned. Ind. 1: 372, 1855; Potentilla wallichiana Ser., Prodr. 2: 574, 1825; Duchesnea wallichiana (Ser.) Nakai ex H. Hara, J. Jap. Bot. 10: 22-23, 1934

Fragaria chrysantha Zoll. \& Moritzi, Syst. Verz. 7, 1846; Duchesnea chrysantha (Zoll. \& Moritzi) Miq., Fl. Ned. Ind. 1: $372,1855$.

Fragaria indica Andrews var. wallichii Franch. \& Sav., Enum. Pl. Jap. 1: 129, 1873; Potentilla indica var. wallichii (Franch. \& Sav.) Th. Wolf, Biblioth. Bot. 71: 666, 1908.

Duchesnea formosana Odash. J. Soc. Trop. Agric. 7: 79, 1935.

Duchesnea indica var. japonica Kitam., Acta Phytotax. Geobot. 15: 160, 1954; Duchesnea indica var. leucocephala Makino f. japonica (Kitam.) M. Mizush., Misc. Rep. Res. Inst. Nat. Resources 45: 68, 1957.

국명: 산뱀딸기

개화기: 5 월.

서식처: 깊은 산의 양지.

분포: 아시아.

분류학적 검토: Li et al. (2003)에 따르면 산뱀딸기(D. chrysantha (Zoll. \& Moritzi) Miq.)는 소엽 길이가 1.5-2.5 $\mathrm{cm}$, 꽃 직경은 $0.5-1.5 \mathrm{~cm}$, 취과가 익으면 엷은 분홍색이 고 취과에 광택이 없고 직경은 $0.8-1.2 \mathrm{~cm}$ 이고, 수과에 주 름이 있는 특징을 가지는 반면, 뱀딸기 $(D$. indica)는 소엽 길이가 2-3.5 cm, 꽃은 직경이 $1.5-2.5 \mathrm{~cm}$, 취과가 익으면 붉은색이고 광택이 나며 직경은 1-2 cm이고, 수과는 눈에 띄지 않는 유두상돌기를 가져 구분된다고 기록하였다. 관 찰 결과 뱀딸기의 소엽과 과실 크기의 변이가 다양하여 산뱀딸기의 특징이 이와 중첩되었다. 수과의 유두상 돌 기 특징 연구 결과에서도 뱀딸기의 경우 돌기가 없거나 발달하여 다양한 변이가 관찰되었으며(Fig. 9C, D), 산뱀 딸기는 미약하게 발달하거나 매우 발달하는 것으로 관찰 되어(Fig. 9E, F), Li et al. (2003)이 지적한 형질 특징들은 두 분류군 간에 중복되었다. 그러나 본 연구 결과 산뱀딸 기는 잎이 연한 녹색 또는 황녹색을 띄며, 소엽이 얇아 다 소 막질의 질감이고, 소엽 형태는 넓은 난형 또는 도란형 이고, 둔두형인데 반하여, 뱀딸기는 잎의 색깔이 녹색-진 녹색이며, 소엽은 다소 두껍고, 소엽 형태는 능형-장타원
형이고 예두인 특징이 확인되었다. 또한 부악편의 크기 (길이/너비)에서 산뱀딸기는 $0.46-0.87 / 0.33-0.89 \mathrm{~cm}$ 정도 로서 $0.55-1.3 / 0.47-1.22 \mathrm{~cm}$ 인 뱀딸기보다 다소 작은 특징 으로 차이가 있었다. 따라서 소엽의 색, 질감, 엽형, 부악 편의 크기 특징이 두 분류군 간의 구별에 유용한 형질로 판단된다.

3) Potentilla L., Sp. Pl. 1: 495, 1753.

국명: 양지꽃속

1) Sect. Nematostylae Gusuleac, Savulescu, Fl. Reipubl. Popularis Roman. 4: 601, 1956.

국명: 돌양지꽃절

(1) Potentilla dickinsii Franch. et Sav., Enum. Pl. Jap. 2: 337, 1878; P. ancistrifolia var. dickinsii (Franch. et Sav.) Koidz., Bot. Mag. (Tokyo) 23: 177, 1909.

P. dickinsii var. breviseta Nakai, Repert. Spec. Nov. Regni Veg. 13:275, 1914.

P. dickinsii var. typica Nakai, Bot. Mag. (Tokyo) 32: 106, 1918.

P. dickinsii var. glabrata Nakai, Bot. Mag. (Tokyo) 32:106, 1918.

P. dickinsii var. para-rugulosa Kitag., J. Jap. Bot. 42: 100, 1967.

국명: 돌양지꽃

개화기: 6-8월.

서식처: 산지 바위 틈.

분포: 한국(황해 이남), 중국, 일본.

분류학적 검토: 지금까지 한국산 P. dickinsii Franch. et Sav. 의 근연 분류군에 대하여 여러 종이 언급되어 왔다. Chung et al. (1949)은 P. ancistrifola Bunge를 당양지꽃으로, P. dickinsii를 돌양지꽃으로 기록하였고, Ahn and Park (1974)은 P. rugulosa Kitagawa를 당양지꽃으로, Lee (1996) 는 P. dickinsii를 돌양지꽃으로, P. rugulosa를 당양지꽃으 로 기록하였다. Li et al. (2003)는 P. ancistrifolia var. ancistrifolia는 근생엽이 2-4쌍, 소엽의 뒷면에 융모 밀집, 소엽 앞면에 두드러진 돌기(bullate)와 망상맥, 성숙한 수 과에 주름과 수과 기부 주변에 융모를 가지는 반면, $P$. ancistrifolia var. dickinsii (Franch. et Sav.) Koidz.는 근생엽 2-3쌍 또는 삼출엽, 소엽 양면에 털이 산재하거나 혹은 무모, 뒷면은 눈에 띄지 않는 망상맥, 앞면에 돌기(bullate) 없고, 수과가 매끄럽거나 약한 주름을 가지는 특징으로 두 분류군의 차이를 기록하였고, var. ancistrifolia가 한국 에도 분포한다고 지적하였다. 그러나 Soják (2004)은 $P$. dickinsii를 P. ancistrifolia의 이명으로 처리하였다. 본 연구 에서는 P. dickinsii 그룹에 대하여 원기재문에 기록된 특 징을 고려하여 국내 및 국외 표본관에서 확보한 표본들 
을 관찰하였다. 이러한 개체들 중 동강과 제천 등의 석회 암지대에 분포하는 식물들(Appendix 1: HKI00787, HKI00803, HKI00833, HKI00835)은 근생엽 과 경생엽이 우상복엽이었으며, 소엽은 난상 타원형-피침형, 엽선이 예두, 엽연의 거치가 고르고, 뒷면의 맥이 돌출하고 털이 많은 특징으로 P. ancistrifolia의 특징과 유사하였으나, 동 일 지역의 일부 개체에서는 전형적인 P. dickinsii의 특징 이 나타나기도 하였다. 소백산, 내장산, 소요산, 대둔산 등의 개체군(Appendix 1: HKI00797, HKI845, HKI866, HKI00789, HKI795, HKI799, HKI805, HKI861)에서는 한 개체에서 P. ancistrifolia와 P. dickinsii의 중첩된 형질이 나 타나기도 하였다. 이러한 개체군을 제외한 지역에서는 근생엽이 주로 우상복엽이거나 삼출엽이었으며, 경생엽 은 삼출엽이었고, 소엽은 원두와 예두, 엽연의 거치는 날 카롭고, 뒷면 맥은 돌출하지 않으며 털이 많은 특징이 나 타나 전형적인 P. dickinsii로 동정되었으며, 드물게 $\mathrm{Li}$ et al. (2003)가 언급한 P. ancistrifolia의 특징을 갖는 개체들 도 발견되었다. 중국과 일본의 P. dickinsii와 P. ancistrifola 식물들을 관찰한 결과에서도 두 종의 식별에 주요한 형 질들의 연속 변이가 관찰되었다. 주요 외부형태 형질을 이용한 주성분분석(PCA) 분석결과에서도 P. ancistrifolia 와 P. dickinsii은 연속되게 나타났으며(Heo, 2009), 두 분류 군 식별에 뚜렷하게 기여하는 형질은 없었다. 결과적으 로 두 분류군은 유연관계가 매우 가까운 것으로 판단되 나, 본 연구에서는 P. ancistrifolia에 대한 언급을 유보하고 자 한다. 추가적인 연구를 통하여 $P$. dickinsii와 $P$. ancistrifolia의 종간 한계를 규명하고, P. ancistrifolia의 정 확한 분류학적 위치 파악 및 한반도 분포 여부를 판단하 여야 할 것이다. 이를 위해서 두 분류군의 기준표본 관찰 이 필요하며, 형질의 중첩이 존재하므로 개체군 수준의 분자분류학적 연구를 통한 종간 한계 규명에 대한 접근 이 필요하다고 판단된다.

한편 Nakai (1909)는 두개의 식물 표본(Hab. Peukhansan. Jul. 28. 1902. fl. et fr. immat.; ibidem. Oct. 14. 1900. fr., T. Uchiyama)을 P. ancistrifolia Bunge로 기록하였다. 후에 Nakai (1914)는 참양지꽃(P. dickinsii var. breviseta Nakai)을 신변종으로 기재하면서 P. ancistrifolia로 동정했던 두 표 본을 기준표본으로 명시하였으며, 기재 특징으로 수과 기부의 털이 수과보다 짧다고 기록하였다. 본 연구에서 전국에 분포하는 다수의 돌양지꽃 $(P$. dickinsii)표본을 관 찰 결과 수과 기부의 털 길이가 수과보다 길거나 짧아 다 양하였다. 따라서 수과 기부의 털 특징만으로 신변종으 로 기재된 var. brevista는 P. dickinsii에 이명처리 됨이 타당 하다고 판단된다.

한라산에 분포하는 좀양지꽃으로 알려진 식물은 처음 에 Chung et al. (1937)과 Chung et al. (1949)에 의해서 긴양 지꽃(P. matsumurae Th. Wolf)으로 기록되었으며, 후에 Chung (1957)이 좀양지꽃(P. matsumurae)으로 언급하여
지금까지 도감 등에 수록되었다(Lee, 1996; Lee, 1999; Lee, 2003). 그러나 다수의 국내 표본 관찰에서 좀양지꽃 은 발견되지 않았으며, 본 연구의 한라산 조사 활동에서 도 발견하지 못하였다. P. matsumurae는 일본과 러시아의 북동부의 사할린과 쿠릴 지역의 고산지대에만 분포한다 고 알려져 있으며(Naruhashi, 2003), 화주 형태가 원뿔형 인 특징으로 딱지꽃절(sect. Conostylae)에 속한다. 그러나 한라산에 분포하는 좀양지꽃으로 추정되는 식물의 경우 식물체가 작고, 근생엽이 삼출엽이며 소엽의 형태 등의 특징에 의해서 P. matsumurae로 오동정한 것으로 추측된 다. 한라산 개체군은 화주 형태가 사상형이며, 화주가 자 방에 아정생하고, 근경은 목질화이며, 잎 뒷면이 분백색 인 특징으로 돌양지꽃절(sect. Nematostylae)에 속한다. 이 뿐 아니라 두 분류군은 여러 형질에서 뚜렷하게 구분되고 있다. 개화시에 P. matsumurae는 근생엽에 넓은 난형의 막 질 인엽이 발달하나 제주도 개체군은 인엽이 퇴화하고, 전자는 다소 산형화서이며 화서의 총포가 심열하거나 또 는 그렇지 않은 반면, 한라산 개체군은 취산화서이며 화 서의 총포가 난상타원형이고 예거치이다. 또한 $P$. matsumurae는 부악편이 장타원형 또는 피침형이며 둔두 또는 원두이나, 제주도 식물의 부악편은 피침형이고 예 두인 특징으로 두 분류군은 현저한 차이가 있었다. 돌양 지꽃 종류로 판단되는 제주도 개체군은 근생엽이 대부분 삼출엽이나 드물게 우상복엽을 갖고 있으며, 잎은 난상 이고, 엽선은 원두이며, 식물체의 크기가 대체로 작아 본 토에 분포하는 돌양지꽃과도 다소 차이가 있는 것으로 밝혀졌다. 형태형질을 이용한 주성분분석(Heo, 2009)에 서도 본토의 돌양지꽃과 구분되었다. 추가적인 연구를 통하여 제주도 개체군에 대한 정확한 분류학적 기재가 이루어져야 할 필요가 있다.

(2) Potentilla dickinsii var. glabrata Nakai, Bot. Mag. (Tokyo) 32: 106, 1918.

국명: 섬양지꽃

개화기: 6-7월.

서식처: 산지 바위 틈.

분포: 한국(울릉도).

분류학적 검토: 울릉도에 제한 분포하는 섬양지꽃 $(P$. dickinsii var. glabrata Nakai)은 소엽이 넓고, 예거치이며, 잎 끝부분에 작은 돌기가 있고, 앞면의 맥 위에 산재하는 털과 뒷면이 분백색이 아닌 특징으로 신변종으로 기재되 었다(Nakai, 1918). 본 연구결과 돌양지꽃의 근생엽은 주 로 우상복엽인데 반하여 섬양지꽃은 삼출엽이었으며, 섬 양지꽃은 돌양지꽃에 비하여 주로 잎에 털이 없거나 드 물고, 잎이 얇은 질감이 확인되었다. 그러나 전국에 분포 하는 돌양지꽃의 경우 설악산과 대둔산 일부 개체에서 삼출엽이 관찰되기도 하였으며, 잎 형태의 경우 돌양지 
꽃의 소엽 변이가 심하여 좁거나 넓은 형태가 모두 나타 나 섬양지꽃과 중첩되기도 하였다. 돌양지꽃 일본 개체 군 관찰에서도 잎 형태와 질감은 섬양지꽃과 매우 유사 하나 잎 뒷면에 털이 존재하는 개체가 관찰되기도 하였 다. Naruhashi (2003)는 P. dickinsii var. glabrata을 P. dickinsii var. dickinsii의 이명으로 처리하기도 하였다. 따 라서 섬양지꽃에 대한 정확한 분류학적 실체를 파악하고 근연분류군과의 유연관계를 파악하기 위해서 분자 마커 등을 이용한 추가적인 연구가 필요하다고 판단된다.

2) Potentilla sect. Conostylae (Th. Wolf) Yü et Li., Fl. Reupublicae Popularis Sinicae. 37: 279. 1985.

\section{국명: 딱지꽃절}

(1) Potentilla chinensis Ser., in DC. Prodr. 2: 581, 1825.

P. exaltata Bunge, Mem. Acad. Imp. Sci. St. Petersbourg ser. 6, Sci. Math. 2: 98, 1831.

P. pennsylvanica var. hypoleuca Regel, Ind. sem. hort. Peterop. 53, 1865.

P. chinensis $\beta$. hirtella Franch. et Sav., Enum. Pl. Jap. 2: 338, 1878; P. chinensis var. hirtella (Franch. et Sav.) Th. Wolf, Biblioth. Bot. 16 (Ht. 71): 181, 1908.

P. chinensis $\zeta$. isomera Franch. et Sav., Enum. Pl. Jap. 2:339, 1878; P. chineniss var. isomera (Franch. et Sav.) Th. Wolf, Biblioth. Bot. 16 (Ht. 71): 182, 1908; P. isomera (Franch. et Sav.) Koidz., Fl. Symb. Or. -As. 24, 1930.

P. chinensis var. lineariloba Franch. et Sav., Enum. P1. Jap. 2: 339, 1878; P. chinensis var. lineariloba (Franch. et Sav.) Th. Wolf, Biblioth. Bot. 16(Ht. 71): 181, 1908; P. chinensis f. lineariloba Franch. et Sav., Makino \& Nemoto, Fl. Jap.: 788, 1925.

P. chinensis $\alpha$. micrantha Franch. et Sav., Enum. Pl. Jap. 2: 338, 1878; P. chinensis var. micrantha (Franch. et Sav.) Th. Wolf, Biblioth. Bot. 16 (Ht. 71): 181, 1908.

P. chinensis E. ramosa Franch. et Sav., Enum. Pl. Jap. 2: 339, 1878; P. chinensis var. ramosa (Franch. et Sav.) Th. Wolf, Biblioth. Bot. 16 (Ht. 71): 181, 1908.

P. chinensis var. latifida Koidz., J. Coll. Sci. Imp. Univ. Tokyo 34: 179, 1913.

P. chineniss var. littoralis Nakai, Rep. Veg. Mt. Diam. 175, 1918.

P. pseudo-chinensis Nakai, Veg. Diamond Mt. 202, 1918; P. chinensis var. pseudo-chinensis (Nakai) Nakai, Bot. Mag. (Tokyo) 33: 57, 1919.

국명: 딱지꽃

개화기: 6-8월.

서식처: 강가와 바닷가 근처의 모래땅.

분포: 한국, 중국, 대만, 일본, 러시아 북동부, 몽고.
분류학적 검토: 딱지꽃 $(P$. chinensis Ser.)은 전국에 분포 하며 소엽 형태에 변이가 심하고, 생육지에 따라 털의 밀 도 여부가 다양하여 여러 종 이하 분류군들이 알려져 왔 다. 이들 중 소엽 열편이 중륵까지 분리되며 선형인 특징 을 가진 식물인 P. chinensis var. lineariloba Franch. et Sav. 가 한국에 분포한다고 기록되었다(Li et al., 2003). 연구결 과 제주도 및 남해안과 동해안의 일부 개체군에서 선형 열편이 발견되기도 하였다. 그러나 강원도 해안가의 경 우에는 개체군 내에서 소엽 형태 변이가 다양하여 날카 로운 선상피침형과 둔한피침형이 함께 관찰되었으며, 때 로는 근생엽의 형태는 둔한피침형이나 경생엽의 형태가 선상피침형인 개체도 발견되었다. 제주도 수월봉 해안가 절벽에서 채집한 개체를 이식하여 관찰한 결과 선형의 소엽이 난상피침형 또는 장타원상피침형으로 변형되기 도 하였다. 따라서 소엽 형질의 변이가 다양하게 나타나 는 점과, 고착된 특징이라기보다는 생육 환경에 따라서 변하기도 하므로 생태적 변이로 판단된다. P. chinensis var. lineariloba는 딱지꽃의 변이 폭에 포함됨으로 딱지꽃 에 이명처리 됨이 타당하다고 판단된다.

털딱지꽃(P. chinensis var. concolor Franch. et Sav.)은 딱 지꽃에 비하여 식물 전체에 털이 밀모하며 식물이 분백 색인 특징으로 기재되었다(Wolf, 1908). 양지꽃족 털 형질 연구결과 전형적인 털딱지꽃은 잎 앞면에 융모가 밀생하 는 반면, 딱지꽃은 대체적으로 잎 앞면에 미세강모가 존 재하는 특징이 나타났다(Heo et al., 2013). 그러나 딱지꽃 의 털 밀도 정도는 개체군 별로 다소 중첩되기도 하였다. 강원도 고성 송지호 개체군(Appendix 1: HKI00346, HKI368, HKI369, HKI392, HKI398, HKI481)에서는 털이 밀 생하는 개체와 그렇지 않은 개체가 함께 발견되었으며, 매우 드물게 한 개체 내에서 경생엽에는 털이 밀생하나, 근생엽에는 그렇지 않은 개체도 발견되었다. 따라서 개 체군 단위의 추가적인 연구를 통하여 털딱지꽃의 정확한 분류학적 실체를 파악할 필요가 있으며, 본 연구에서는 털딱지꽃에 대한 기재는 따로 다루지 않았다.

원산딱지꽃(P. niponica Th. Wolf)은 근생 소엽이 7-15개 정도(7쌍 이하)이며, 소엽 사이에 부소엽이 없고, 소엽은 중렬하며, 열편은 각각 5-6개이고, 열편 끝은 둔하고 형태 는 피침상 난형 또는 장타원상 난형이고, 악편과 부악편의 크기가 거의 같은 특징으로 기재되었다(Wolf, 1908). 연구 결과 딱지꽃의 소엽은 4-14쌍이며, 소엽 형태는 장타원형, 타원형, 도란형으로 다양하고, 부소엽은 있거나 없으며, 부 악편의 모양은 선상피침형-난상피침형으로 악편 보다 좁 거나 또는 악편과 유사한 특징을 보여 Wolf (1908)가 기재 한 원산딱지꽃의 특징과 형질의 연속성이 나타났다. 또한 $\mathrm{TI}, \mathrm{PE}$, 국내 여러 표본관의 표본을 검토한 결과에서도 딱 지꽃와 원산딱지꽃의 형질의 연속성이 관찰되었다. 원산 딱지꽃은 딱지꽃의 변이 폭에 해당된다고 여겨지지만, 추 가적인 연구를 통하여 분류학적 처리를 시도하고자 한다. 
(2) Potentilla discolor Bunge, Enum. Pl. China Bor. 25, 1833.

P. formosana Hance, Ann. Scii. Nat. Bot. Ser. 5, 5: 212, 1866; P. dikinsii Bunge var. formosana (Hence) Franch., Pl. Delavay. 3: 212, 1890.

국명: 솜양지꽃

개화기: 5-6월.

서식처: 바닷가.

분포: 한국, 중국, 일본, 대만, 동북러시아.

분류학적 검토: 솜양지꽃은 방추형의 뿌리를 갖고, 소 엽이 3쌍 이하이며 엽연에 거치가 있는 특징을 가져, 소 엽이 4-14쌍이고 소엽 엽연에 깊거나 얕은 열편이 있는 딱지꽃과는 확인하게 구분된다.

(3) Potentilla nivea L., Sp. Pl.: 499, 1753.

P. prostrata Rottb. subsp. floccosa Soják, Candollea, 44: 741-751, 1989.

국명: 은양지꽃

개화기: 6-7월.

서식처: 고산지대 바위와 건조한 지역.

분포: 북반구에 널리 분포(아시아-유럽, 북미의 아한대 지역).

분류학적 검토: Soják (1989)은 P. nivea연구에서 본 분 류군의 두 개의 기준표본을 관찰한 결과 일반적으로 알 려진 P. nivea L.가 아님을 확인하였다. 후에 Eriksen et al. (1999)은 이러한 두 기준표본을 엽병의 털, 영양형질, 분 포지역 특성으로 각각 P. arenosa (Turcz.) Juz.와 $P$. chamissonis Hultén임을 밝혔다. 이에 따라서 전 세계에 넓 게 분포하는 P. nivea로 알려진 식물에 대한 재명명의 필 요성을 언급하였다. 그러나 Eriksen et al. (1999)은 보편적 으로 사용하던 식물 이름에 대하여 새로운 명명을 부여 할 경우 분류에 혼란을 야기하므로, 지금까지 일반적으 로 P. nivea로 알려졌던 식물들의 이름을 P. nivea로 보존 하기를 주장하였다. 따라서 Eriksen et al. (1999)은 P. nivea 의 새로운 기준표본을 지정하였으며, 엽병에 부드럽고, 길며, 굴곡 있는 납작한 털(floccose hair type)을 가진 특징 으로 근연 분류군인 P. arenosa와 P. chamissonis와의 차이 를 기재하였으며, 후에 이러한 결과가 반영되어 P. nivea 는 보존명으로 인정되었다(Brummitt, 2000). 우리나라 백 두산에 분포하는 식물은 털 특징 관찰결과 엽병에 납작 한 융모형의 털(floccose villous hair)이 관찰되었으므로 $P$. nivea 임이 확인되었다(Heo et al., 2013).

(4) Potentilla anemonifolia Lehm., Ind. Sem. Hort. Hamburg 9. 1853.

국명: 가락지나물
개화: 4-6월.

서식처: 다소 습기 찬 곳.

분포: 한국, 중국북서부, 일본.

분류학적 검토: 국내에서 가락지나물의 학명은 $P$. anemonifolia Lehm. (Lee, 1996), P. kleiniana Wight \& Arn. (Chung et al., 1949; Park, 1949; Lee, 1999; Lee, 2003), P. kleiniana var. robusta (Franch. et. Sav.) Kitagawa (Chung, 1957, 1965, 1974; Ahn and Park, 1974) 등으로 사용되어 혼란이 있어왔다. 확인 결과 Kalkman (1968)은 $P$. kleiniana와 P. anemonifolia를 P. sundaica Kuntze의 이명 으로 처리하였으나, Soják (2004)은 P. kleiniana를 P. anemonifolia의 이명으로 처리하였으며, Li et al. (2003)은 P. kleiniana를 정명으로 인정하고, 이명으로 $P$. anemonifolia와 P. bodinieri H. Léveillé.를 기록하였다. 후 에 Naruhashi et al. (2005)는 P. anemonifolia와 P. sundaica 는 형태형질과 생활사에서 뚜렷한 차이로 독립된 종으 로 인정하였으며, P. kleiniana를 P. sundaica의 이명으로 처리하였다. Naruhashi et al. (2005)는 연구에서 $P$. anemonifolia는 자가불화합성(self-incompatible)하며 2배 체이며, 주로 한국, 중국의 북서부, 일본에 분포하는 반 면, P. sundaica는 자가합성하고(self-compatible) 4배체이 며, 히말라야에서 동남아시아와 서남부 중국까지 분포 하는 특징을 가진다고 주장하였다. 본 연구결과 한국에 분포하는 분류군은 Naruhashi et al. (2005)가 지적한 특징 중 꽃잎의 길이와 너비 비율은 P. anemonifolia와 유사하 였고, 악편과 부악편 특징은 P. sundaica와 유사하였다. 그 외에 꽃잎의 길이, 너비, 면적은 두 분류군의 중간 특 징을 나타내었다(Heo, 2009). 이렇듯 한국산 개체군의 형태는 P. anemonifolia와 P. sundaica의 중첩된 형질을 나 타내고 있으나, 본 연구에서는 소엽이 무모이거나 드물 게 털이 나타나는 특징과 분포지역 특징에 의해서 $P$. anemonifolia로 기록하였다. 추후 한국산 개체군에 대한 염색체 연구가 필요하며, 근연 분류군 간의 분류학적 한 계를 설정하고 유연관계를 파악하기 위하여 추가적인 분자분류학적 연구 등이 수행되어야 한다.

(5) Potentilla cryptotaeniae Maxim., Bull. Acad. Imp. Sci. Saint-Pétersbourg 19: 162-163, 1874; Tridophyllum cryptoteniae (Maxim.) Greene, Leafl. Bot. Observ. Crit. 1: 189, 1906.

P. cryptotaeniae var. obovata Th. Wolf, Biblioth. Bot. 16 (Ht. 71) 406, 1908.

P. aegopodiifolia H. Lev., Feddes, Rep. Sp. Nov. Regni Veg. 7:198, 1909.

P. cryptotaeniae var. insularis Kitag., Rep. Inst. Scii. Res. Manchoukuo 1: 257, 1937.

P. cryptotaeniae var. insularis Kitag. f. radicans Kitag., Rep. Inst. Scii. Res. Manchoukuo 1: 258, 1937. 
P. cryptotaeniae var. genuina Kitag., Rep. Inst. Sci. Res. Manchoukuo 1: 256, 1937.

P. cryptotaeniae var. radicans T. T. Yu et C.L.Li, Fl. Reipubl. Popularis Sin. 37: 319, 1985.

국명: 물양지꽃

개화기: 7-9월.

서식처: 산지의 냇가 근처.

분포: 한국, 중국, 일본, 북동 러시아.

분류학적 검토: 물양지꽃은 섬유형의 뿌리가 발달하며, 줄기가 직립하거나 옆으로 퍼지다 위를 향하며, 삼출엽 이고, 경생엽이 발달하고, 소엽은 긴피침형-난상피침형 이고, 엽연은 예거치 혹은 복예거치를 가지며, 잎과 엽병 의 미세강모 표면에 돌기가 발달하여 다른 분류군과 잘 구분된다.

(6) Potentilla centigrana Maxim., Bull. Acad. Imp. Sci. St.-Petersbourg 19:163, 1873.

P. reptans var. trifoliolata A. Gray, Mem. Amer. Acad. Arts n.s. $6: 387,1859$.

P. centigrana $\alpha$. japonicam Maxim., Bull. Acad. Imp. Sci. St.-Petersbourg 19: 164, 1873; P. centigrana var. japonica (Maxim.) Th. Wolf, Biblioth. Bot. 16(Ht. 71): 407, 1908.

P. centigrana $\beta$. mandshuricam Maxim., Bull. Acad. Imp. Sci. St.-Petersbourg 19: 164, 1873; P. centigrana var. mandschurica (Maxim.) Th. Wolf, Biblioth. Bot. 16(Ht. 71): 407, 1908.

국명: 좀딸기

개화기: 5-6월.

서식처: 산지 그늘 진 곳.

분포: 한국, 중국, 일본, 북동 러시아.

분류학적 검토: 좀딸기는 섬유질의 뿌리를 가지며, 경 생엽은 도란형, 넓은 도란형, 난형, 또는 도란상 타원형이 고, 화서는 대부분 단생하는 꽃이 엽액에 액생하거나 또 는 줄기에 정생하며, 취산화서도 관찰되어 다른 분류군 들과 구분된다. 또한 좀딸기의 소엽에는 표피 상납질 결 정체가 나타나므로 절내 다른 분류군과도 확연한 차이가 있다(Heo et al., 2013).

(7) Potentilla amurensis Maxim., Prim. Fl. Amur. 98, 1859. 국명: 좀개소시랑개비

개화기: 5-6월.

서식처: 하천가 모래땅과 진흙.

분포: 한국, 중국, 일본, 러시아 북동부.

분류학적 검토: 좀개소시랑개비는 전국(Appendix 1)에 마르고 양지바른 땅에서 서식하고 있으나, 개소시랑개비
보다 발견하기가 쉽지는 않다. 좀개소시랑개비의 근생엽 은 삼출엽의 정소엽이 심열하여 장상처럼 보이거나 삼출 엽을 갖는 반면에 개소시랑개비는 우상복엽을 갖는 특징 으로 차이가 있다고 판단된다(Fig. 11). 본 종은 P. amurensis Maxim. (Naruhashi, 2003)로 기록되거나 또는 P. supina var. ternata Peterm. (Li et al., 2003)으로 처리되기도 하였다. 정 확한 학명을 확인하기 위해서 추가적인 연구가 필요하다.

(8) Potentilla supina subsp. paradoxa (Nutt. ex Torr. \& A. Gray) Soják, Folia Geobot. Phytotax. 4: 207, 1969; P. paradoxa Nutt. ex Torr. \& A. Gray, Fl. N. Amer. 1: 437, 1840.

국명: 개소시랑개비

개화기: 5-7월.

서식처: 해변가 모래땅과 진흙.

분포: 아시아, 유럽, 북미, 북부 아프리카.

분류학적 검토: 개소랑개비는 P. paradoxa Nutt. ex Torr. \& A.Gray (Park, 1949; Ahn and Park, 1974) 또는 P. supina L. (Chung et al., 1937; Lee, 1996; Lee, 1999; Lee, 2003)로 기록되어 왔다. Shishkin and Yuzepchuk (1985)는 $P$. paradoxa가 아시아에 분포하는 분류군이며 수과에 돌기 가 발달하여 P. supina와 차이가 있다고 언급하였으나, 몇 몇 학자들은 P. paradoxa를 P. supina의 이명으로 처리하기 도 하였다(Lee, 1996; Li et al., 2003). Soják (2004)은 $P$. supina 가 개화 후에 악편이 휘어지고, 수과는 복부가 약하 게 볼록하며, 회색 또는 갈색이고, 작고 넓고 둔한 주름을 갖는 특징으로 기록하였으며, P. paradoxa를 P. supina subsp. paradoxa (Nutt. ex Torr. \& A. Gray) Soják로 처리하 면서, 개화 후에 악편이 직립하고, 수과의 복부가 많이 볼 록하며, 수과에 뚜렷하고 좁은 주름의 특징을 기재하였 다. 한국산 분류군 연구결과 개화 후에 악편은 직립하거 나 또는 휘는 특징이 한 개체 내에 혼재하여 나타났으나, 수과의 특징은 복부가 볼록하며 표면에 깊고 뚜렷한 주 름이 나타나므로 Soják (2004)이 언급한 P. supina subsp. paradoxa와 유사하였다. 따라서 본 연구에서는 개소시랑 개비를 P. supina subsp. paradoxa로 인정하였다. P. supina subsp. paradoxa와 원종 간의 정확한 분류학적 한계를 판 단하기 위하여 원기준표본 관찰 및 국외 개체군을 포함 한 추가적인 연구가 필요하다고 사료된다.

3) Potentilla sect. Potentilla (Syme) Yü et Li., Fl. Reupublicae Popularis Sinicae. 37: 323, 1985.

국명: 양지꽃절

(1) Potentilla fragarioides var. major Maxim., Mem. Acad. Imp. Sci. St. -Petersbourg Divers Savans 9: 95, 1859.

Potentilla japonica Blume, Bijdr. Fl. Ned. Ind.: 1105, 1826.

Potentilla sahalinensis Juz. Not. Syst. Herb. Inst. Bot. Acad. Sci. URSS 17: 234, 1955. 

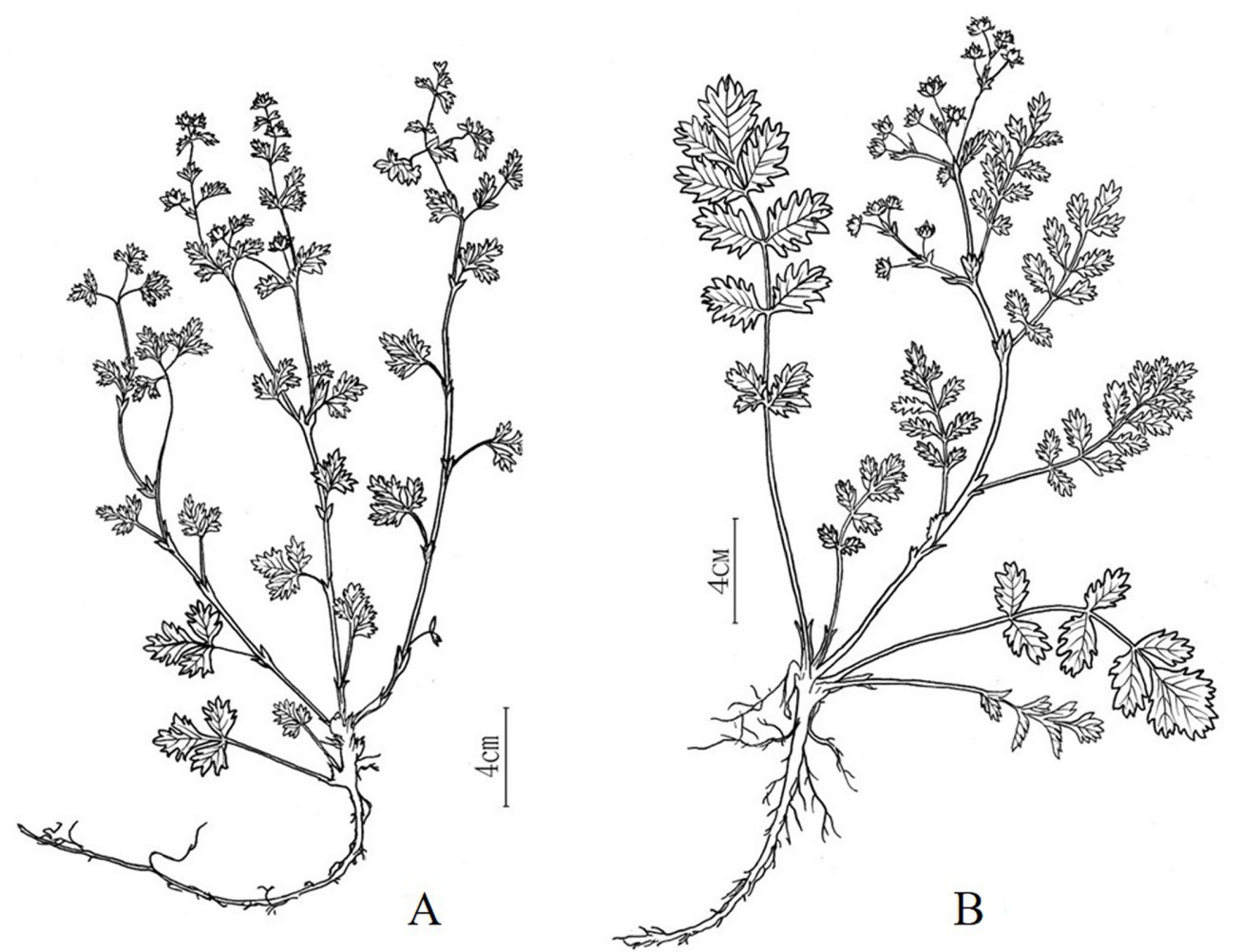

Fig. 11. Potentilla amurensis Maxim. (A) and P. supina subsp. paradoxa (Nutt. et Torr \& A. Gray) Soják (B).

국명: 양지꽃

개화기: 3-7월.

서식처: 산지와 들판의 양지바른 곳.

분포: 한국, 중국, 일본, 북동러시아.

분류학적 검토: 양지꽃은 포복경이 발달하지 않고, 소 엽 수가 9장 정도이며 식물체가 원변종인 P. fragarioides var. fragarioides L.보다 큰 특징으로 $P$. fragarioides var. major Maxim. (1859)으로 사용되었다(Lee, 1996; Lee, 1999; Lee, 2003). 그러나 이미 이러한 특징으로 $P$. sprengeliana Lehm. (1820)이 기재되었기 때문에 $P$. fragarioides var. major는 P. sprengeliana의 이명으로 정리 되기도 하였다(Naruhashi, 2003). 후에 P. sprengeliana의 기 준표본을 확인한 Soják (2008b)은 P. sprengeliana을 비합법 명으로 처리하고, Potentilla stolonifera Lehm. ex Ledeb.을 인정하였다. 한편 Li et al. (2003)은 P. fragarioides var. major 을 P. fragarioides의 이명으로 처리하기도 하였다. 추가적 인 연구를 통하여 양지꽃의 정확한 학명을 밝히고, 분류 군의 한계를 파악할 필요가 있다. Lee (1993)는 강원도 면 산에 분포하며, P. yokysaiana에 비해 키가 크고 소엽 수가 많은(3-7개) 특징을 가진 식물을 P. yokysaiana var. multijuga T.B. Lee (면산양지꽃)로 발표했으나, Isotype $(\mathrm{KH})$ 확인결과 면산양지꽃은 양지꽃과 마찬가지로 근생
엽이 우상엽이며 포복경이 발달하지 않고, 소엽 형태 및 질감도 양지꽃과 매우 유사하였다. 그러므로 면산양지꽃 은 양지꽃의 변이 폭에 포함되므로 이명으로 처리함이 타당하다고 판단된다.

(2) Potentilla stolonifera var. quelpaertensis Nakai, Repert. Spec. Nov. Regni Veg. 13: 276, 1914; P. japonica var. quelpaertensis (Nakai) Nakai, Bull. Nat. Sci. Mus. Tokyo 31: 58, 1952.

국명: 제주양지꽃

개화기: 4-5월.

서식처: 산지의 양지바른 곳.

분포: 한국(제주도), 북동 러시아, 중국, 일본.

분류학적 검토: 제주양지꽃은 식물이 매우 소형이고 포복경이 존재하며, P. stolonifera for. japonica Th. Wolf와 유사하나 줄기가 더 가늘고 소엽이 작은 특징으로 기재 되었다(Nakai, 1914). 연구 결과 제주양지꽃의 식물체 크 기는 해발 고도에 따라 다양한 변이 $(5-19.6 \mathrm{~cm})$ 가 관찰되 어, 양지꽃의 크기와 중첩되기도 하였다. 그러나 제주양 지꽃은 포복경이 매우 발달하였으며, 양지꽃은 포복경이 발달하지 않으므로 두 분류군은 잘 구분된다. 한편 핵 DNA의 ITS와 엽록체 DNA 염기서열들 분석 결과에서는 
제주양지꽃과 양지꽃이 분화되지 않고 같은 분계조를 형 성하였으며(Heo et al., Unpubl. Data), 양지꽃속에 대한 엽 록체 DNA 염기서열 전체를 해독한 연구 결과에서도 제 주양지꽃, 양지꽃, 세잎양지꽃은 하나의 분계조를 형성 하는 것이 확인되었다 (Heo et al., 2019; Park et al., 2019). 따라서 제주양지꽃의 분화는 비교적 최근에 이루어 진 것으로 판단되며, 제주양지꽃과 근연 분류군들의 유연관 계에 대한 추가적인 연구가 필요하다고 판단된다.

(3) Potentilla freyniana Bornm., Mitth. Thüring. Bot. Vereins n.s. 20: 12, 1904.

P. fragiformis var. japonica A. Gray, Mem. Amer. Acad. Arts n.s. 6: 387, 1859.

P. fragarioides var. ternata Maxim., Bull. Acad. Imp. Sci. St.-Petersbourg 19: 165, 1873; P. ternata (Maxim.) Freyn, Oesterr. Bot. Z. 52: 62, 1902.

국명: 세잎양지꽃

개화기: $3-5$ 월.

서식처: 산야.

분포: 한국, 중국, 일본, 북동러시아.

분류학적 검토: 세잎양지꽃은 전국에 분포하며, 서식 지에 따라 식물체의 크기와 근생엽의 발달 정도에 변이가 심하고, 소엽의 형태는 타원형, 난형, 넓은 난형, 좁은 난형, 난상원형, 도란상 원형 또는 능상 난형으로 매우 다양하다. 주로 포복경이 발달하지 않고, 드물게 포복경이 존재하는 개체가 발견되며, 근경이 비후하고, 화경 기부에 포가 매우 발달하는 특징으로 털양지꽃과 차이가 있다.

(4) Potentilla squamosa Soják, Preslia, Praha, 74: 437, 2002.

P. freyniana var. villosa Nakai, Bull. Nat. Sci. Mus., Tokyo 31: 58, 1952.

P. koreana Im \& Ikeda, J. Jap Bot. 76: 125-128, 2001.

국명: 털양지꽃

개화기: 4-5월.

서식처: 산지.

분포: 한국특산.

분류학적 검토: 털양지꽃은 Nakai (1952)에 의해 $P$. freyniana var. villosa로 발표되었으나, 후에 Ikeda and Im (2001)이 P. freyniana var. villosa Nakai, nom. nud.임을 발 견하고 P. koreana H. Ikeda \& Im로 명명하였다. 한편 Soják (1992)은 북한에 분포하는 P. fragarioides와 유사한 형태 의 분류군을 P. coreana Soják로 발표하였다. 따라서 Soják (2002)은 P. koreana는 P. coreana와 후일동일명(later hononym)임을 지적하고, 털양지꽃의 학명을 P. squamosa Soják으로 재명명하였다.
(5) Potentilla yokusaiana Makino, Bot. Mag. (Tokyo) 24: 142, 1910.

P. freyniana var. grandiflora Th. Wolf, Biblioth. Bot. 16(Heft 71): 640, 1908.

국명: 민눈양지꽃

개화기: 4-5월.

서식처: 산지의 그늘지고 습한 곳.

분포: 한국, 중국, 일본.

분류학적 검토: 민눈양지꽃은 습한 지역에 서식하며, 포복지가 발달하고, 소엽과 엽병에 선모가 매우 발달하 고, 근생엽은 삼출엽이며 소엽이 능형으로 양지꽃절 내 의 다른 분류군과 잘 구분된다.

\section{고 찰}

한국산 양지꽃족에 대하여 외부형태형질 비교연구, 과 실의 미세구조 관찰 및 문헌 조사를 통한 분류학적 연구 를 수행하였다. 전통적으로 자방에서의 화주 위치와 화 주 형태는 양지꽃족내 분류체계에서 중요한 형질로 알려 져 왔다(Wolf, 1908). 또한 최근 연구에서 양지꽃아족의 수술은 두 개의 화분낭을 가지며, 딸기아족은 한 개로 된 화분낭을 갖는 특징이 밝혀졌다(Soják, 2008a).

본 연구에서 암술의 미세관찰 연구 결과 한국산 딸기 아족은 화주가 기저생, 아기저생, 측생하였으며, 양지꽃 아족은 대부분 아정생하고 눈양지꽃속만이 측생 또는 아 정생하였다. 이전 연구들(Li et al., 2003; Dobeš and Paul, 2010)과 마찬가지로 화주의 위치는 아족 간의 분류에 유 용한 형질이었다. 화주 모양은 딸기아족의 물싸리속, 딸 기속, 물싸리풀속은 곤봉형이었으며, 검은낭아초속은 사 상형이었다. 양지꽃아족에서는 눈양지꽃속은 원통형, 뱀 딸기속은 사상형이었으며, 양지꽃속에서는 돌양지꽃절 은 사상형, 양지꽃절은 곤봉형(민눈양지꽃 제외), 딱지꽃 절은 원뿔형이었다. 따라서 화주의 모양은 양지꽃속의 절간 분류에 어느 정도 유용한 형질로 나타났다.

수과 표면의 미세형질은 양지꽃족의 분류에는 유용한 형질이 아니었으며, 단지 일부 분류군에서 차이점이 있었 다. 딸기아족의 물싸리와 검은낭아초, 양지꽃아족의 눈양 지꽃과 솜양지꽃의 과피 표면에는 주름이 발달하지 않거 나 미약하였다. 그 외의 나머지 양지꽃아족 분류군은 표 면에 주름 구조가 관찰되었다. 주름형 분류군들 중에 뱀 딸기속의 뱀딸기와 산뱀딸기는 돌기가 확인되었으며, 좀 딸기와 가락지나물은 돌기가 존재하고 주름은 매우 뚜렷 했으며, 개소시랑개비와 좀개소시랑개비는 날개 같은 뚜 렷한 주름만이 확인되어 다른 분류군과 차이가 있었다.

한국산 딸기아족에는 본 연구에 포함된 물싸리속 (Dasiphora), 물싸리풀속(Sibbaldianthe), 딸기속(Fragaria), 검은낭아초속(Comarum) 외에 연구에 포함시키지 못한 좀 
낭아초속(Chamaerhodos; Lee et al., 2007)과 너도양지꽃속 (Sibbaldia; Lee et al., 2007)까지 총 7속이 존재한다. 한국산 양지꽃아족은 양지꽃속(Potentilla), 뱀딸기속(Fragaria), 눈 양지꽃속(Argentina)의 3속으로 정리되었다. 지금까지 양 지꽃속으로 알려져 왔던 눈양지꽃속(Argentina)은 근생 엽 기부의 탁엽이 엽병의 앞면에 부착되는 특징으로 측 면에 위치하는 양지꽃속(Potentilla)과는 잘 구분되며 (Soják, 2010), 분자분류학적 연구결과에서도 눈양지꽃속 (Argentina)은 양지꽃아족의 나머지 속들과 자매군을 형 성하여 독립된 속이 지지되고 있다(Dobeš et al., 2015).

분류군 수준에서 살펴보면 딸기속의 흰땃딸기 $(F$. nipponica subsp. chejuensis)는 우리나라 여러 도감 등에서 F. nipponica (Lee, 1999; Lee, 2003)로 사용되어 왔으나, 식 물체의 크기가 작고 제주도 한라산에 제한 분포하는 특 징으로 한국 특산종으로 처리됨을 지지한다(Staudt and Olbricht, 2008). 추가적인 연구를 통하여 흰땃딸기의 정확 한 분류학적 위치를 파악하고, 근연종들 $(F$ nipponica complex)과의 비교분석이 필요하다. 학자마다 학명사용 에 혼란이 있었던 눈양지꽃(Argentina egedii)은 잎 뒷면에 곱슬거리는 털이 밀모하고(Heo et al., 2013), 형태적으로 측소엽은 5-7쌍, 거치는 7-9쌍, 거치는 다소 둔하거나 또 는 날카로운 예거치와 심피는 50 개 정도의 특징을 가지므 로, 근연종들인 A. anserina var. anserina와 A. anserina var. grandis와는 구분되었다. 뱀딸기속의 산뱀딸기는 존재여 부에 있어서 혼란이 있어왔으며, 형태학적인 연구가 이루 어지지 않았다. 연구결과 산뱀딸기(D. chrysantha)는 잎이 연한 녹색 또는 황녹색이고, 소엽이 얇아 다소 막질이며, 소엽 형태는 넓은 난형 또는 도란형이고, 둔두이며, 화피 는 도심장형이었고, 중부 이남의 산지에서만 발견되었다. 이러한 특징으로 인해서 전국에 분포하며 잎이 녹색-진 녹색이고, 소엽이 다소 두껍고, 소엽 형태는 능형-장타원 형이고, 예두이며, 꽃잎은 도란형 또는 좁은 도란형인 뱀 딸기(D. indica)와는 잘 구분되었다. 한국산 양지꽃속의 돌 양지꽃(P. dickinsii)의 근연 분류군으로 알려진 당양지꽃 은 P. ancistrifola (Chung et al., 1949) 또는 P. rugulosa (Ahn and Park, 1974)로 언급되어 왔다. Li et al. (2003)는 소엽 및 수과 특징에 근거하여 돌양지꽃(P. ancistrifolia var. dickinsii)을 당양지꽃(P. ancistrifolia var. ancistrifolia)의 변 종으로 파악하였으나, Soják (2004)은 돌양지꽃을 당양지 꽃의 이명으로 처리한 바 있다. 본 연구에서 원기재문 특 징과 국내 및 국외 표본관의 표본들을 관찰한 결과 동일 개체군에서 두 분류군의 특징을 갖는 개체들이 존재하거 나, 한 개체에서 중첩된 형질이 관찰되기도 하였고, 중국 과 일본의 표본 관찰 결과에서도 주요 형질들의 연속된 변이가 관찰되었다. 외부형태 형질을 이용한 주성분분석 (principle component analysis) 분석결과도 두 분류군 식별 에 뚜렷하게 기여하는 형질은 없었다(Heo, 2009). 따라서 유연관계가 가까운 두 분류군에 대한 기준표본 관찰 및
개체군 수준의 분자분류학적 연구를 수행하여 종간 한계 를 규명하여야 할 것이다. 한국 특산종으로 알려진 섬양 지꽃(P. dickinsii var. glabrata)에 대하여 Naruhashi (2003)는 돌양지꽃의 이명으로 처리하였다. 연구결과 섬양지꽃은 주로 돌양지꽃에 비하여 잎에 털이 무모이거나 드물고, 근생엽이 삼출엽이며, 얇은 잎의 질감의 특징을 나타내어 구분되었다. 딱지꽃(P. chinensis) 복합체 중에서 털이 밀모 하며 식물체가 분백색인 특징으로 기재된 털딱지꽃 $(P$. chinensis var. concolor; Wolf, 1908)은 잎 앞면에 융모가 밀 생하는 반면, 딱지꽃은 대체적으로 잎 앞면에 미세강모가 존재하는 특징이 보고되었다(Heo et al., 2013). 그러나 딱 지꽃의 털 밀도 정도는 개체군 별로 다소 중첩되기도 하 므로, 털딱지꽃의 정확한 분류학적 실체를 파악하기 위해 서는 개체군 단위의 추가적인 연구가 필요하다. 딱지꽃과 구분되는 소엽 형태와 부소엽의 존재, 그리고 악편 크기 의 특징으로 기재된 원산딱지꽃(P. niponica)의 실체를 파 악하기 위하여 직접적인 관찰 및 $\mathrm{TI}, \mathrm{PE}$, 국내 여러 표본관 의 표본을 검토한 결과 딱지꽃과 원산딱지꽃의 형질의 연 속성이 관찰되었다. 양지꽃족에서는 서식지와 영양상태 등의 생육조건에 따라서 잎의 크기가 커지고, 잎의 수가 증가되는 등의 변이가 보고되었다(Eriksen, 1999). 그러므 로 개체군에 따른 딱지꽃의 잎 형태 변이는 유전적인 요 인뿐만 아니라 환경적인 요인이 작용한 결과로 판단된다. 원산딱지꽃은 딱지꽃의 변이 폭에 해당된다고 여겨지지 만, 추후 기준표본과의 비교 연구 및 분자분류, 수리분류 등의 추가적인 연구를 통하여 원산딱지꽃의 정확한 실체 여부를 검토해야 한다고 판단된다.

ORCID: Kyeong-In HEO https://orcid.org/0000-0002-69518102; Sangroyng LEE https://orcid.org/0000-0001-5366022X; Yongsung KIM https://orcid.org/0000-0002-53499226; Jongsun PARK https://orcid.org/0000-0003-0786-4701

\section{Acknowledgments}

This study was supported by Flora of Korea grant funded from the Ministry of Environment in Korea (No. 052-081070) and InfoBoss Research Grant (IBP-0001). We are deeply indebted to two anonymous reviewers for their critical reviews and corrections on the manuscript. We also would like to thank to Dr. Jongduk Jung, managing director in Northeastern Asia Biodiversity Institute, and Dr. Chan-Ho Park in National Institute for Biological Resources, for helpful comments and suggestions on this work.

\section{Conflict of Interest}

The authors declare that there are no conflicts of interest. 


\section{Literature Cited}

Ahn, H. S. and M. K. Park. 1974. Resources Plant of Korea. Gukjemunhwasa Press, Seoul. (in Korean)

Brummitt, R. K. 2000. Report of the Committee for Spermatophyta: 50. Taxon 49: 799-808.

Chung, T. H. 1957. Korean Flora. Sinjinsa Publ. Co., Seoul. (in Korean)

Chung, T. H. 1965. Illustrated Encyclopedia of Fauna and Flora of Korea. Vol. 5. Tracheophyta. Samhwa Publisher, Seoul, 232 pp. (in Korean)

Chung, T. H. 1974. Koran Flora. Imunsa Press, Seoul, 82 pp (in Korean).

Chung, T. H., B. S. Do, D. B. Lee, and H. J. Lee. 1937. Folk Names of Korean Plants. Choseon Museumol. Soc., Seoul. P. 121. (in Korean)

Chung, T. H., B. S. Do, and H. J. Sim. 1949. Nomina Plantarum Koreanum I. (Herbs). Chosun Biology Society, Seoul, 235 pp. (in Korean)

Dobeš, C., A. Lückl, L. Kausche, S. Scheffknecht, D. Prohaska, C. Sykora and J. Paule. 2015. Parallel origins of apomixis in two diverged evolutionary lineages in tribe Potentilleae (Rosaceae). Botanical Journal of the Linnean Society 177: 214-229.

Dobeš C and J. Paule. 2010. A comprehensive chloroplast DNA based phylogeny of the genus Potentilla (Rosaceae): implications for its geographic origin, phylogeography and generic circumscription. Molecular Phylogenetics and Evolution 56: $156-175$.

Eriksen, B. 1996. Mating systems in two species of Potentilla from Alaska. Folia Geobotanica et Phytotaxonomica 31: 333344.

Eriksen, B. 1999. Species concepts in apomictic plants: different solutions to the same problem. The Species Concept in the High North: APanarctic Flora Initiative. Det Norske Videnskaps-Akademi. I. Matematisk Naturvitenskapelig Klasse, Skrifter, Ny Serie 38: 73-80.

Eriksen, B., B. Jonsell and Ö. Nilsson. 1999. Proposal to conserve the name Potentilla nivea (Rosaceae) with a conserved type. Taxon 48: 165-166.

Eriksson, T., M. J. Donoghue and M. S. Hibbs. 1998. Phylogenetic analysis of Potentilla using DNA sequences of nuclear ribosomal internal transcribed spacers (ITS), and implications for the classification of Rosoideae (Rosaceae). Plant Systematics and Evolution 211: 155-179.

Eriksson, T., M. Lundberg, M. Töpel, P. Östensson and J. E. E. Smedmark. 2015. Sibbaldia: a molecular phylogenetic study of a remarkably polyphyletic genus in Rosaceae. Plant Systematics and Evolution 301: 171-184.
Eriksson, T., M. S. Hibbs, A. D. Yoder, C. F. Delwiche and M. J. Donoghue. 2003. The phylogeny of Rosoideae (Rosaceae) based on sequences of the internal transcribed spacers (ITS) of nuclear ribosomal DNA and the trnL/F region of chloroplast DNA. International Journal of Plant Sciences 164: 197-211.

Feng, T., M. J. Moore, M.-H. Yan, Y.-X. Sun, H.-J. Zhang, A.-P. Meng, X.-D. Li, S.-G. Jian, J.-Q. Li and H.-C. Wang. 2017. Phylogenetic study of the tribe Potentilleae (Rosaceae), with further insight into the disintegration of Sibbaldia. Journal of Sytematics and Evolution 55: 177-191.

Hancock, J. F., C. E. Finn, J. J. Luby, A. Dale, P. W. Callow and S. Serçe. 2010. Reconstruction of the strawberry, Fragaria $\times$ ananassa, using genotypes of $F$. virginiana and $F$. chiloensis. HortScience 45: 1006-1013.

Heo, K. I. 2009. A systematic study of genus Potentilla s.l. in Korea (Rosaceae). Ph. D. Dissertation, Sungkyunkwan University, Suwon, Korea. (in Korean)

Heo, K.-I., S. Lee, M. Yoo, S. Lee, Y. Kwon, S. Y. Lim, S. Kim and S.-C. Kim. 2013. The taxonomic implication of trichome and epicuticular waxes in tribe Potentilleae (Rosaceae) in Korea. Korean Journal of Plant Taxonomy 43: 106-117.

Heo, K.-I., J. Park, Y. Kim and W. Kwon. 2019. The complete chloroplast genome of Potentilla stolonifera var. quelpaertensis Nakai. Mitochondrial DNA Part B 4: 1289-1291.

Hutchinson, J. 1964. The Genera of Flowering Plants. Clarendon Press, Oxford. Pp. 195-197.

Ikeda, H. and H. T. Im. 2001. A new species of Potentilla (Rosaceae) from Korea. Journal of Japanese Botany 76: 125-128.

Kalkman, C. 1968. Potentilla, Duchesnea, and Fragaria in Malesia (Rosaceae). Blumea 16: 325-354.

Kalkman, C. 1988. The phylogeny of the Rosaceae. Botanical Journal of the Linnean Society 98: 37-59.

Klackenberg, J. 1983. The holarctic complex Potentilla fruticosa (Rosaceae). Nordic Journal of Botany 3: 181-191.

Kurtto, A. and T. Eriksson. 2003. Atlas Florae Europaeae notes. 15. Generic delimitation and nomenclatural adjustments in Potentilleae (Rosaceae). Annales Botanici Fennici 40: 135141.

Lawrence, G. H. M. 1970. Taxonomy of Vascular Plants. The Macmillan Company, New York, 823 pp.

Lee, S. T., K.-J. Kim, B.-Y. Lee, B.-H. Choi, J.-H. Park and J.-Y. Yang. 2007. Rosoideae. In The Genera of Vascular Plants of Korea. Park, C.-W. (ed.), Academy Publishing Co., Seoul. Pp. 543-567.

Lee, T. B. 1976. Vascular plants and their uses in Korea. Bulletin of the Kwanak Arboretum 1: 1-137. (in Korean)

Lee, T. B. 1993. For Find of Native Plant in Korea. Korea National Arboretum, Pocheon. Pp. 239. (in Korean) 
Lee, T. B. 2003. Coloured Flora of Korea. Hyangmunsa Press, Seoul, 2096 pp. (in Korean)

Lee, W. C. 1996. Lineamenta Florae Koreae. Academy Press, Seoul, 2383 pp. (in Korean)

Lee, W. S. 2004. Plant Taxonomy. Wooseong Press, Seoul, 575 pp. (in Korean)

Lee, Y. N. 1999. Flora of Korea. Kyohaksa Press, Seoul, 1237 pp. (in Korean)

Leht, M. 1996. Cladistic analysis of data published in "Monographie der Gattung Potentilla L." by Th. Wolfe. Proceedings of Estonian Academy of Sciences 45: 171-180.

Leht, M. 1997. The genus Potentilla in Estonia, Latvia and Lithuania: distribution, morphology and taxonomy. Dissertation, University of Tartu, Tartu.

Li, C., H. Ikeda and H. Ohba. 2003. Potentilla L. In Flora of China, Vol. 9. Pittosporaceae through Connaraceae. Wu, ZY. Raven, PH. Hong, DY (eds.), Science Press, Beijing and Missouri Botanical Garden Press, St. Louis, MO. Pp. 291-328.

Mabberley, D. J. 2002. Potentilla and Fragaria (Rosaceae) reunited. Telopea 9: 793-801.

Morgan, D. R., D. E. Sotis and K. R. Robertson. 1994. Systematic and evolutionary implications of rbcL sequence variation in Rosaceae. Journal of Botany 81: 890-903.

Mosyakin, S. L. and N. M. Shiyan. 2017. The genus Sibbaldianthe (Rosaceae): a nomenclatural overview and new combinations. Phytotaxa 296: 101-117.

Nakai, T. 1909. Flora Koreana I. Journal of the College of Science, Imperial University of Tokyo 26: 191-199.

Nakai, T. 1911. Flora Koreana II. Journal of the College of Science, Imperial University of Tokyo 31: 478-479.

Nakai, T. 1914. LIX. Plantae novae Coreanae et Japonicae. II. Fedde Repertorium Specierum Novarum Regni Vegetabilis 13: 267-278.

Nakai, T. 1918. Notulae ad plantas Japoniae et Koreae XVI. Bot. Mag. (Tokyo) 32: 106.

Nakai, T. 1952. A Synoptical Sketch of Korean Flora. Bulletin of the National Science Museum. No. 31. Natioanl Science Museum, Tokyo, $152 \mathrm{pp}$.

Naruhashi, N. 2003. Rosoideae. In Flora of Japan, Vol. IIb. Iwatsuki, K., D. E. Boufford and H. Ohba (eds.), Kodansha, Tokyo. Pp. 145-212.

Naruhashi, N., T. Nishikawa and Y. Iwatsubo. 2005. Taxonomic relationship between Japanese Potentilla anemonefolia and Himalayan P. sundaica (Rosaceae). Journal of Phytogeography and Taxonomy 53: 1-11.

Ohwi, J. 1965. Flora of Japan. Smithsomian Institution, Washington, D.C. Pp. 517-528.

Panigrahi, G. and B. K. Dikshit. 1985. Systematics of the genus
Potentilla L. - (Rosaceae Juss.) - its infrageneric classification and evolutionary trends. Bulletin of the Botanical Survey of India 27: 177-196.

Park, M. K. 1949. An Enumeration of Korean Plants. Ministry of Education, Government of the Republic of Korea, Seoul, 176 pp. (in Korean)

Park, J., K.-I. Heo, Y. Kim and W. Kwon. 2019. The complete chloroplast genome of Potentilla fragarioides var. major Maxim. Mitochondrial DNA Part B 4: 1265-1266.

Paule, J. and J. Soják. 2009. Taxonomic comments on the genus Sibbaldiopsis Rydb. (Rosaceae). Journal of the National Museum (Prague) 178: 15-16.

Potter, D., T. Eriksson, R. C. Evans, S. Oh, J. E. E. Smedmark, D. R. Morgan, M. Kerr, K. R. Robertson, M. Arsenault, T. A. Dickinson and C. S. Campbell. 2007. Phylogeny and classification of Rosaceae. Plant Systematicsand Evolution 266: 543.

Lei, J. J., L. Xue, R. X. Guo, and H. P. Dai. 2016. The Fragaria species native to China and their geographical distribution. In VIII International Strawberry Symposium 1156. Pp. 37-46.

Robertson, K. R. 1974. The genera of Rosaceae in the southeastern United States. Journal of the Arnold Arboretum 55: 303332, 344-401, 611-662.

Rousi, A. 1965. Biosystematic studies on the species aggregate Potentilla anserina L. Annales Botanici Fennici 2: 47-112.

Rydberg, P. A. 1898. A monograph of the North American Potentilleae. Memoirs from the Department of Botany of Columbia University 2: 1-223.

Schulze-Menz, G. K. 1964. Rosales. In A. Engler's Syllabus der Pflanzenfamilien. 12th ed. Melchior, H. (ed.), Gerbruder Borntraeger, Berlin. Pp. 193-243.

Shah, M. and C. C. Wilcock. 1993. Infrageneric classification fo the genus Potentilla L. (Rosaceae) in Pakistan and Kashmir. Edinburgh Journal of Botany 50: 173-179.

Shishkin, B. K. and S. V. Yuzepchuk. 1985. Flora of the U.S.S.R. Vol. X. Bishen Singh Mahendra Pal Singh, Dehra Dun and Koeltz Scientific Books, Koenigstein. Pp. 59-167.

Soják, J. 1989. Notes on Potentilla (Rosaceae): 8. P. nivea L. agg. Candollea 44: 741-762.

Soják, J. 1992. Notes on Potentilla XIII. Further new taxa from Asia. Preslia 64: 211-222.

Soják, J. 2002. A new name for Potentilla koreana Ikeda et Im. Preslia 74: 437.

Soják, J. 2004. Potentilla L. (Rosaceae) and related genera in the former USSR (identification key, checklist and figures) Notes on Potentilla XVI. Botanische Jahrbücher für Systematik, Pflanzengeschichte und Pflanzengeographie 125: 253-340.

Soják, J. 2008a. Notes on Potentilla XXI. A new division of the 
tribe Potentilleae (Rosaceae) and notes on generic delimitations. Botanische Jahrbüucher für Systematik, Pflanzengeschichte und Pflanzengeographie 127: 349-358.

Soják, J. 2008b. (1857-1858) Proposals to conserve the name Potentilla bipinnatifida against $P$. normalis and P. missourica and the name $P$. stolonifera against $P$. sprengeliana (Rosaceae). Taxon 57: 1361-1362.

Soják, J. 2010. Argentina Hill, a genus distinct from Potentilla (Rosaceae). Thaiszia 20: 91-97.

Staudt, G. 2003. Notes on Asiatic Fragaria species: III. Fragaria orientalis Losinsk. and Fragaria mandshurica spec. nov. Botanische Jahrbücher 124: 397-419.

Staudt, G. and K. Olbricht. 2008. Notes on Asiatic Fragaria spe- cies V: F. nipponica and F. iturupensis. Botanische Jahrbücher, 127: 317-341.

Töpel, M., M. Lundberg, T. Eriksson and B. Eriksen. 2011. Molecular data and ploidal levels indicate several putative allopolyploidization events in the genus Potentilla (Rosaceae). PLoS Currents 3: RRN1237.

Trelawny, J. G. 1983. Wildflowers of the Yukon and northwestern Canada, including adjacent Alaska. Sono Nis Press. cited in Miyanishi, K., Eriksson, O., \& Wein, R. W. 1991. The biology of Canadian weeds. 98 Potentilla anserina L. Canadian Journal of Plant Science, 71 (3), 791-801.

Wolf, T. 1908. Monographie der Gattung Potentilla. Biblioth. Bot. 16 (Ht. 71): 1-714.

\section{한국산 양지꽃족(장미과)의 분류학적 연구 \\ 허경인 · 이상룡 ${ }^{1}$ 김용성 - 박종선 ${ }^{*} \cdot$ 이상태 ${ }^{2 *}$}

InfoBoss Co., Ltd., InfoBoss Research Center, 일본 토호쿠대학교 식물원 ${ }^{1}$, 성균관대학교 생명과학과 ${ }^{2}$

적 요: 한국산 양지꽃족(tribe Potentilleae) 식물 7속 24종에 대하여 외부형태 형질과 과실 미세구조 관찰및 문헌 조사를 통한 분류학적 연구를 수행하였다. 화주가 암술에 위치하는 특징과 화주의 모양은 양지꽃족의 아족 및 속간 분류에 유용한 형질이었다. 딸기아족(subtribe Fragariinae)은 화주가 아기저생 또는 측생하였으며 수술에는 1 개의 화분낭을 갖는 반면에, 양지꽃아족은 화주가 대부분 자방에 아정생하며, 드물게 측생하고, 수술 에 2개의 화분낭을 갖는 특징으로 구분되는 것으로 밝혀졌다. 딸기아족에는 물싸리속, 물싸리풀속, 검은낭아 초속, 딸기속이 포함되며, 각 속은 양지꽃속과는 구분되는 독립된 속으로의 처리를 지지한다. 양지꽃속으로 처리되어 왔던 눈양지꽃은 양지꽃아족에서 유일하게 화주가 측생/아정생하는 특징과 탁엽이 엽병의 앞면에 부착하는 특징으로 독립된 눈양지꽃속으로 처리됨을 지지한다. 종 수준에서의 연구 결과 흰땃딸기(딸기속)는 식물체가 잎 포함하여 전반적으로 작고, 한라산에서만 제한 분포하는 특징으로 특산종으로 처리가 타당하다 고 판단된다. 산뱀딸기(뱀딸기속)는 뱀딸기에 비하여 잎이 연한 녹색 또는 황녹색, 소엽이 얇고 다소 막질이 며, 넓은 난형 또는 도란형의 소엽 등을 갖는 특징으로 뱀딸기와 잘 구분된다. 다양한 외부형태학적 변이를 보여 분류군의 한계에 대한 논란이 있어 왔던 양지꽃속의 돌양지꽃 복합체와 딱지꽃 복합체에 대하여 추가 적인 분류학적 연구와 개체군 수준에서의 분자분류학적 연구가 필요하다.

주요어: 양지꽃족, 양지꽃아족, 딸기아족, 외부형태학적 형질, 과실의 표면무늬 


\section{Appendix 1.}

\section{(1) Dasiphora fruticosa (L.) Rydb.}

NORTH KOREA. Baekdusan Mt., 10 Jul 1983, Anonymous s.n. (KH 11496); Kankyohokudo, Hakutozan Mt., Jul 1931, T.Ishidoya s.n. (KYO); ?, 1914.?, T. Nakai 27 (TI 190); ?, Jul 1941, T. Nakai s.n. (TI 189); ?, 19 Jun, 24 Jun, 24 Jul, Jul 31 , 1930, J. Ohwi s.n. (KYO); ?, 22 Aug 1932, S. Kitamura s.n. (KYO). Hamgyeongbuk-do: Hwasan-gun, Samjang, 20 Aug 1933, G. Koidzumi s.n. (KYO); Myohyangsan Mt., 22 Jul 1972, Anonymous s.n. (KH 11490). Hamgyeongnam-do: Weoncheri, 20 Jun 1932, J. Ohwi s.n. (KYO); ?, 15 Jun 1932, J. Ohwi s.n. (KYO); ?, 27 Jul 1933, G. Koidzumi s.n. (KYO); ?, 3 Oct 1935, S. Okamoto s.n. (KYO).

CHINA. Jangbaeksan Mt., 21 Jun 2002, S. T. Lee et al. s.n. (SKK), 30 Jul 2007, S. T. Lee et al. s.n. (SKK); Wonji, 27 Jun 2004, Park J. H., Cho S. H. s.n. (KH 7457).

\section{(2) Sibbaldianthe semiglabra (Soják) Mosyakin \& Shiyan}

NORTH KOREA. Geumgangsan Mt., 5 Aug 1982, Anonymous s.n. (KH 141494); Hamgyeongnam-do: 5 Aug 1933 , Anonymous s.n. (KYO M10-23); Jueul, Jun 1933, s.n. (KYO M10-24); Oct 25-27 ?, Anonymous 1376 (KYO M10-22); Kanhokni, 28 May 1940, S. Hoguihi s.n. (KYO M10-21); Kankyohoku-do, Hakutozan, Jul 1931, T. Ishidoya s.n. (KYO M1027); Myohyangsan Mt., 10 Aug 1969, Anonymous s.n. (KYO); ?, 15 Jun 1930, J. Ohwi s.n. (KYO M10-26); ?, 13 Jul 1930, J. Ohwi s.n. (KYO M10-25).

(3) Fragaria $x$ ananassa (Weston) Duchesne

KOREA. Seoul: Gwanaksan Mt., 2 Jun 1996, H. Y. Lee s.n. (SKK B200507062051); Myeongryun-dong, 1 May 1954, Y. H. Yu s.n. (SKK 26365-6). Gyeonggi-do: Cheonmasan Mt., 5 May 1993, H. J. Gang s.n. (SKK). Chungcheongnam-do: Daenanjido, 17 May 1965, Lee, Chung s.n. (SKK 26364); Jogaesan Mt., 3 May 1992, S. T. Kim s.n. (SKK 24460, b24085).

(4) Fragaria nipponica subsp. chejuensis Staudt \& Olbricht

KOREA. Jejudo: Hallasan Mt., Eorimok, 20 Jun 2003, W. L. Chen et al. HKI01199 (SKK); Seobukbyeok, 12 Jun 2007, S. R. Lee et al. s.n. (SKK).

(5) Fragaria mandshurica Staudt

CHINA. Jangbaeksan Mt., 21 Jun 2002, S. T. Lee et al. HKI01186-8 (SKK), 28 Jul 2007, S. T. Lee et al. HKI01192, 1195 (SKK), 29 Jul 2007, S. T. Lee et al. HKI01189-1191, 1193-4, 1197-8 (SKK); Idobaekhwa, 27 Jul 2007, S. T. Lee et al. HKI01196 (SKK).

(6) Comarum plaustre L.

NORTH KOREA. Hamgyeongbuk-do, 8 Aug 1912, Anonymous s.n. (KYO 7064), 9 Aug 1912, Anonymous s.n. (KYO 7030); Baekam, 18 Sep 1940, T. Nakai s.n. (TI); ?, 24 Jul 1930, J. Ohwi s.n. (KYO 2630), 31 Jul 1930, J. Ohwi s.n. (KYO 2844).

CHINA. Yeongil, 27 Jul 2007, S. T. Lee et al. HKI00871-880 (SKK).

(7) Argentina egedii (Wormsk. ex Hornem.) Rydb.

KOREA. Gangwon-do: Gyeongpoho, 9 Aug 19749, W. T. Lee 8062 (KWNU); Hwajinpo, 25 Jul 1977, Y. B. Gil 8063 (KWNU), 27 May 1995, S. H. Park p0242 (KH), 21 Jul 1999, Y. M. Lee Gwang11567-8 (KH); Naksandaegyo, 27 Aug 2004 , K. I. Heo et al. HKI00518, 520-1, 525, 539-546 (SKK), 29 Jun 2007, K. I. Heo, S. W. Lee HKI00571 (SKK); Naksansa, 28 May 1996, T. B. Lee 7937 (SNUA 25098-25106); Songjiho, 3 Jul 1979, W. T. Lee 8064-5 (KWNU), 27 Aug 2004, K. I. Heo et al. HKI00509-11, 514-6, 522, 524, 526-534 (SKK), 4 Jun 2005, K. I. Heo HKI00186, 5008, 512-3, 517, 519, 523, 5357, 547-556, 558-566, 568-570, 572 (SKK), 30 Jul 2005, K. I. Heo et al. HKI538, 555, 557 (SKK), 29 Jun 2007, K. I. Heo, S. W. Lee HKI00567, 573 (SKK); ?, T. B. Lee s.n. (SNUA 25094).

NORTH KOREA. Hamgyeongnam-do, Muncheon-gun, ? 1939, Anonymous s.n. (SNU 5522), Wonsan, 8 Jul 1909, T. Nakai s.n. (TI); Hamgyeongbuk-do, 8 Aug 1918, T. Nakai 7163 (TI).

\section{(8) Duchesnea indica (Andrews) Focke}

KOREA. Gangwon-do: Bukbaesan Mt., 6 Jun 1976, W. T. Lee 7703 (KWNU); Chuncheon-si, 29 May 1983, W. T. Lee 7720, 7722 (KWNU), Jungdo, 5 May 1975, W. T. Lee 7698 (KWNU); Chunseong, 13 Aug 1975, W. T. Lee 7702 (KWNU); Daedeoksan Mt., 18 Jun 2005, K. I. Heo, J. E. Go HKI01029 (SKK), 20 Jun 2006, S. T. Lee et al. HKI00944 (SKK); Dutasan Mt., 8 May 1987, Jo et al. s.n. (SKK 26269), 14 May 1990, Jo et al. s.n. (SKK 26260), S. G. Lee et al. s.n. (SKK 26259), Anonymous s.n. (SKK 26284); Guryongsan Mt., 25 May 1995, C. H. Lee s.n. (SKK 27149); Gyeongpoho, 22 May 1986, W. 
T. Lee 7729 (KWNU); Jeongjoksan Mt., 11 Oct 1987, W. T. Lee 7734 (KWNU); Myeonsan Mt., ?. S. T. Lee et al. HKI93840 (SKK); Samyeongsan Mt., 9 May 1983, W. T. Lee 7716-7 (KWNU), 29 May 1983, W. T. Lee 7719, 7721 (KWNU); Seolaksan Mt., 31 Jul 1962, T. H. Chung s.n. (SKK 26202); Sogeumgang, 18 May 1981, W. T. Lee 7710-1 (KWNU); Taegisan Mt., 16 Jun 1990, W. T. Lee 7738 (KWNU); Jeonjin-ri, 29 Jun 2007, K. I. Heo, S. W. Lee HKI00982, 1017-8, 1020 (SKK). Seoul: Bukhansan Mt., 23 May 1954, W. T. Lee s.n. (SKK 26227), 19 Jun 1955, T. H. Chung s.n. (SKK 26199), 6 May 1962, W. T. Lee s.n. (SKK 26233), 6 Jul 1982, D. C. Kim s.n. (SKK 26195), 28 May 1988, J. H. Kim s.n. (SKK 26295), 22 Jun 1988, N. W. Gang s.n. (SKK 26304), 25 May 1996, I. S. Im s.n. (SKK B200507062039); Bulamsan Mt., 27 May 1989, T. R. Kim s.n. (SKK 26256, 26280); Changgyeongwon, 3 Oct 1958, T. H. Chung s.n. (SKK 26221); Dobongsan Mt., 15 May 1955 , W. T. Lee s.n. (SKK 26225-6), 6 Jun 1989, G. S. Gang s.n. (SKK 26305); Gwanaksan Mt, 10 Aug 1974, Anonymous s.n. (KNU 9417), 30 May 1989, S. Y. Lee s.n. (SKK 26303); Jongmyo, 25 Jul 1956, T. H. Chung s.n. (SKK 26224); Myeongryundong, 13 Jun 1981, K. S. Chung s.n. (SKK 26267); Woomyeonsan Mt., 12 Jun 1996, J. Y. Lee s.n. (SKK B200507062023). Gyeonggi-do: Bogwangsa, 6 Jun 1981, S. S. Yeom s.n. (SKK 26311); 7 May 1983, S. S. Yeom s.n. (SKK 26268); Cheolmasan Mt., 26 Mar 1994, G. H. Chung s.n. (SKK); Cheoncheon-dong, 28 Jun 1982, S. G. Lee s.n. (SKK 26264), 6 Jun $1984, B$. B. Choi s.n. (SKK 26163), 9 Jun 1996, B. H. Park s.n. (SKK B200507062015), H. N. Lee s.n. (SKK B200507062021); Cheonggyesan Mt., 6 Jun 1996, S. Y. Kim s.n. (SKK B200507062017); Cheonmasan Mt., 21 May 1988, J. H. Kim S.n. (SKK 26297), S. J. Won s.n. (SKK 26294), W. J. Mun s.n. (SKK 26296), 4 Jun 1988, G. T. Kim s.n. (SKK 26192), 19 May 1989, E. Y. Jo s.n. (SKK 26255), 24 May 1991, J. E. Kim s.n. (SKK 26449), 4 Jun 1991, Y. S. Lee s.n. (SKK 26248); Chukryeongsan Mt., 28 Apr 1991, Park et al. s.n. (SKK 26254), S. W. Park et al. s.n. (SKK 26253); Daeseong-ri, 13 May 1981, S. Y. Byeon, Y. J. Wi s.n. (SKK 26307), 10 Jun 1981, Kim et al. s.n. (SKK 26262); Daeyami-dong, 25 May 1995, G. A. Seo s.n. (SKK 27829), 31 May 1995, D. B. Jo s.n. (SKK 27019), G. Y. Kim s.n. (SKK A200506271050), 7 Jun 1995, H. H. Lee s.n. (SKK B200508192120); Gwangdeoksan Mt., 25 Jun 1994, G. E. Yoo, W. T. Lee 9110 (KWNU), 5 Jul 2005, K. I. Heo et al. HKI00995, 1000, 1022-3, 1028 (SKK); Gwanggyosan Mt., 9 May 1993, M. K. Kang s.n. (SKK), Y. J. Song s.n. (SKK), 17 May 1995, H. J. Park s.n. (SKK 25966), 24 May 1995, J. H. Lee s.n. (SKK 27029), S. M. Lee s.n. (SKK 27017); Gwangmyeong-si, 6 Jun 1995, B. Y. Park s.n. (SKK 26021); Gwangreung, 3 Jul 1954, Y. H. Yu s.n. (SKK 26234-5), 15 May 1960, T. H. Chung s.n. (SKK 26236); Jangheung, 4 Jun 1982, J. M. Kim s.n. (SKK 26319); Myeongjisan Mt., 13 May 1989, W. T. Lee 7735 (KWNU), 27 May 1990, H. S. Park s.n. (SKK 26257); Namhansanseong, 6 Jun 1995, S. M. Lee s.n. (SKK B200507062027); Osan-si, 5 May 1983, J. M. Park s.n. (SKK 26316); Paldalsan Mt., 24 Apr 1996, H. Y. Lee s.n. (SKK B200507062024), 8 Jun 1996, Y. A. Oh s.n. (SKK B200507062022), 9 Jun 1996, S. H. Park s.n. (SKK B200507062018); Pyeongtaekcheon, 10 Jun 2000, C. H. Lee et al. HKI00999 (SKK); Seongnam-si, 6 Jun 1996, S. S. Sim s.n. (SKK 27531); Sorisan Mt., 26 May 1990, H. J. Lee s.n. (SKK 26286); Soyosan Mt., 27 Jun 1959, W. T. Lee s.n. (SKK 26207-8), 6 Jun 1960, W. T. Lee s.n. (SKK 26209), 10 Jul 1960, Y. S. Kim s.n. (SKK 26244), 3 Aug 1960, W. T. Lee s.n. (SKK 26210), 17 Oct 1960, W. T. Lee s.n. (SKK 26206), 28 May 1988, C. Y. Maeng s.n. (SKK 26293), 29 May 1988, J. Y. Lee s.n. (SKK 26291), 17 May 1991, Y. H. Jang s.n. (SKK 26250), 18 May 1991, J. G. Gang s.n. (SKK 26247); Surisan Mt., 30 May 1995, K. S. Kim s.n. (SKK 26301 ), 31 May 1995, B. Y. Park s.n. (SKK B200508192108), J. K. Kim s.n. (SKK 23833), M. H. Bae s.n. (SKK 27827), S. H. Kim s.n. (SKK 27859), 2 May 1996, H. I. Sim s.n. (SKK B200507062020), 8 Jun 1996, S. Y. Yoo s.n. (SKK B200507062025), J. Y. Kim s.n. (SKK 27588), 22 Apr 2005, K. I. Heo, J. E. GoHKI01027 (SKK), 31 May 2005, Kim et al. s.n. (SKK); Yangpyeonggun, 22 May 1996, S. I. Kim s.n. (SKK B200507062019); Yongin-si, 30 May 1995, S. Y. Park s.n. (SKK 24034); Yongmunsan Mt., 10 Aug 1983, S. T. Lee s.n. (SKK), 3 Jun 1989, D. H. Shin s.n. (SKK 26289), 2 Jun 1990, J. H. Seo s.n. (SKK 26298). Incheon-si: Deokjeokdo, 10 Jun 1976, H. K. Lee s.n. (SKK 26266), 22 May 1986, Gwak et al. s.n. (SKK 26276), 23 May 1986, C. G. Paek et al. s.n. (SKK 26317); Ganghwado, 29 Jul 1958, T. H. Chung s.n. (SKK 26219); Songdo, 30 Apr 1993, D. Y. Han s.n. (SKK). Chungcheongbuk-do: Cheongwon-gun, 5 Aug 1960, H. H. Koo s.n. (SKK 26205); Eumseong-gun, 1 May 1994, B. J. Gong s.n. (SKK); Sobaeksan Mt., 19 May 1995, C. Lee et al. s.n. (SKK A200506271045); Sokrisan Mt., 23 May 1959, W. T. Lee s.n. (SKK 26213-6), 26 May 1990, H. Y. Jo s.n. (SKK 26281), J. W. Chae s.n. (SKK 26300), 27 May 1990, E. Y. Lee s.n. (SKK 26299), T. H. Kim s.n. (SKK 26258). Chungcheongnam-do: Cheonripo, 26 Sep 1980, J. J. Choi s.n. (SKK 26271), S. M. Hwang s.n. (SKK 26246); Daenanjido, 17 May 1965, Chung, Lee s.n. (SKK 26231-2); Ggujinamugol, 18 May 2001, S. T. Lee et al. HKI01024 (SKK); Gyeryongsan Mt., 3 Jun 1957, T. H. Chung s.n. (SKK 26223), 3 Aug 1957, T. H. Chung s.n. (SKK 26222); Jogaesan Mt., 3 May 1992, G. T. Sim et al. s.n. (SKK 26252), Kim et al. s.n. (SKK); Manripo, 19 May 1984, Anonymous s.n. (SKK 26265); Namhangang, 23 Jun 1993, S. J. Yeo s.n. (SKK); Oeyeondo, 2 Aug 1977, W. T. 
Lee 7706 (KWNU). Gyeongsangbuk-do: Bohyeonsan Mt., 6 Jun 1991, J. S. Kim et al. 96 (KNU 8840); Chuijeongsan Mt., 09 Oct 19839, S. W. Jin s.n. (KNU); Gowoonsa, 13 May 1973, Anonymous s.n. (KNU 9041); Ilweolsan Mt., 12 Jun 1987, Y. K. Jung s.n. (KNU); Juheulsan Mt., 8 May 1999, J. H. Park et al. 5358, 5544 (KNU), 18 Jun 1999, J. H. Park et al. 5995 (KNU); Mungyeongsaejae, 18 Jun 1999, J. H. Park et al. 5930 (KNU); Sangju-si, Heungguk-ri, 5 Aug 1974, Anonymous s.n. (SKK 26265); Namhangang, 23 Jun 1993, S. J. Yeo s.n. (SKK); Sangju-si, Heungkuk-ri, 5 Aug 1974, Anonymous s.n. (KNU 8597); Sobaeksan Mt., 27 May 1973, S. R. Park s.n. (KNU 8822), 2 Jun 1974, G. S. Choi s.n. (KNU 9592-3); Ulleungdo, 26 Jul 1973, W. T. Lee 7697 (KWNU), 1 Oct 1981, W. T. Lee 7714 (KWNU), 23 Apr 2003, G. E. Yoo 622 (KWNU), 16 Jun 2004, K. I. Heo, J. E. Go HKI01004 (SKK); Weolseong-gun, 18 Aug 1986, Anonymous s.n. (KNU 8383); Woonmunsa, 5 May 2001, J. Y. Yang 275 (KNU). Daegu-si: Kyeongbuk Univ., 26 Aug 1977, Anonymous s.n. (KNU 18084), 20 Oct 1983, S. J. Jin s.n. (KNU 502-3), 24 Oct 1983, N. C. Park s.n. (KNU); Seohyeon-dong, 25 Jul 1979, G. J. Hyeon s.n. (KNU 8749). Gyeongsangnam-do: Cheonghwangsan Mt., 24 May 1986, Anonymous s.n. (KNU 10953), 29 Jul 1986, M. H. Kim s.n. (KNU 18753); Gajisan Mt., 29 Jul 1964, S. Y. Oh 1099 (KNU); Garasan Mt., 25 Apr 2005, S. T. Lee et al. HKI00946-7 (SKK); Geumsan Mt., 7 Jun 1979, G. S. Jang s.n. (SKK 26320), H. J. Yu s.n. (SKK 26318), M. S. Chung s.n. (SKK 26272), 31 May 1982, Anonymous s.n. (SKK 26245), 14 May 1988, S. C. Kim s.n. (SKK 26270), W. S. Lee et al. s.n. (SKK 26290), 12 May 1991, C. H. Lee et al. s.n. (SKK 26251); Haegeumgang, 10 Aug 1982, W. T. Lee 7715 (KWNU); Mangwoonsan Mt.,11 Aug 1955, T. H. Chung s.n. (SKK 26243); Muyongsan Mt., 8 Jun 1977, Y. M. Park s.n. (SKK 26315); Namhae-gun, Sangju, 8 Jun 1979, Y. I. Ahn s.n. (SKK 26314). Ulsan-si: 8 Jun 1977, J. M. Song s.n. (SKK A200507271014). Jeollabuk-do: Biando, 23 Oct 1958, C. D. Lee s.n. (SKK 26220); Byeonsan Mt., 13 May 1981, M. K. Hong, G. D. Park s.n. (SKK 26310); Daedunsan Mt., 2 Jul 2004, G. E. Yoo 2100 (KWNU); Deokyoosan Mt., 4 Aug 1959, H. H. Chung s.n. (SKK 26218), T. H. Kim s.n. (SKK 26211); Maisan Mt., 3 Jul 2004, G. E. Yoo 2096, 2099 (KWNU); Naebyeonsan Mt., 2 May 2007, S. T. Lee et al. HKI01003, 1008-12, 1015-6 (SKK); Naejangsan Mt., 5 May 1988, G. M. Im s.n. (SKK 26261), 24 May 2003, W. L. Chen et al. HKI00943, 957, 962, 998, 1002 (SKK); Seonwoonsan Mt., 5 May 2005, S. T. Lee et al. HKI00976, 988, 996, 1021 (SKK), 3 May 2007, S. T. Lee et al. HKI00981, 984, 1005-7, 1013-4 (SKK), 25 May 2008, K. I. Heo, Y. S. Kim HKI00941-2, 945, 965-975, 977-978 (SKK); Wido, 3 Aug 1963, T. H.Chung s.n. (SKK 26196-7, 26200). Jeollanam-do: Baekwoonsan Mt., 20 ? 1996, W. T. Lee 7739 (KWNU); Cheomchalsan Mt., 14 Apr 2003, W. L. Chen et al. HKI00964 (SKK); Daedunsan Mt., 15 Jul 1963, S. H. Park s.n. (SKK 26228); Geomundo, 8 Aug 1965, T. H. Chung s.n. (SKK 26198); Hongdo, 12 Apr $2003, W$. L. Chen et al. HKI00980 (SKK); Jirisan Mt., May 1994, S. M. Kim et al. s.n. (SKK 24803); Oenarodo, 9 Aug 2003 , K. I. Heo, J. E. Go HKI01026 (SKK); Sanghwangbong, 7 May 2005, J. E. Go, Im s.n. (SKK A200508111036); Wando-gun, 7 Aug 1960, T. H. Chung s.n. (SKK 26204), 13 Apr 2003, W. L. Chen et al. HKI01025 (SKK); Yeseodo, 4 Aug 1981, Anonymous s.n. (KNU 3771). Jejudo: Dongbaekdongsan Mt., 10 Jun 2007, K. I. Heo et al. HKI01030-2 (SKK); Jeju, 13 Nov $1964, W$. T. Lee s.n. (SKK 26230), 10 Jun 2007, K. I. Heo et al. HKI00979, 1019 (SKK); Ongpo-ri, 10 Jun 2007, K. I. Heo et al. HKI00997, 1033 (SKK); Sangchujado, 28 Jul 1964, W. T. Lee s.n. (SKK 26229); Sanyang-ri, 21 Jun 2003, W. L. Chen et al. HKI01001 (SKK); Seoguipo, 23 Jul 1954, T. H. Chung s.n. (SKK 26237-9).

(9) Duchesnea chrysantha (Zoll. \& Moritzi) Miq.

KOREA. Jeollanam-do: Seonwoonsan Mt., 3 May 2007, S. T. Lee et al. HKI00983, 985-9 (SKK), 25 May 2008, K. I. Heo, Y. S. Kim HKI00948-956, 958-961, 963, 990-994 (SKK).

(10) Potentilla dickinsii Fran.

KOREA. Gangwon-do: Baekamsan Mt., 11 Jun 1968, Anonymous s.n. (SNU 2205-8), 28 Jul 2003, G. E. Yoo 527 (KWNU); Buyongsan Mt., 25 Jul 2003, G. E.Yoo 1078 (KWNU); Cheongoksan Mt., 3 Aug 1973, W. T. Lee 8018 (KWNU); Chiaksan Mt., 1 Aug 1975, W. T. Lee 8019, 8051 (KWNU); Daeryongsan Mt., 8 Oct 1975, W. T. Lee 8020 (KWNU); Donggang, 24 May 2002, S. T. Lee et al. HKI00787, HKI00803, HKI00833, HKI00835 (SKK), 29 May 2006, K. I. Heo et al. HKI00772-6, HKI00779-86, HKI00834 (SKK); Dutasan Mt., 29 Aug 1988, Anonymous s.n. (SKK b8817); Gongjaksan Mt., 10 Aug 1977, K. M. Yoon 8030 (KWNU), 28 Aug 1981, W. T. Lee 8037 (KWNU); Goseong-gun, Hyangrobong, 18 Jun 1967, Anonymous s.n. (SNU 831-2); Gwangdeaksan Mt., 28 Aug 2014, S. T. Lee et al. IB-00545 (IN); Jeombongsan Mt., 24 Jun $1987, S . T$. Lee et al. s.n. (SKK b8711); Obongsan Mt., 13 Jul 1975, W. T. Lee 8057 (KWNU), 14 Jul 1975, W. T. Lee 8028 (KWNU); Odaesan Mt., 28 Jul 2004, G. E. Yoo 2114-5 (KWNU); Samaksan Mt., 6 Aug 1975, W. T. Lee 8058 (KWNU), 8 Aug 1979 , W. T. Lee s.n. (KWNU 8036); Samyeongsan Mt., 15 Aug 1992, S. T. Lee et al. s.n. (SKK b8804-5); Seolaksan Mt., 11 Jul 1977, B. G. Yoon 8027 (KWNU), 7 Jul 1993, H. S. Gwak s.n. (SKK 24983), 2 May 1982, M. Y. Kim, S. P. Hong s.n. (SKK 
b8710); Seolaksan Mt., Biryongpokpo, 11 May 2007, S. T. Lee et al. HKI00842-4 (SKK); Seolaksan Mt., Gongryongneungseon, 30 Aug 2003, K. I. Heo et al. HKI00847, 848, 850, 853, 860, 863 (SKK); Seolaksan Mt., Hangyeryeong, 26 Jun 2003, S. T. Lee et al. HKI00796, 00801, 00864 (SKK), 29 Jun 2006, J. H. Lee et al. s.n. (SKK), 7 Jul 2006, S. T. Lee et al. s.n. (SKK); Seolaksan Mt., Jangsudae, 26 Jun 2003, S. T. Lee et al. HKI00802, 849, 855, 859 (SKK), 28 Aug 2004, K. I. Heo et al. HKI00837, 846, 856-8, 865 (SKK); Seolaksan Mt., Osaekyaksu, 26 Jul 1984, Anonymous s.n. (SKK b8680); Taebaeksan Mt., 16 Jun 1996, J. S. Song s.n. (SNU 86728), 16 Sep 2006, K. I. Heo et al. HKI00838-40 (SKK); Yeongweol-gun, 31 Aug 1967, W. T. Lee 8126 (KWNU); Yonghwasan Mt., 6 Jul 1976, B. G. Yoon 8024 (KWNU). Seoul-si: Dobongsan Mt., 14 Jun 1959.6.14, N. J. Park s.n. (SKK b8702); Bukhansan Mt., 20 Aug 1930, B. S. Do s.n. (SNU 5501), 27 Jul 1931, B. S. Do s.n. (SNU 5513), 12 Jun 1954, C. S. Kim s.n. (SKK), 26 Jun 1954, W. T. Lee s.n. (SKK b8801-3), 6 Jul 1982, D. C. Kim s.n. (SKK b8814, 8677), 21 Jul 1991, S. T. Kim s.n. (SKK 24391, 24393), 6 Jul 2006, K. I. Heo et al. HKI00841 (SKK). Gyeonggi-do: Gapyeonggun, 29 Jun 1992, J. H. Mun 151-2 (SNU); Gwangreung, 15 Jun 1960, D. M. Yu s.n. (SKK b8695), ? 1966, T. H. Chung s.n. (SKK B8833), ? 1967, T. H. Chung s.n. (SKK B8834-5); Myeongseongsan, 16 Aug 1989, J. S. Kim s.n. (SNU 69835); Samseongsan, 7 Aug 1993, S. W. Park s.n. (SKK b8806-7); Soyosan Mt., 27 Jun 1959, H. C. Lee s.n. (SKK b8693-4), 5 Jun 1960, C. G. Lee s.n. (SKK b8688), 5 Jun 1960, W. T. Lee s.n. (SKK b8810), 10 Jul 1960, T. H. Chung s.n. (SKK b8682-3), 11 Sep 1960, W. T. Lee s.n. (SKK b8689-91), 6 Jul 1982, K. S. Lee s.n. (SKK b8675), J. H. Song s.n. (SKK b8709), S. H. Ahn s.n. (SKK 8712), S. H. Han s.n. (SKK 8676), 27 Jun 1991, C. H. Lee s.n. (SKK b8681); Surisan Mt., 11 Oct 2016, Y. S. Kim et al. IB-00449 (IN); Taehwasan Mt., 17 Jul 2003, K. I. Heo HKI00800, 00851, 00852, 00854,00862 (SKK); Woonaksan Mt., 23 Jun 1990, W. T. Lee 8053 (KWNU), 26 Jul 1990, C. H. Lee s.n. (SKK b8678), 9 Sep 1990, W. T. Lee 8045 (KWNU), 9 Jul 1991, W. T. Lee 8055 (KWNU), 29 Jun 1992, J. H. Mun s.n. (SNU); Yumyeongsan, 29 Jun 1986, T. H. Lee s.n. (SKK b8815). Chungcheongbuk-do: Danyang-gun, 29 Sep 1986, W. T. Lee 8040 (KWNU); Gunjasan Mt., 17 Aug 1959, W. T. Lee s.n. (SKK b8792); Jecheon-si, Maepo-eup, 18 Jun 2003, J. O. Hyun, H. K. Park 2003252-5 (KH); Oseosan Mt., 21 Jun 1997, S. K. Lee s.n. (SNU); Sobaeksan Mt., 4 Aug 1959, I. S. Yang s.n. (KNU), 16 Aug 1989, W. T. Lee 8042 (KWNU), 19 Jul 2003, K. I. Heo et al. HKI00797, 845, 866 (SKK), 5 Jul ?, H. G. Choi s.n. (SNU), 30 Aug ?, H. G. Choi s.n. (SNU); Sokrisan Mt., 22 Jun 1938, B. S. Do, H. J. Sim s.n. (SNU 5512), 7 Aug 1959, W. T. Lee s.n. (SKK b8793), 1961.7.23, S. Y. Oh 3519, 4768 (KNU), 7 Aug 1990, W. T. Lee 8054 (KWNU). Chungcheongnam-do: Anmyeondo, 3 May 1992, O. H. Lee et al. s.n. (SKK b28734); Daedunsan, 1958.7.18, S. H. Park s.n. (SKK b8685); Gayasan, 1956.8.24, T. H. Chung s.n. (SKK b8799); Gwangcheon-eup, 21 Jun 1997, S. K. Lee s.n. (SNU 88257); Gyeryongsan Mt., 3 Aug 1957, T. H. Chung s.n. (SKK b86998701, 8796, 8797, 8800, 8832), 28 Jul 1979, W. T. Lee 8034-5 (KWNU), 22 Jun 1988, J. G. Chung s.n. (SKK b8679); Yeonggigun, 21 May 1988, G. O. Hyeon s.n. (SKK b26641). Gyeongsangbuk-do: Geumosan Mt., 11 Jul 1958, W. Kim s.n. (KNU), 31 May 2003, W. L. Chen et al. HKI00794 (SKK); Hoengaksan Mt., 19 Aug 1989, W. T. Lee 8043 (KWNU); Joryeongsan Mt., 20 Sep 1987, Y. E. Kim s.n. (SNU 65117). Daegu-si: Palgongsan Mt., 1 Jun 2003, W. L. Chen et al. HKI00788, 01140 (SKK). Gyeongsangnam-do: Bulmosan, 1977.8.8, W. T. Lee 8029 (KWNU); Gayasan, 1932.7.22, B. S. Do s.n. (SNU 5503), 18 May 1968, I. W. Yang s.n. (KNU), 3 Sep 1991, W. T. Lee 8056 (KWNU); Geumsan Mt., 14 May 1988, G. T. Kim et al. s.n. (SKK 26842). Ulsan-si: Sinbulsan Mt., 12 Aug 1977, W. T. Lee 8031, 8052 (KWNU). Jeollabuk-do: Deokyoosan Mt., 2 Aug 1959, T. H. Chung s.n. (SKK b8794-5), 16 May 1964, W. T. Lee s.n. (SKK b8687, b8808); Minjujisan Mt., 11 Aug 1976 , W. T. Lee 8022 (KWNU), 17 Jun 1992, W. T. Lee 8046 (KWNU); Naejangsan Mt., 14 Jun 2003, K. I. Heo, S. H. Kim HKI00789791, 795, 799, 805, 861 (SKK); Seonwoonsan Mt., 3 May 2007, S. T. Lee et al. HKI00836 (SKK). Jeollanam-do: Baekwoonsan Mt., 21 Jul 1992, W. T. Lee 8047 (KWNU), 20 Jun 1999, W. T. Lee 8048 (KWNU); Jirisan Mt., 3 Aug 1939, B. S. Do, H. J. Sim s.n. (SNU 5504-7, 5511), 15 Aug 1962, I. S. Yanng s.n. (KNU), 8 Aug 1965, I. S. Yanng s.n. (KNU), 1972.7.9, J.H.Ahn s.n. (SNU 46923-5), 2004.6.15, H.N.Park s.n. (SKK), 2006.8.25, S. R. Lee s.n. (SKK); Weolchulsan, 1976.8.21, W. T. Lee s.n. (KWNU 8025). Jejudo: Hallasan Mt., 5 Aug 1960, W. T. Lee s.n. (SKK b8686, 8698), 31 Jul 2003, K. I. Heo et al. HKI00777 (SKK), Eorimok, 2003.7.31, K. I. Heo s.n. (SKK), Janggumok, 2003.7.31, K. I. Heo et al. HKI00792-3 (SKK), Mansedongsan, 2006.9.1, K. I. Heo et al. HKI00769, 770, 771, 778, 868, 870 (SKK), Seobukbyeok, 12 Jun 2007, S. R. Lee et al. s.n. (SKK), Yeongsil, 21 Jun 2003, W. L. Chen et al. HKI00804, 869 (SKK), 2004.5.22, S. T. Lee et al. HKI00613-4, 903 (SKK), 2004.9.24, S. T. Lee et al. HKI00611 (SKK), 2005.5.8, S. T. Lee et al. HKI00612 (SKK), 21 Jun 2007, S. R. Lee et al. s.n. (SKK); Sangumburi, 22 Jun 2003, W. L. Chen et al. HKI00867 (SKK)

NORTH KOREA. Geumgangsan Mt., 30 Jul 1928, K. Kondo (SNU 8049, 8050), 28 Jul 1934, B. S. Do s.n. (SNU 5502), 10 May 1936, Anonymous s.n. (SNU 5518), 24 Sep 1938, B. S. Do, H. J. Sim s.n. (SNU 5509), 11 Aug 1943, B. S. Do, H. 
J. Sim s.n. (SNU 5510), 12 Aug 1943, B. S. Do, H. J. Sim s.n. (SNU 5508), 28 Jun 2005, G. E. Yoo, C. H. Lee s.n. (SKK); Seoheung, 3 Aug 1937, Anonymous s.n. (SNU), 10 Aug 1942, Anonymous s.n. (SNU), 6 Sep 1942, Anonymous s.n. (SNU); Yangdeok, 15 Jun 1928, T. Nakai s.n. (SNU 5591).

\section{(11) Potentilla dickinsii var. glabrata Nakai}

KOREA. Gyeongsangbuk-do: Ulleungdo, 3 Jun 1917, T. Nakai s.n. (SNU 5521), 22 May 2005, C. H. Lee, K. I. Heo HKI01200-207 (SKK), 20 Jul 2005, J. H. Kim, J. O. Kim s.n. (SKK), 2006.5.27, M. A. Jeong s.n. (SKK).

(12) Potentilla chinensis Ser.

KOREA. Gangwon-do: Ayajin, 2003.8.15, K. I. Heo et al. HKI00315, 350, 415, 418 (SKK); Ayajin-beach, 2004.7.20, S. T. Lee et al. HKI00333-4, 495 (SKK); Baekmagoji, 24 Jul 1987, W. T. Lee 7993 (KWNU); Chiaksan Mt., 30 Jun 1982 , S. M. Yang, S. H. Lee s.n. (SKK 26584); Daeamsan Mt., 17 Aug 2003, K. I. Heo et al. HKI00318, 330, 371-2, 374, 378-8, 442, 480, 491 (SKK); Chiseokjeong, 3 Aug 1933, B. S. Do, H. J. Sim s.n. (SNU 5588); Dowongyegok, 15 Aug 2003, K. I. Heo et al. HKI00331-2, 486 (SKK); Gangseon-ri, 16 Aug 2004, K. I. Heo et al. HKI00335-6, 413-4, 475-8, 485, 489 (SKK); Gapyeong-gun, Cheonryong-dong, 1987.6.29, W. T. Lee 7990 (KWNU); Gongjaksan, 1977.8.10, W. T. Lee 7977 (KWNU), 4 Sep 1979, W. T. Lee 7982 (KWNU); Goseong-gun, Hakya-ri, 15 Aug 2004, K. I. Heo et al. HKI00407 (SKK); Gyeongpodae, 30 Oct 1966, T. H. Chung, C. S. Yuk s.n. (SKK b8736), 10 Sep 1988, W. T. Lee 7999 (KWNU); Ildong, 6 Aug 1958, H. Y. Mun s.n. (SKK 26529); Jangjeon, 28 Jul 1916, T. Nakai s.n. (SNU 5602); Jeonjinri, 29 Jun 2007, K .I. Heo, S. W. Lee HKI003007-9, 311, 319-21, 327-9, 351-6, 362-7, 412, 416-7, 439, 473, 479 (SKK); Jinbu-myeon, 26 Jul 2003, K. I. Heo et al. HKI00385, 881 (SKK); Mintongseon, 8 Jul 1997, S. H. Park p0240 (KH); Mokpungho, 9 Aug 1974, W. T. Lee 7996 (KWNU); Muljicheon, 26 Aug 2004, K. I. Heo et al. HKI00314, 326, 494 (SKK); Myeongjisan Mt., 27 Jun 1991, K. E. Kim s.n. (SKK 26570); Odaesan Mt., 26 Jul 2003, K. I. Heo et al. HKI00345, 444, 468-9, 470-1 (SKK); Oeongchi-beach, 30 Jul 2005, K. I. Heo et al. HKI00408-10, 497-507 (SKK); Ongdae-ri, 15 Aug 2003, K. I. Heo et al. HKI00382-3, 387, 466, 492 (SKK); Palbongsan Mt., 23 Jul 1978, W. T. Lee 7979 (KWNU); Sanbuk-ri, 16 Aug 2003, K. I. Heo et al. HKI00322-4, 384, 472, 493 (SKK); Seokam-ri, 15 Aug 2003, K. I. Heo et al. HKI00376, 487 (SKK); Seolaksan Mt., 12 Aug 1959, K. H. Lee s.n. (SKK 26496), G. H. Lee s.n. (SKK 26541), 25 Aug 1960, T. H. Chung s.n. (SKK 26497-500, 542, 565); Sokcho, 19 Jul 1977, W. T. Lee 7997 (KWNU); Sokcho-beach, 25 Jun 2003, S. T. Lee et al. HKI00450 (SKK), 20 Jul 2004, S. T. Lee et al. HKI00347, 403-4, 451-7, 483-4 (SKK); Songjiho, 3 Jul 1979, W. T. Lee 7998 (KWNU), 20 Jul 2004, S. T. Lee et al. HKI00496 (SKK), 29 Jun 2007, K. I. Heo, S.W.Lee HKI00346, 368-9, 392-8, 481-2 (SKK); Songjiho-beach, 15 Aug 2003, K. I. Heo et al. HKI00406, 411, 419-21, 424-432 (SKK), 20 Jul 2004, S. T. Lee et al. HKI00422-3 (SKK), 2004.8.15, K. I. Heo et al. HKI00377, 390, 464-5 (SKK); Wonsam-ri, 15 Aug 2003, K. I. Heo et al. HKI00312, 325, 441, 467 (SKK); Woonbong-ri, 15 Aug 2003, K. I. Heo et al. HKI00313, 316, 379-81, 389, 490 (SKK); Yangsan-ri, 1982.6.26, Anonymous s.n. (SKK 26590); Yeongok-beach, 2004.6.5, K. I. Heo, J. E. Go HKI00399-402, 405, 433 (SKK); Seoul-si: Bukhansan Mt., 12 Jun $1954, W . T$. Lee s.n. (SKK 26515), 5 Jul 1958, W. T. Lee s.n. (SKK 26566, 26568), 6 Jul 1982, D. C. Kim s.n. (SKK 26579); Gwanaksan Mt., ? May 1985, Y. J. Ji s.n. (SKK 26577); Seongbuk-dong, 11 Nov 1967, T. H. Chung s.n. (SKK 26582). Gyeonggi-do: Anyangcheon, 30 Jul 1958, S. S. Kim s.n. (SKK 26531); Baekwoonsan Mt., 1 Oct 1983, W. T. Lee 7985 (KWNU), 2 Oct 1983 , W. T. Lee 7987-8 (KWNU); Bupyeong-gun, 15 Aug 1958, J. S. Chung s.n. (SKK 26558); Cheonmasan Mt., 26 Jul $1978, J$. G. Hang 7980 (KWNU), 20 May 1989, B. Y. Park s.n. (SKK 26589); Chilbosan Mt., 9 Jul 1993, S. T. Lee et al. s.n. (SKK 9958-9); Chilgapsan Mt., 26 Jul 1979, W. T. Lee 7981 (KWNU); Deokjuksan Mt., 1 Aug 1958, T. H. Chung s.n. (SKK 26353); Gunjabong, 18 Jul 1982, S. T. Lee et al. s.n. (SKK 26572), S. P. Hong et al. s.n. (SKK 26573); Gwangreung, 12 Jun 1954 , C. S. Kim s.n. (SKK 26561-2), 14 Oct 1954, T. H. Chung s.n. (SKK 26516-8, 26557); Goyang-si, Sindo-eup, 20 May 1988, J. H. Lee s.n. (SKK 26585); Myeongjisan Mt., 27 Jun 1991, S. M. Han s.n. (SKK 26514), J. E. Kim s.n. (SKK 26553), J. Im s.n. (SKK 26554), A. S. Kim s.n. (SKK 26555), Y. S. Lee s.n. (SKK b8746); Oido, 11 Aug 1982, S. T. Lee et al. s.n. (SKK 26576); Seosamneung, 4 Jul 1982, J. H. Ahn s.n. (SKK 26578); Sindo-eup, 20 May 1988, J. H. Lee s.n. (SKK 26585); Soyosan, 27 Jun 1959, T. H. Chung s.n. (SKK 26559), W. T. Lee s.n. (SKK 26564), 23 May 1989, J. Y. Heo s.n. (SKK 26551$), 26$ May 1989, Y. S. Park s.n. (SKK 26586), 27 Jul 1990, H. J. Cha s.n. (SNU 73461, 73725-6). Incheon-si: Eulwangri-beach, 25 Aug 2004, K. I. Heo et al. HKI00306, 882 (SKK); Ganghwado, 25 Jul 1958, T. H. Chung s.n. (SKK 26534), 27 Jul 1958, T. H. Chung s.n. (SKK 26532-3); Yeongjongdo, 1983.10.2, W. T. Lee 7986 (KWNU). Chungcheongbuk-do: Gunjasan, 1959.8.17, W. T. Lee s.n. (SKK 26547); Sokrisan, 19595.23, W. T. Lee s.n. (SKK 26546). Chungcheongnam-do: Cheonripo, 26 Sep 1980 , H. J. Yu, G. H. Sim s.n. (SKK 26571); Daedunsan Mt., 14 Jul 1959, S. H. Park s.n. (SKK 26526); Daenanjido, 17 Jul 1965 , 
Chung, Lee s.n. (SKK 26524); Dangjin-gun, 12 Jul 1958, Anonymous s.n. (SKK 26536); Gayasan Mt., 24 Aug $1956, T$. H. Chung s.n. (SKK 26537); Manripo, 13 Aug 1981, Y. H. Chung s.n. (SNU 54111); Yesangun, Gobuk, 17 Aug 1958, Anonymous s.n. (SKK 26528). Gyeongsangbuk-do: Baekamsan Mt., 28 Jul 2003, G. E. Yu 525 (KWNU); Bisulsan Mt., 28 Jun 1958, S. Y. Oh s.n. (KNU 14920, 40), 17 Jul 1958, S. Y. Oh s.n. (KNU 14948-9); Bohyeonsan Mt., 14 Jun 1981, Anonymous s.n. (KNU); Bulguksa, 18 Jul 1932, B. S. Do s.n. (SNU 5592); Chaeyaksan Mt., 2 Aug 1971, S. Y. Oh 2508 (KNU); Dondalsan Mt., 28 Jul 1971, S. Y. Oh 934 (KNU); Euiseong-gun, Bongyang-myeon, 5 Aug 1971, Anonymous s.n. (KNU 11137), Gowoonsa, 20 May 1973, M. S. Kim s.n. (KNU 8996); Galmibong, 4 Aug 1971, S. Y. Oh 1108 (KNU); Ilweolsan Mt., 25 Oct $1961, W$. T. Lee s.n. (SKK 26544), 4 Aug 1971, S. Y. Oh 759 (KNU), 1 Jul 1987, Anonymous s.n. (KNU); Juwangsan Mt., 10 Aug 1983, S. Y. Oh s.n. (KNU), 16 Jul 1985, Anonymous s.n. (KNU); Maebongsan Mt., 6 Aug 1971, S. Y. Oh 925 (KNU); Mungyeongsi, 9 Aug 1971, S. Y. Oh 422 (KNU), Bongjeong-ri, ?, S. Y. Oh 948 (KNU), Jakcheon-ri, 1971.8.18, S. Y. Oh 1944 (KNU), Jeongok-ri, 14 Aug 1971, S. Y. Oh 1820 (KNU), Magwang-ri, 9 Aug 1971, S. Y. Oh 1941 (KNU); Sangju-si, Donghaesa, 10 Aug 1971, S. Y. Oh 1162-3 (KNU); Sobaeksan, Heuibangsa, 1974.6.23, H. Y. Lee s.n. (KNU 2411), 2001.3.29, S. K. Seo s.n. (KNU 8801); Tongdalsan, 1971.8.13, S. Y. Oh 1838 (KNU); Weolseong, 2 Jul 1981, Y. H. Chung s.n. (KNU 54113); Yecheongun, Jiksan-dong, 7 Aug 1958, J. M. Ahn s.n. (SKK 26530), 21 Jul 1971, S. Y. Oh 616 (KNU); Yeongdeok-gun, Daebu-dong, 12 Aug 1971, S. Y. Oh 1160 (KNU), Mudeungsan Mt., ?, S. Y. Oh 806 (KNU); Yeongil-gun, Iin-dong, 8 Aug 1971, S. Y. Oh 1110 (KNU); Yeongju-gun, Seongnae-dong, ?, S. Y. Oh 814 (KNU), Socheon-ri, 1 Aug 1971, S. Y. Oh 2647 (KNU); Yeongyanggun, Imam-ri, 6 Aug 1971, S. Y. Oh 2599 (KNU). Daegu-si: Kyeongbuk Univ., 26 Jul 1997, W. H. No, Y. S. Seo 9 (KNU), 1977.4.18 Anonymous s.n. (KNU); Palgongsan Mt., 10 Aug 1960, S. Y. Oh s.n. (KNU 10344, 523). Gyeongsangnam-do: Daleumsan Mt., 5 Jul 1981, Y. H. Chung s.n. (SNU 54123); Geomundo, 9 Aug 1965, T. H. Chung s.n. (SKK 26501-4), 7 Aug 1965, T. H. Chung s.n. (SKK 26505-513); Namhae-gun, 11 Aug 1955, T. H .Chung s.n. (SKK b8787). Woolsan-si: Bangeojin, 8 Jun 1977, E. K. Lee s.n. (SKK A200508121024). Jeollabuk-do: Biando, 23 Oct 1958, C. D. Lee s.n. (SKK 26527); Deokyuksan Mt., 2 Aug 1959, T. H. Chung s.n. (SKK 26548-9, b8785); Gaeyado, 16 Oct 1949, B. S. Do, H. J. Sim 5597 (SNU); ?, 17 Oct 1949, B. S. Do, H. J. Sim s.n. (SNU 5598). Jeollanam-do: Bogildo, 7 Aug 1960, T. H. Chung s.n. (SKK b8758); Jindo-gun, 1 Aug 1956, T. H. Chung s.n. (SKK 26538-40), Jukcheong-ri, 7 Aug 1960, T. H. Chung s.n. (SKK 26545); Muhaksan Mt., 27 Jul 1961, T. H. Chung s.n. (SKK 26581); Myeonsan Mt., 13 Jun 1981, J. Y. Choi, S. K. Sim s.n. (SKK 26580); Oenarodo, 10 Aug 2003, K. I. Heo, J. E. GoHKI00291, 373, 375, 443, 460-1, 474 (SKK); Palyeongsan Mt., 19 Aug 1976, W. T. Lee 7971 (KWNU); Sinan-gun, Dochodo, 23 Aug 1976, W. T. Lee 7972, 7973 (KWNU); Wooido, 21 Jul 1979, C. O. Lee s.n. (SNUA 24939); Yeguisan Mt., 1986.8.15, S. T. Lee et al. s.n. (SKK 26575). Jejudo: Abuoreum, 2003.6.22, W. L. Chen et al. HKI00297 (SKK); Dongbaekdonsan, 2003.6.21, W. L. Chen et al. HKI00296 (SKK), 30 Aug 2006, K. I. Heo et al. HKI00883-4 (SKK), 10 Jun 2007, K. I. Heo et al. HKI00292-3, 301-4 (SKK); Donnae-ri, 23 Jul 1986, Y. J. Chung s.n. (SKK 26583); Geumyeong, 20 Jul 1954, T. H. Chung s.n. (SKK 26519-23); Hallasan, 6 Aug 1960, W. T. Lee s.n. (SKK 26552); Kimnyeong-beach, 2003.6.23, W. L. Chen et al. HKI00391, 445, 449 (SKK), 2007.6.10, K. I. Heo et al. HKI002945, 298-300 (SKK); Sangchujado, 27 Jul 1964, W. T. Lee s.n. (SKK 26525); Seongsan, Ilchulbong, 23 Jul 1986, Y.J.Chung s.n. (SKK 26574); Songaksan Mt., 1 Aug 2003, K. I. Heo et al. HKI00290, 370, 437, 446-7, 459, 463, 488 (SKK); Suweolbong, 1 Aug 2003, K. I. Heo et al. HKI00448, 458, 462 (SKK), 23 Sep 2004, S. T. Lee et al. HKI00305 (SKK), 11 Jun 2007, K. I. Heo et al. HKI00436 (SKK); ?, 19 Jul 1935, B. S. Do, H. J. Sim s.n. (SNU 5596, 5600), 28 Jul 1947, H. J. Sim s.n. (SNU 5593-5, 5601).

CHINA. Idobaekhwa, 27 Jul 2007, S. T. Lee et al. HKI00386, 438 (SKK); Manju, ?, B.S.Do s.n. (SNU 5599).

(13) Potentilla discolor Bunge

KOREA. Gangwon-do: Gangreung-si, 14 Jun 1981, W. T. Lee 8061 (KWNU); Hujin, 15 May 1990, Y. J. Chung, C. H. Lee s.n. (SKK 26790, b8788, 8816, 8827-8); Gyeongpodae, 18 May 1964, T. B. Lee et al. s.n. (SNUA 25080); Myeonsan Mt., 10 Jun 1990, S. H. Oh s.n. (SNU 74198); Okgye, 20 Jul 1977, W. T. Lee 8060 (KWNU). Seoul-si: Bukhansan Mt., 21 May 1991, C. H. Lee s.n. (SKK b8817); Dobongsan Mt., 5 May 1995, S. K. Cho s.n. (SKK 23846); Gwanaksan Mt., 13 Jun 1979, Y. S. Park s.n. (SNU 49642), 22 May 1981, S. G. Nam s.n. (SNU 52958), 27 May 1985, D. W. Kim s.n. (SNU 72196); Seoul N.U., 16 May 1985, J. H. An s.n. (SNU 71671). Gyeonggi-do: Cheoncheon-dong, 6 Jun 1984, H. K. Choi s.n. (SKK b8830); Daeseong-ri, 13 Jun 1981, S. Y. Byeon, Y. D. Wi s.n. (SKK b8789); Geumgok-ri, 2 Jun 1968, G. J. Hong s.n. (SNU 72170), H. W. Yun s.n. (SNU 72131); Gwangreung, 28 May 1984, M. S. Kim s.n. (SNU 61674); Manho-ri, 17 May $1964, T$. B. Lee et al. s.n. (SNUA 20575, 25070-4, 25076-7, 25081); Soyosan Mt., 29 May 1988, J. Y. Lee s.n. (SKK b8819), W. S. 
Lee s.n. (SKK b8829); Pyeongtaek-si, Eoyeon-ri, 7 Jun 1963, T. B. Lee et al. s.n. (SNUA 25079); Naegi-ri, 7 Aug $1952, T$. B. Lee s.n. (SNUA 25078). Chungcheongbuk-do: Boeun-gun, 8 May ?, M. S. Ha s.n. (SKK b8791). Gyeongsangbuk-do: Bugu-ri, 27 Jul 1980, Y. C. Chung s.n. (SNU 51747), 30 Jun 1981, Y. H. Chung s.n. (SNU 54263); Hyangrobong, 1 Jun 1972, D. W. Lee s.n. (SNU 46059), S. G. Kim s.n. (SNU 46061); Juheulsan Mt., 1 May 1979, S. W. Lee s.n. (SNU 49732); Weolseong, 2 Jul 1981, Y. H. Chung s.n. (SNU 54260, 54262); Wonri-ri, 28 Apr 2016, Y. S. Kim et al. IB-00293 (IN). Jeollabuk-do: Naesosa, 8 May 1989, S. M. Park et al. s.n. (SKK b8790). Jeollanam-do: Hyangrobong, 1 Jun 1972, M. I. Chae s.n. (SNU 46060); Ipamsan Mt., 12 May 1985, G. J. Chung s.n. (SNU 71506-7), 13 May 1985, T. H. Kim s.n. (SNU 71447); Jindo-gun, 1 Aug 1956, T. H. Chung s.n. (SKK b8821-2); Jirisan, 1969.7.19, J. H. Ahn s.n. (SNU 45137); Yoodalsan, 1982.5.18, M. Y. Kim s.n. (SKK b8820). Jejudo: Hallasan, 1960.7.25, T. H. Chung s.n. (SKK b8824-6), 7 Aug 1960, W. T. Lee s.n. (SKK b8823), 30 Apr 1973, W. T. Lee 8059 (KWNU); Kimryeong-ri, ?, S. T. Lee et al. HKI00936 (SKK); Myosanbong, 9 May 2005, S. T. Lee et al. HKI00343 (SKK); Seonheul-ri, 21 Jun 2003, W. L. Chen et al. HKI00341 (SKK); Suweolbong, 11 Jun 2007, S. T. Lee et al. HKI00340, 342 (SKK); ?, 7 Jun 1975, T. B. Lee s.n. (SNUA 25082, 25093).

(14) Potentilla nivea L.

NORTH KOREA. Baekdusan Mt., 13 Aug 1913, T. Nakai 79 (TI), 10 Aug 1914, T. Nakai 2715 (TI), 26 Jul ?, Anonymous s.n. (KYO 10128); Baekmasan Mt., 4 Aug 1917, G. Koidzumi s.n. (KYO); Gwanmobong, 19 Jul 1918, T. Nakai 7160 (TI), Jul 1932, J. Ohwi s.n. (KYO), ?, Anonymous s.n. (KYO 1018), 19 Jul 1936, B. S. Do s.n. (SNU 5523-4); Heunganryeong, Jun 1931, K. yamatsuta s.n. (TI 175); Kankyohokudo, Hakutozan, Jul 1931, T. Ishidoya s.n. (KYO); Mudeungbong, 8 Aug 1914, T. Nakai 2714 (TI).

CHINA. Jangbaeksan, 21 Jun 2006, S. T. Lee et al. HKI01220-4 (SKK).

(15) Potentilla anemonifolia Lehm.

KOREA. Gangwon-do: Bulamsan Mt., 27 May 1989, T. R. Kim s.n. (SKK 26655); Chiaksan Mt., 3 Jun 1989, S. G. Hwang s.n. (SKK 26657); Gongjaksan Mt., 25 May 1979, Y. M. Kim 7954 (KWNU), 1 Jun 1979, W. T. Lee 7955-6 (KWNU); Samaksan Mt., 20 May 1988, S. J. Won s.n. (SKK 26964); Sokcho-beach, 25 Jun 2003, S. T. Lee et al. HKI00184 (SKK). Seoul-si: Bukhansan Mt., 28 May 1988, J. H. Kim s.n. (SKK 26653), M. A. Jeong s.n. (SKK 26654); Dobongsan Mt., 14 Jun $1959, H$. J. No s.n. (SKK 26662-4), 9 Aug 1959, T. H. Chung s.n. (SKK 26675-6, 26680), 27 Jun 1988, B. S. Kim s.n. (SKK 26283), 27 May 1989, J. H. Kim s.n. (SKK 26648); Gwanaksan Mt., 6 Jun 1986, I. S. Kim s.n. (SKK 26762), 6 Jun 1989, H. S. Gwak s.n. (SKK 26960); Jongmyo, 25 Jul 1956, T. H. Chung s.n. (SKK 26667-8). Gyeonggi-do: Bucheon-si, 20 May 1989 , Y. S. Chung s.n. (SKK 26656); Cheoncheon-dong, 6 Jun 1982, G. H. Sim s.n. (SKK 26643), 6 Jun 1984, B. B. Choi s.n. (SKK 26688); Cheonmasan Mt., ? 1983, Y.I. Kim s.n. (SKK 26684), 25 Apr 1987, M. J. Kim s.n. (SNU 71577), 23 May 1988, J. H. Na s.n. (SKK 26650), 4 Jun 1988, G. T. Kim s.n. (SKK 26652); Daeseong-ri, 20 Jun 1981, S. W. Jo, S. H. Choi s.n. (SKK 26701), 21 May 1989, D. H. Kim s.n. (SKK 26884); Daeyami-dong, 1995.5.31, S. T. Lee s.n. (SKK B200508192188); Donggureung, 16 Jun 1965, Y. C. Chung s.n. (SKK 26681); Geumgok-ri, 2 Jun 1985, S. H. Choi s.n. (SNU 71665); Gwanggyojeosuji, 13 Jun 2004, K. I. Heo et al. HKI00102, 127, 129 (SKK); Gwangreung, 12 Jun 1954, T. G. Joo s.n. (SKK 26674$), 15$ Aug 1958, S. T. Lee s.n. (SKK 26673), 31 May 1961, T. H. Chung s.n. (SKK 26677-9), 2 Apr 1972, J. H. Ahn s.n. (SNU 46054), 18 Jun 1972, J. H. Ahn s.n. (SNU 46058), 7 Jun 1981, M. H. Jo, G. S. Jeon s.n. (SKK 26685); Senyoosam-ri, 25 Jun 1982, J. H. Ahn s.n. (SKK 26591, 26637); Siheung-si, 20 Aug 1957, K. T. Kim s.n. (SKK 26665); Songchu, 15 May 1983, M. S. Kim s.n. (SKK 26714); Sorisan Mt., 26 May 1990, E. Y. Shin, J. H. Jo s.n. (SKK 26658), M. G. Jeong, H. J. Lee s.n. (SKK 26647); Soyosan Mt., 26 May 1989, E. Y. Jo s.n. (SKK 26649), S. E. Hong s.n. (SKK 26651); Surisan Mt., 5 Jul 1982 , Y. G. Chung s.n. (SKK 26642), Y. H. Chung s.n. (SKK 26644), 31 May 1995, H. J. Jung s.n. (SKK b23930), 27 May 2003, K. I. Heo, S. H. Kim HKI00103, 119, 121, 124, 128, 182 (SKK), 31 May 2005, M. H. Lim et al. s.n. (SKK A2005071210101); Woojeong-myeon, 23 May 1982, H. J. Kim s.n. (SKK 26645); Yongmunsan Mt., 10 Oct 1959, T. H. Chung s.n. (SKK 26660). Chungcheongbuk-do: Duaksan Mt., 10 Oct 1959, W. T. Lee s.n. (SKK 26659). Chungcheongnam-do: Anmyeondo, 6 Jun 1986, G. R. Park, Y. J. Chung s.n. (SKK 26646); Daedunsan Mt., 31 May 1964, S. H. Park s.n. (SKK 26683); Gayasan Mt., 24 Aug 1956, T. H. Chung s.n. (SKK 26669-70); Gyeryongsan Mt., 23 Aug 1957, T. H. Chung s.n. (SKK 26666); Taejosan Mt., 11 Jun 1988, M. Y. Kim s.n. (SNU 67014). Gyeongsangbuk-do: Yeongyang, 20 May 1982, W. C. Park s.n. (SKK 26592). Jeollabuk-do: Deokyoosan Mt., 4 Aug 1959, T. H. Chung s.n. (SKK 26661), 16 May 1964, W. T. Lee s.n. (SKK 26682). Jeollanam-do: Byeonsan Mt., 13 May 1981, J. Y. Choi, S. J. Sim S.n. (SKK 26686); Cheongryong-ri, 19 May 2002, K. I. Heo et al. HKI00120, 136 (SKK); Jindo-gun, 1 Aug 1956, T. H. Chung s.n. (SKK 26687); Jirisan Mt., 8 May 1987, G. D. Kim 
s.n. (SNU 72407), Y. S. Yang s.n. (SNU 71422). Jejudo: Abuoreum, 22 Jun 2003, W. L. Chen et al. HKI00133 (SKK); Dongbaekdongsan Mt., 21 Jun 2003, W. L. Chen et al. HKI00134 (SKK), 23 Jun 2003, W. L. Chen et al. HKI00125 (SKK), 10 Jun 2007, K. I. Heo et al. HKI00100, 132, 135 (SKK); Donneko, 23 Sep 2004, S. T. Lee et al. HKI00101, 131 (SKK); Hallasan Mt., 30 Jul 2003, K. I. Heo et al. HKI00126, 183 (SKK), 8 May 2005, S. T. Lee et al. HKI00117 (SKK); Myosanbong, 9 May 2005, S. T. Lee et al. HKI00104, 109, 111-2, 116, 118, 130, 185, 935 (SKK), 10 Jun 2007, K. I. Heo et al. HKI00113 (SKK); Ongpo-ri, 10 Jun 2007, K. I. Heo et al. HKI00110, 114-5, 122-3 (SKK); Seoguipo, 23 Jul 1954, T. H. Chung s.n. (SKK 26671-2); Seonheul-ri, 23 May 2004, S. T. Lee et al. HKI00105-8, 137 (SKK).

(16) Potentilla cryptotaeniae Maxim.

KOREA. Gangwon-do: Baekamsan Mt., 28 Jul 2003, G. E. Yoo 526 (KWNU); Balwangsan, 2000.6.19, C. H. Lee et al. HKI00289 (SKK); Chiaksan, 29 Jul 1975, W. T. Lee 8004 (KWNU), 5 Jul 1990, Y. J. Chung et al. s.n. (SKK 24384); Daeamsan Mt., 31 Jul 1990, W. T. Lee 8016 (KWNU), 17 Aug 2003, K. I. Heo et al. HKI00220, 236-7, 252-5, 270, 280 (SKK); Daedeoksan Mt., 29 Apr 2006, K. I. Heo, M. H. Yoo HKI00248-9 (SKK); Daeryongsan Mt., 10 Aug 1975, W. T. Lee 8005 (KWNU); Daeseongsan Mt., 12 Jul 1993, S. T. Lee et al. s.n. (SKK b8707-8); Eungboksan, 16 Oct 2004, G. E. Yoo 2112 (KWNU); Garasan Mt., 7 Jul 1979, W. T. Lee 8007 (KWNU); Gariwangsan Mt., 21 Jul 1995, S. T. Lee, C. H. Lee s.n. (SKK B200508182191-2); Gayasan Mt., 25 Aug 1971, W. T. Lee 8001 (KWNU); Gongjaksan Mt., 10 Aug 1977, K. M. Yoon 8008 (KWNU), 4 Sep 1979, W. T. Lee 8012 (KWNU); Gyebangsan Mt., 26 Jul 2003, K. I. Heo et al. HKI00287 (SKK); Hwaaksan Mt., 7 Jun 1975, W. T. Lee 8003 (KWNU); Jeombongsan Mt., 11 Aug 2005, S. T. Lee et al. HKI00239, 247, 913 (SKK), 24 Aug 2006, K. I. Heo HKI00233-4, 261-2 (SKK); Naksansa, 26 Jul 2003, K. I. Heo et al. HKI00256 (SKK); Obongsan Mt., 4 Sep 1977, S. S. Shin 8009 (KWNU), W. T. Lee 8010 (KWNU); Odaesan Mt., 14 Jun 1986, S. T. Lee, Y. J. Chung s.n. (SKK 26780), 5 Jun 2004, K. I. Heo, J. E. Go HKI00216, 281 (SKK), 18 Sep 2004, K. I. Heo, J. E. Go HKI00212-5, 217, 221-3, 230-2, 238, 257-8, 269, 272, 274-7, 279, 282-3, 286, 288, 912 (SKK); Samaksan Mt., 9 Sep 1973, W. T. Lee 8002 (KWNU), 8 Aug 1979, W. T. Lee 8011 (KWNU); Seolaksan Mt., 16 Jul 1995, C. H. Lee s.n. (SKK); Taebaeksan Mt., 24 May 2002, S. T. Lee et al. HKI00918-21 (SKK), 16 Sep 2006, K. I. Heo et al. HKI00218-9, 235 (SKK); Yonghwasan Mt., 4 Jul $1976, B$. I. Yoon 8006 (KWNU). Gyeonggi-do: Gwangdeoksan Mt., 12 Oct 1992, W. T. Lee 8017 (KWNU), 1 May 2005, C. H. Lee, K. I. Heo HKI00250 (SKK), 5 Jul 2005, K. I. Heo et al. HKI00268, 271, 273 (SKK); Taehwasan Mt., 12 Jul 2003, K. I. Heo HKI00226-9. 259-60 (SKK). Chungcheongbuk-do: Sobaeksan Mt., 18 Jul 2003, K. I. Heo et al. HKI00246, 278,251 (SKK). Jeollabuk-do: Deokyoosan Mt., 4 Aug 1959, T. H. Chung s.n. (SKK b8703-5), 13 Jul 2002, S. T. Lee et al. HKI00284-5 (SKK), 18 Oct 2006, K. I. Heo et al. HKI00914-7 (SKK).

NORTH KOREA. Geumgangsan Mt., 25-26 Jul 1928, K. Kondo 8000 (KWNU).

CHINA. Idobaekhwa, 27 Jul 2007, S. T. Lee et al. HKI240-5, 263-7 (SKK).

(17) Potentilla centigrana Maxim.

KOREA. Gangwon-do: Chuncheon-si, Jungdo, 5 May 1975, W. T. Lee 8153 (KWNU), 15 May 1982, W. T. Lee 8162 (KWNU); Dutasan Mt., 1993.5.15, J. C. Chung et al. s.n. (SKK b8730); Gyebangsan Mt., 16 Jun 1993, G. E. Yoo, W. T. Lee 8174 (KWNU); Jeombongsan Mt., 20 Jun 1992, W. T. Lee 8171 (KWNU), 11 Aug 2005, S. T. Lee et al. HKI00197-200 (SKK), 21 Jun 2006, S. T. Lee et al. HKI183, 192-6, 901 (SKK); Odaesan Mt., 14 Jun 1986, S. T. Lee et al. s.n. (SKK 26852, 268601), 6 Jun 2000, C. H. Lee et al. HKI00211 (SKK), 18 May 2003, S. T. Lee et al. HKI00187 (SKK), 3 Aug 2003, S. T. Lee et al. HKI00210 (SKK), 3 Jun 2004, G. E. Yoo 2026 (KWNU), 4 Jun 2004, K. I. Heo, J. E. GoHKI00182, 184-6, 188-191, 2016, 208-9, 900 (SKK), 26 Jul 2004, G. E. Yoo 2027 (KWNU); Samyeongsan Mt., 28 May 1983, W. T. Lee 8163 (KWNU). Seoul-si: Dobongsan Mt., 27 Jun 1988, S. H. Kim s.n. (SKK b8727). Jeollanam-do: Hyeonsan-myeon, 13 Apr 2003 , K. I. Heo, J. E. GoHKI00207 (SKK). Jejudo: 5 May 1975, W. T. Lee 8154 (KWNU). ?, 20 Jun 1897, V. Komarov 895 (TI);

NORTH KOREA. Geumgangsan, 23-24 Jul 1928, K. Kondo s.n. (TI 223); Hamgyeongnam-do, 19 Aug 1935, T. Nakai s.n. (TI 15543).

\section{(18) Potentilla amurensis Maxim.}

KOREA. Gangwon-do: Baekunsan Mt., 26 May 2003, E. S. Jeon ESJeon30397 (KH). Seoul-si: Nanji-do, 28 May 1993 , S. H. Park L961 (KH), 30 Apr 2000, S. H. Park s.n. (KH 13915), 1 May 2002, S. H. Park ParkSH21028, 35, 37, 60 (KH). Gyeonggi-do: Sannam-ri, 14 May 2003, S. H. Park ParkSH30679 (KH); Yangpyeong-gun, 15 May 2002, E. S. Jeon s.n. (KH). Chungcheongbuk-do: Wolalksan Mt., 3 May 2002, S. H. Park ParkSH21214 (KH). Chungcheongnam-do: Hwoeseonghyugyeso, 9 May 2002, E. S. Jeon s.n. (KH). Gyeongsangbuk-do: Gyeongju-si, 9 May 2002, E. S. Jeon L678 (KH). 
Gyeongsangnam-do: Changnyeong-gun, 17 May 2004, E. S. Jeon ESJeon40790 (KH); Yeonhwasan Mt., 18 Apr 2003, W. K. Paek eong3-030418-0189 (KH).

(19) Potentilla supina subsp. paradoxa (Nutt. et Torr \& A. Gray) Soják

KOREA. Gangwon-do: Cheolwon-gun, 18 Jun 1987, W. T. Lee 8141 (KWNU); Chuncheon-si, 15 Jun 1976, B. K. Yoon 8132 (KWNU), 8 Jul 1980, W. T. Lee 8136 (KWNU), 13 Jul 1983, W. T. Lee 8138 (KWNU); Gyeongpo-beach, 15 Jun 2004, K. I. Heo, J. E. Go HKI00144-5 (SKK); Hwacheon-gun, 16 Jun 1987, W. T. Lee 8139 (KWNU); Ingu-beach, 26 Aug 2004, K. I. Heo et al. HKI00158-9, 174, 180-1 (SKK), 29 Jun 2007, K. I. Heo, S.W. Lee HKI00177-9, 225 (SKK); Jeonjin-beach, 16 Aug 2003, K. I. Heo et al. HKI00164-5, 170 (SKK); Naksan-beach, 14 May 2004, K. I. Heo, J. E. Go HKI00171-2, 175 (SKK); Sokcho-beach, 14 May 2004, K. I. Heo, J. E. Go HKI00147-8, 155, 166-8, 173, 157 (SKK); Songjiho-beach, 15 Aug 2003, K. I. Heo et al. HKI00138-140, 160-162 (SKK); Susang-ri, 17 Jun 1987, W. T. Lee 8140 (KWNU), 8 Aug 1987, W. T. Lee 8144 (KWNU); Yanggu-gun, 11 Jun 2004, G. E. Yu 2030-1 (KWNU); Yeonyeopsan Mt., 20 Jul 1997, W. T. Lee 8148 (KWNU); Yeongrangho, 18 Jul 1977, W. T. Lee 8134 (KWNU); Yonghwasa, 15 Jun 1977, B. G. Yoon 8133 (KWNU). Seoulsi: Sinsa-dong, 5 May 1992, S. H. Park 8147 (KWNU). Gyeonggi-do: Ansan-si, Oct 1995, S. H. Park s.n. (KH KNAH014132); Deokso-ri, 25 May 1971, W. T. Lee 8129 (KWNU); Hagwanggyo-jeosuji, 13 Jun 2004, K .I. Heo et al. HKI00146, 149, 150, 156, 176 (SKK); Sangjeonghosu, 16 Jun 1974, W. T. Lee 8130 (KWNU). Incheon-si: Ganghwado, 30 Jun 1967, Y. H. Chung, Y. S. Kang s.n. (SNU 40704), 24 Jun 1968, Y. H. Chung, Y. S. Kang s.n. (SNU 43138, 140, 145), 5 Aug 1969, Y. S. Kang s.n. (SNU 44279). Chungcheongnam-do: Gyeryongsan Mt., 29 Jul 1979, W. T. Lee 8135 (KWNU). Jejudo: Gosan-ri, 21 Jun 2003, W. L. Chen et al. HKI00169 (SKK).

CHINA. Jangbaeksan, 21 Jun 2002, S. T. Lee et al. HKI00141-3, 151-4, 163 (SKK).

(20) Potentilla fragarioides var. major Maxim.

KOREA. Gangwon-do: Baekdamsa, 23 Sep 1966, T. B. Lee et al. s.n. (SNU); Bukbaesan Mt., 11 Apr 1976, W. T. Lee 8073 (KWNU); Bulamsan Mt., 8 Apr 1989, S. W. Park, J.H.Gu s.n. (SKK 26887, 26893); Chiaksan Mt., 6 Jun 19956, S. Y. Park s.n. (SKK b23923); Daeamsan Mt., 13 May 2000, C. S. Chang s.n. (SNU); Daedeoksan Mt., 10 Sep 1973, S. D. Kim, G. H. Sin s.n. (KNU), 18 May 2004, K. I. Heo, J. E. Go s.n. (SKK A200507271029), 18 Jun 2005, K. I. Heo et al. HKI01118 (SKK), 29 Apr 2006, K. I. Heo, M. H. Yoo HKI 01062-6 (SKK); Dongdaesan Mt., 16 May 1996, W. T. Lee 8098 (KWNU); Dutasan Mt., 7 May 1987, Y. J. Chung s.n. (SKK 26878), 14 May 1990, H. K. Seol et al. s.n. (SKK 26944), H. Y. Lee et al. s.n. (SKK 26957), J. H. Kim et al. s.n. (SKK 26285), 15 May 1990, S. T. Kim s.n. (SKK 26890); Gariwangsan Mt., 11 Jun 1993, T. B. Lee s.n. (SNU), 23 Apr 2006, K. I. Heo, J. E. Gos.n. (SKK B200507222118, B200507222120); Geumdaebong, 13 May 2001, C. H. Lee et al. HKI00733 (SKK); Gongjaksan Mt., 14 May 1979, W. T. Lee 8081 (KWNU); Gyebangsan Mt., 26 Jul 2003, K. I. Heo et al. s.n. (SKK); Hambaeksan Mt., 4 May 1999, W. T. Lee 8102-3 (KWNU); Jeombongsan Mt., 1 May 2006, K. I. Heo et al. HKI00814-5, HKI01070 (SKK), 12 May 2007, S. T. Lee et al. HKI01053 (SKK); Myeonsan Mt., 26 May 1993, T. B. Lee s.n. (KH), 11 Jun 1993, T. B. Lee s.n. (KH), 30 Apr 2006, K. I. Heo et al. HKI01071-2 (SKK); Naksansa, 13 May 2004, K. I. Heo, J. E. Go HKI01132-6 (SKK); Obongsan Mt., 2 May 1989, W. T. Lee 8096 (KWNU); Odaesan Mt., 14 Jun 1986, S. T. Lee et al. s.n. (SKK 26875), 5 Jun 1988, S. W. Lee s.n. (SKK 26778), 6 Jun 2000, C. H. Lee et al. s.n. (SKK B200507112038-9, B200507112041), 18 May 2003, S. T. Lee et al. HKI01127-8, HKI01091, HKI00895-6 (SKK), 5 Jun 2004, K. I. Heo, J. E. Go HKI01081-5 (SKK); Oeongchi-beach, 30 Jul 2005, K. I. Heo et al. HKI01076-9 (SKK); Samaksan Mt., 18 Apr 1981, W. T. Lee 8082 (KWNU), 23 Apr 1983, W. T. Lee 8087-8 KWNU); Samcheoksi, Hujin, 21 May $1999, J$. H. Lee s.n. (SKK B200507112040); Seolaksan Mt., 11 May 2007, S. T. Lee et al. HKI01034-6, HKI01051-2, HKI01061 (SKK); Taebaeksan Mt., 11 May 1996, Y. S. Gueon et al. s.n. (SKK b24492), G. H. Lee et al. s.n. (SKK), J. H. Kim et al. s.n. (SKK), 16 Jun 1996, J. S. Song 87 (SNU 86728), 28 Apr 2002, K. I. Heo et al. s.n. (SKK), 2 May 2004, K. I. Heo et al. HKI01101, HKI01103-14, HKI01142, HKI01145 (SKK), S. J. Kim et al. s.n. (SKK), 5 Jun 2004, K. I. Heo, J. E. Go s.n. (SKK A200507271025), 15 May 2005, S. T. Lee et al. s.n. (SKK B200507222138-9), N. I. Gong et al. s.n. (SKK B200507222135-6), H. S. Ha et al. s.n. (SKK), S. T. Lee et al. HKI01143-4 (SKK), ?, I. S. Lim et al. s.n. (SKK); Yanggugun, Palrangri,17 Aug 2003, K. I. Heo et al. s.n. (SKK); Yeongok-beach, 4 Jun 2004, K. I. Heo, J. E. Go HKI00897 (SKK A200507222163-4, A200507222172). Seoul-si: Banpo, 1 May 1996, G. M. Yun s.n. (SKK); Bukhansan Mt., 22 Apr $1962, W$. T. Lee s.n. (SKK26931), 8 May 1962, W. T. Lee s.n. (SKK26930), 28 May 1988, W. Y. Kim s.n. (SKK 26965), 26 May 1991, B. Sim s.n. (SKK 26804); Dobongsan Mt., 27 Apr 1955, W. T. Lee s.n. (SKK 26921-2), 19 May 1955, W. T. Lee s.n. (SKK 26730), 13 Aug 1958, W. T. Lee s.n. (SKK 26612), 29 May 1960, Y. S. Chung s.n. (SKK 26920), 5 May 1993, S. O. Jo s.n. 
(SKK b8597), M. A. Seong s.n. (SKK 10103), M. J. Kim s.n. (SKK), Y. H. Chang s.n. (SKK b8598); Gwanaksan, 1982.5.? Y. J. Ji s.n. (SKK 26866), 12 Apr 1992, B. J. Kim s.n. (SKK b8948), 27 Mar 1994, S. K. Oh s.n. (SNU 79149); Neung-dong, 27 Apr 1996, T. H. Chung s.n. (SKK); Wooi-dong, 28 Jun 1959, T. H. Chung s.n. (SKK 26894-8). Gyeonggi-do: Anyang-si, ?, S. S. Kim s.n. (SKK 26910-2); Bogwangsa, 7 May 1983, S. S. Yeom s.n. (SKK 26708); Bugok-dong, 25 Apr 1993, E. Y. Chang s.n. (SKK b8946); Bundang-gu, 21 Apr 1996, J. H. Choi s.n. (SKK), J. Y. Kim s.n. (SKK); Cheolmasan Mt., ? Mar 1994, J. Y. Chang, E. J. Kim s.n. (SKK b8965-6); Cheonggyesan Mt., 27 Mar 1994, B. W. Han s.n. (SKK b8964), 20 Apr 1996, Y. J. Kim s.n. (SKK); Cheonmasan Mt., 12 Apr 1992, B. H. Choi s.n. (SKK 23815), 9 Apr 1994, H. H. Yoo s.n. (SKK b8949), H. J. Eom s.n. (SKK b8963), 30 Apr 1994, J. H. Jo s.n. (SKK b8970), K. S. No s.n. (SKK b8957), 1 May 1994, J. W. Park s.n. (SKK b8980), 30 Mar 2002, S. T. Lee et al. HKI01119 (SKK); Chukryeongsan, 27 Apr 1991, S. W. Park, S. W. Lee s.n. (SKK 26636), 1996.4.13, J. Y. Park s.n. (SKK), 2005.4.5, M. H. Im et al. s.n. (SKK B200507222053), 27 Apr 2007, K. I. Heo et al. HKI01049 (SKK); Gapyeong-gun, 5 May 1993, M. K. Jo s.n. (SKK 10100), J. C. Chung s.n.(SKK 10108$), 7$ May 1995, J. H. Ahn s.n. (SKK B200508192081), 28 Apr 1996, B. H. Park s.n. (SKK); Gwanak arboretum, 7 Apr $2003, S$. T. Lee et al. s.n. (SKK); Gwangdeoksan, 27 Apr 2005, S. T. Lee et al. HKI01129 (SKK), 5 Jul 2004, S. T. Lee et al. HKI0108890 (SKK); Gwanggyosan Mt., 17 Apr 1993, S. T. Lee s.n. (SKK b8947), J. E. Han s.n. (SKK b8926), H. J. Gang s.n. (SKK b8927), 13 Jun 2004, K. I. Heo, J. E. Go HKI01087, HKI01097 (SKK); Gwangju-si, 9 Aug 1985, Y. W. Kim s.n. (SKK 26906); Gwangreung, 1 May 1954, W. T. Lee s.n. (SKK 26927-8), 14 Oct 1954, T. H. Chung s.n. (SKK 26615), 12 Jun 1955, Anonymous s.n. (SKK 26609-10, 26615, 26902-4), 17 Aug 1957, M. W. Lee s.n. (SKK 26924-5), 14 Oct 1984, T. H. Chung s.n. (SKK 26614); Hantaek botanical garden, ?, S. T. Lee et al. s.n. (SKK B200507222073-4); Hwayasan, 27 Mar 2004, K. I. Heo et al. s.n. (SKK A200507271017), 5 Apr 2005, J. Kim et al. s.n. (SKK B200507222058); Ildong-myeon, 6 Aug 1958, H. Y. Mun s.n. (SKK 26909); Munaksan Mt., 27 May 1989, J. Y. Kim s.n. (SKK 26288); Myeonggisan Mt., 18 Apr 1993, J. H. Yang s.n. (SKK b8953), E. S. Lee s.n. (SKK b8766), J. M. Oh s.n. (SKK 10101), 1993.5.5, P. W. Shin s.n. (SKK b8925), H. I. Kim s.n. (SKK 10104), 16 Apr 1994, G. H. Chung s.n. (SKK b8969); Seooreung, 10 Apr 1966, T. H. Chung s.n. (SKK 26869-74); Siheung-si, Gujungmul, 21 May 1990, H. I. Kim s.n. (SKK 26633); Sorisan Mt., 26 May 1990, E. Y. Shin, J. H. Jo s.n. (SKK 26889); Soyosan Mt., 3 Aug 1960, T. H. Chung s.n. (SKK 26932-3), 4 Aug 1960, T. H. Chung s.n. (SKK 26899-26901), 17 Apr 1983, W. J. Chung s.n. (SKK 26694), J. S. Joo s.n. (SKK 26273), S. H. Lee s.n. (SKK 26599), 19 Apr 1983, M. S. Seon s.n. (SKK26279), 28 May 1988, Y. J. Park s.n. (SKK 26970); Surisan Mt., 24 Apr 1944, S. O. Lee, S. Y. Lee s.n. (SKK b8950), 30 Apr 1994, J. J. Yun s.n. (SKK b8945), Y. H. Jo s.n. (SKK b8971), I. G. Yun s.n. (SKK 10116), 31 May 1995, Y. C. Kim s.n. (SKK b23915), 1996.4.19, S. G. Kim s.n. (SKK), J. H. Kim s.n. (SKK), 24 Apr 1996, S. Y. Kim s.n. (SKK), S. Y. Yoo s.n. (SKK), 8 Apr 2005, K. I. Heo et al. HKI01124 (SKK B200507222076); Suwon-si, 28 Jun 1982, S. G. Lee s.n. (SKK 26353), 21 Jun 1986, T. R. Gueon s.n. (SKK 26784); Woonaksan Mt., 28 Apr 1991, W. G. Baek, S. C. Chang 8097 (KWNU); Yeomgwangsuryeonwon, 6 May 2004, S. T. Lee et al. HKI01123, HKI01137 (SKK); Yongmunsan Mt., 11 May 2003, S. T. Lee et al. HKI00898 (SKK); Yumyeongsan Mt., 30 Apr 2006, C. H. Lee et al. s.n. (SKK). Incheon-si: Bupyeong-dong, 15 Aug 1958 , J. S. Chung s.n. (SKK 26913); Deokjeok-do, 24 May 1963, W. T. Lee s.n. (SKK 26611), 22 May 1986, M. R. Joo s.n. (SKK 26275, 26940), C. G. Baek et al. s.n. (SKK 26939), 23 May 1986, Anonymous s.n. (SKK 26862-3, 26877, 26937-8, 26941, 26949), 26 May 1986, Anonymous s.n. (SKK 26936); Eulwang-ri, 25 Aug 2004, K. I. Heo et al. HKI01099, HKI01100 (SKK); Ganghwa-do, 29 Jul 1958, T. H. Chung s.n. (SKK 26907-8); Mansu-dong, 25 Apr 1993, B. Y. Kim s.n. (SKK b8764); Songdo, 30 Apr 1993, D. Y. Han s.n. (SKK b8967). Chungcheongbuk-do: Duaksan Mt., 9 Oct 1959, W. T. Lee s.n. (SKK 26905); Hwaam-dong, 7 May 1983, H. S. Jo s.n. (SKK 26695), 1 May 1954, Y. H. Yoo s.n. (SKK 26935); Jecheon-si, 28 Nov 2004, T. Y. Kim s.n. (SKK); Sobaeksan Mt., 19 May 1995, K. A. Suh et al. s.n. (SKK B200508192002), 20 May 1995, S. H. Kim et al. s.n. (SKK B200508192118), 20 May 2006, C. H. Lee et al. HKI01040-8, HKI01054 (SKK), 7 May 1973, S. G. Lee s.n. (KNU 8445), 9 May 1973, S. I. Na s.n. (KNU 8466), 20 May 1973, S. G. Lee s.n. (KNU 8800); Weolaksan Mt., 27 May 1990, C. B. An et al. s.n. (SKK 26945), 5 Apr 2002, S. T. Lee et al. HKI01096, HKI01093 (SKK). Chungcheongnam-do: Anmyeondo, 20 Aug 1956, T. H. Chung s.n. (SKK 26616); Cheonripo, 26 Sep 1980, Y. I. Ahn s.n. (SKK 26716); Daedunsan Mt., 20 Jul 1959, S. H. Park s.n. (SKK 26929); Daenangido, 17 May 1965, Lee, Chung s.n. (SKK 26928); Dangjin-myeon, 18 May 2001, S. T. Lee et al. HKI01139 (SKK); Gayasan Mt., 24 Aug 1956, T. H. Chung s.n. (SKK 26919); Geumseulsan Mt., 18 Apr 1959, S. Y. Oh s.n. (KNU 13308); Gyeryeongsan Mt., 3 Aug 1984, T. H. Chung s.n. (SKK 26613 ), 22 Jun 1988, W. S. Lee s.n. (SKK 26971); Manripo, 19 May 1984, Anonymous s.n. (SKK 26865, 26876); Sapkyocheon, 8 May 1983, M. H. Kim s.n. (SKK 26702). Gyeongsangbuk-do: Bohyeonsan Mt., 27 Aug 1998, J. H. Park et al. 4680 (KNU); Bulguksa, 13 
May 1973, C. H. Lee s.n. (KNU 9461); Geumosan Mt., 31 May 2003, W. L. Chen et al. HKI0088-9, HKI01116 (SKK); Sangjusi, 6 May 1990, M. S. Ha s.n. (SKK 26632); Woondalsan, 2000.4.29, C. S. Chang s.n. (SNU). Daegu-si: Biseulsan, 1958.10.20, S. Y. Oh s.n. (KNU), 18 Apr 1997, J. H. Park et al. s.n. (KNU 4000); Kyeongbuk Univ., 18 Apr 1977, Anonymous (KNU 10696); Palgongsan Mt., 26 Apr 1960, S. Y. Oh 3854 (KNU), 27 May 1989, Y. J. Lee s.n. (KNU), 1 Jun 2003, W. L. Chen et al. HKI00887 (SKK). Gyeongsangnam-do: Garasan Mt., 25 Apr 2005, C. H. Lee et al. HKI01117, HKI01120, HKI01126 (SKK); Geumsan, 14 May 1988, S. J. Won et al. s.n. (SKK 26888), G. T. Kim et al. s.n. (SKK 26842), W. S. Lee et al. s.n. (SKK 26962), S. H. Kim et al. s.n. (SKK 26956); Gunghang-ri, 24 Apr 1994, H. J. Lee s.n. (KNU 7); Mangwoonsan Mt., 19 May 2000, C. H. Lee et al. s.n. (SKK 25045); Wonhyosan Mt., 21 Aug 2002, S. W. Park et al. s.n. (KNU 106). Busan-si: Geumjeongsan Mt., 26 Apr 1992, S. T. Kim s.n. (SKK b24090). Ulsan-si: Sinbulsan, 5 Apr 2003, S. H. Jo et al. s.n. (KNU 382). Jeollabuk-do: Deokyusan, 2 Aug 1959, H. H. Chung s.n. (SKK 26904); Naejangsan Mt., 14 Jun 2002, K. I. Heo, E. J. Kim HKI00892-4 (SKK); Seonwoonsan Mt., 3 May 2007, S. T. Lee et al. HKI01050, HKI01067-9 (SKK). Jeollanam-do: Bangjukpo, 9 Aug 2003, K. I. Heo, J. E. Go s.n. (SKK); Bongraesan Mt., 10 Aug 2003, K. I. Heo, J. E. Go HKI00725 (SKK); Heuksando, 12 Apr 2003, W. L. Chen et al. s.n. (SKK); Hongdo, 12 Apr 2003, W. L. Chen et al. HKI01115, HKI01138 (SKK); Hyeonsan-myeon, 2003.4.13, W. L. Chen et al. HKI01125, HKI01166 (SKK); Jindo, 14 Apr 2003, W. L. Chen et al. HKI891 (SKK); Namwon-si, 10 Apr 1994, S. Y. Kim s.n. (SKK 23782, 23786); Nojeokbong, 28 Apr 1996, Anonymous s.n. (SKK); Oenarodo, 10 Aug 2003, K. I. Heo, J. E. Go HKI01086, HKI01092, HKI01094-5 (SKK). Jejudo: Chujado, 17 Jul $1985, S$. T. Lee s.n. (SKK 26943); Hallasan, 20 Jun 2003, W. L. Chen et al. HKI00890 (SKK); Myosanbong, 9 May 2005, S. T. Lee et al. s.n. (SKK B200507222160); Ongpo-ri, 10 Jun 2007, K. I. Heo et al. HKI00715-6 (SKK).

NORTH KOREA. Geumgangsan Mt., 10 May 1936, B. S. Do s.n. (SNU 5518).

CHINA. Idobaekhwa, 27 Jul 2007, S. T. Lee et al. HKI01080, HKI01141 (SKK); Jangbaeksan Mt., 21 Jun 2002, S. T. Lee et al. HKI01165, HKI01167-8 (SKK).

(21) Potentilla stolonifera var. quelpaertensis Nakai

KOREA. Gyeonggi-do: Hantaek botanical garden, 28 Mar 2004, K. I. Heo HKI00763 (SKK); 10 Apr 2004, K. I. Heo HKI00748-62 (SKK). Jejudo: Dongbaekdongsan Mt., 10 Jun 2007, K. I. Heo et al. HKI00434-5, 717, 720-1 (SKK); Hallasan Mt.: 5 Oct 1913, T. Nakai s.n. (SNUA 25452), 23 May 1971, T. B. Lee s.n. (SNUA 25451), 21 Jun 2003, W. L. Chen et al. HKI00712 (SKK), Eorimok, $30 \mathrm{Jul}$ 2003, K. I. Heo et al. HKI00734-5, 11 Jun 2007, K. I. Heo et al. HKI00722-4 (SKK), Janggumok, 31 Jul 2003, K. I. Heo et al. HKI00736-7 (SKK), Seobukbyeok, 21 Jun 2007, S. R. Lee et al. s.n. (SKK), Witseoreum, 21 Jun 2003, W. L. Chen et al. HKI00832 (SKK), 30 Jul 2003, K. I. Heo et al. HKI00719 (SKK), Yeongsil, 30 Jul 2003, K. I. Heo et al. HKI00739-40 (SKK), 22 May 2004, S. T. Lee et al. HKI00731, 742-5 (SKK), 8 May 2005, S. T. Lee et al. HKI00732, 741, 746-7, 768 (SKK); Myosanbong, 9 May 2005, S. T. Lee et al. HKI00726-9 (SKK); Sangunburi, 22 Jun 2003, W. L. Chen et al. HKI00713 (SKK); Weolseong, 23 Jun 2003, W. L.Chen et al. HKI00718 (SKK); ?, 5 Jun 1975 , T. B. Lee s.n. (SNUA 25457), 6 Jun 1975, T. B. Lee s.n. (SNUA 25453, 25455-6).

(22) Potentilla freyniana Bornm.

KOREA. Gangwon-do: Baekdeoksan Mt., 2 May 1986, W. T. Lee 8014-5 (KWNU); Cheongoksan Mt., 15 May $1993, S$. T. Lee et al. s.n. (SKK 23769); Chiaksan Mt., 9 May 1976, W. T. Lee 8107 (KWNU), 27 May 1995, S. S. Jo s.n. (SKK B200508192109), 3 May 2002, S. T. Lee et al. HKI00821 (SKK); Chunseong, Dongmyeon, 30 May 1987, W. T. Lee 8117-8 (KWNU); Daeryongsan Mt., 20 Apr 1975, W. T. Lee 8104-5 (KWNU), 9 May 1983, W. T. Lee 8013 (KWNU); Dutasan Mt., 7 May 1987, Y. J. Chung s.n. (SKK); Gariwangsan Mt., 23 Apr 2005, K. I. Heo, J. E. Go HKI00806 (SKK); Myeongseongsan Mt., 27 Apr 1989, W. T. Lee 8120-1 (KWNU); Naksansa, 2004.5.14, K. I. Heo, J. E. Go HKI00615-8, 00817, 01216 (SKK); Odaesan Mt., 26 Apr 1998, H. W. Lee, S. J. Lee s.n. (SNU); Taebaeksan Mt., 16 Jun 1996, J. S. Song s.n. (SNU 86706). Seoul-si: Bukhansan Mt., 6 Jul 2006, S. T. Lee et al. HKI00607-8 (SKK); Dobongsan Mt., 5 May 1993, H. Y. Chung s.n. (SKK b8598), M. J. Kim s.n. (SKK 10102), 8 May 1993, S. J. Yeo s.n. (SKK 10115, 10170); Gwanaksan Mt., 29 May 1993, W. Y. Yu, S. I. Lee s.n. (SNU 77213); Neun-dong, 27 Apr 1996, S. H. Park s.n. (SKK); Wooi-dong, 28 Jun 1959, T. H. Chung s.n. (SKK). Gyeonggi-do: Cheonggyesan Mt., 27 May 1990, S. S. Kim s.n. (SKK b8860); Cheonmasan Mt., 3 May 1985 , J. O. Hyeon s.n. (SNU 62468), 26 May 1990, B. W. Choi s.n. (SKK b8857, 8938), D. Y. Seo s.n. (SKK b8936-7), 27 Apr 1991, E. Y. Choi s.n. (SNU 79893), 30 Apr 1994, J. H. Jo s.n. (SKK 10109), 5 May 1998, J. H. Suh s.n. (SNU 89182); Gwangdeoksan Mt., 28 May 2005, S. T. Lee, K. I. Heo HKI01212, 01214-5 (SKK), 5 Jul 2005, K. I. Heo et al. HKI01209-10 (SKK); Gwanggyosan Mt., 13 Jun 2004, K. I. Heo, J. E. Go s.n. (SKK B200508182145); Gwangreung, 30 Apr 1933, B. S. Do, H. J. 
Sim s.n. (SNU 5526), 15 May 1960, J. J. Han s.n. (SKK b8836, 8864-5), K. J. Aem s.n. (SKK b 8866-7), Y. K. Yun s.n. (SKK b8863), 17 Apr 1973, J. A. Lee et al. s.n. (SNU 47387); Myeongjisan Mt., 27 May 1990, G. H. Yu s.n. (SKK b8858), Y. J. Kim s.n. (SKK b8861), 5 May 1993, S. Lee s.n. (SKK 10111), 16 Apr 1994, B. W. Han s.n. (SKK10114), G. H. Chung s.n. (SKK b8969), Y. H. Kim s.n. (SKK 10113); Paldalsan Mt., 24 May 1995, B. Y. Park s.n. (SKK B200508192227); Soyosan Mt., 3 Aug 1960, T. H. Chung s.n. (SKK b8837-8); Surisan Mt., 24 Apr 1994, S.O.Lee, S. Y. Lee s.n. (SKK 10112$)$, 16 May 2005, K. I. Heo et al. HKI00822, 01213 (SKK); Yeongwang-suryeonwon, 16 May 2004, S. T. Lee et al. HKI00586, 816 (SKK); Yongmunsan, 5 May 1983, G. J. Lee s.n. (SKK b8935), 11 May 2003, S. T. Lee et al. HKI00818, 01219 (SKK); ?, 16 Apr 1972, S. G. Kim s.n. (SNU 45749). Incheon-si: Songdo, 30 Apr 1993, D. Y. Han s.n. (SKK b8967). Chungcheongbuk-do: Jincheon-gun, Mujebong, 25 May 1988, W. T. Lee 8119 (KWNU); Minjujisan Mt., 12 May 1989, Y. M. Kim s.n. (SNU 69579); Sobaeksan Mt., 30 May 2006, C. H. Lee et al. HKI00578-9, 00587-590, 592-4, 609 (SKK); Sokrisan Mt., 26 May 1990, Y. J. Oh s.n. (SKK b8856). Chungcheongnam-do: Seosan-gun, Cheonrimun, 26 Sep 1980, Y. I. An s.n. (SKK). Gyeongsangbukdo: Juheulsan Mt., 10 May 1991, J. S. Chung 58 (SNU 80255). Jeollabuk-do: Byeonsan Mt., 1989.5.8, W. R. Lee et al. s.n. (SKK b8841), 6 May 1993, J. Y. Chung, H. J. Jo s.n. (SNU 77142); Naebyeonsan Mt., 5 May 1993.5.5, J. S. Kim, J. H. Yeon s.n. (SNU 77245), J. Y. et al. s.n. (SNU 77074-5), 6 May 1993, J. H. Song et al. s.n. (SNU 77518), 2 May 2007, S. T. Lee et al. HKI00575-6, 585, 591, 598-600 (SKK); Seonwoonsan, 2005.5.5, S. T. Lee et al. HKI00820, 01209, 01217-8 (SKK), 2007.5.3, S. T. Lee et al. HKI00574, 577, 580-4 (SKK). Jeollanam-do: Baekwoonsan Mt., 8 May 1984, Y. D. Kim s.n. (SNU); Hongdo, 12 Apr 2003, W. L. Chen et al. HKI00819 (SKK); Jangchunje, 19 May 2005, H. T. Im. 5184 (CNU); Jogyesan Mt., 3 May 1992, J. Y. Kim et al. s.n. (SKK b8731), S. E. Kim et al. s.n. (SKK b8735); Sotaedong, 9 Aug 1972, S. J. Kim s.n. (CNU 010516-02). Gwangju-si: Mudeungsan, 21 May 2000, H. T. Im. 5714, 5753 (CNU), 28 May 2000, H. T. Im. 5806-7 (CNU), 11 May 2005, H. T. Im. 5387 (CNU). Jejudo: Dongbaekdongsan Mt., 10 Jun 2007, K. I. Heo et al. HKI00601 (SKK); Hallasan Mt., 20 Jun 2003, W. L. Chen et al. s.n. (SKK), 8 May 2005, S. T. Lee et al. HKI01211 (SKK); Ongpo-ri, ?, K. I. Heo et al. HKI00602-6 (SKK); Weoljeong, 23 Jun 2003, W. L. Chen et al. s.n. (SKK); Yongdang-ri, 22 Jun 2003, W. L. Chen et al. HKI00610 (SKK); ?, 7 May 1911, Tauet 5570 (TI 292); ?, Jun 1907, U. Faurie 1579 (TI); ?, K. I. Heo et al. HKI005956 (SKK); ?, 5 May 1933, R. K. Smith s.n. (TI 290).

CHINA. Jangbaeksan Mt., 4 Jun 2006, C. S. Lee s.n. (SKK)

(23) Potentilla squamosa Soják

KOREA. Gangwon-do: Donggang, 29 May 2006, K. I. Heo et al. HKI00624-9 (SKK); Dutasan Mt., 15 May 1990, S. T. Kim s.n. (SKK b8930), 15 May 1993, H. J. Park et al. s.n. (SKK 10105), J. C. Chang s.n. (SKK b8933), 17 Apr 2003, W. L. Chen et al. HKI00597, 632, 634, 641, 648, 809 (SKK); Gariwangsan Mt., 23 Apr 2005, K. I. Heo, J. E. GoHKI00656, 811 (SKK); Hwanseongul, 25 Apr 2007, S. T. Lee et al. HKI00639-40, 651-2, 654, 657 (SKK); Jongjibong, 5 Jan 2001, W. T. Lee 53927-8 (KWNU); Jukdo-beach, 29 Jun 2007, K. I. Heo, S. W. Lee HKI00630-1 (SKK); Myeonsan Mt., 26 May 1990, S. H. Oh s.n. (SNU 74309), 5 May 2000, W. T. Lee 28129 (KWNU), 30 Apr 2006, K. I. Heo et al. HKI00636-8, 649-50, 810 (SKK), 20 Jun 2006, S. T. Lee et al. HKI00932-4 (SKK); Naksansa, 14 May 2004, K. I. Heo, J. E. Go HKI00621, 642-7, 798, 812 (SKK); Odaesan Mt., 26 Apr 1998, H. W. Lee, S. J. Lee 98-103,4 (SNU); Samhwasa, 17 Apr 2003, W. L. Chen et al. HKI00655, 808 (SKK); Seolaksan Mt., ?, T.\&F. Yamazaki s.n. (TI 191); Sogeumgang, 24 May 1986, W. T. Lee 7731, 8116 (KWNU); Sokcho-si, 19 Jul 1977, W. T. Lee 8159 (KWNU). Gyeonggi-do: Gwangreung, ? 2006, J. S. Kim s.n. (SKK). Chungcheongbuk-do: Sobaeksan Mt., 1 May ?, H. G. Choi 505 (SNU); Weolaksan Mt., 16 May 1986, H. K. Park s.n. (SNU), J. Y. Yu s.n. (SNU 61560), M. G. Lee s.n. (SNU 61608), Y. H. Choi s.n. (SNU 61762), 29 Apr 1988, J. H. Lee s.n. (SNU 67973), 5 May 1988, J. H. Lee s.n. (SNU 70403). Gyeongsangbuk-do: Bohyeonsan Mt., 19 Apr 1998, J. H. Park et al. s.n. (KNU 4591); Geomosan Mt., 17 May 1958, W. Kim s.n. (KNU); Juheulsan Mt., 16 May 1988, H. S. Kim, Y. K. Lee s.n. (SNU 65765), S. H. Song, S. B. Chung s.n. (SNU 66609), 10 May 1991, J. S. Shin s.n. (SNU 75073), K. D. Kim s.n. (SNU 75214), Y. B. Ku s.n. (SNU 75154); Mungyeongsaejae, 27 May 2006, S. R. Lee, M. H. Yoo s.n. (SKK). Gyeongsangnam-do: Garasan Mt., 25 Apr 2005, C. H. Lee et al. HKI00622-3 (SKK); Geojedo, Oknyebong, 5 May 1928, T. Nakai s.n. (TI 289); Geojejayeonhyuyangrim, 25 Apr 2005, C. H. Lee et al. HKI633, 635 (SKK); Geumsan Mt., 29 Apr 1928, T. Nakai s.n. (SNU 5525); Mireuksan Mt., 24 Apr 2005, C. H. Lee et al. HKI00620 (SKK). Jeollanam-do: Baekwoonsan Mt., 8 May 1984, Y. D. Kim s.n. (SNU 61552).

(24) Potentilla yokusaiana Makino

KOREA. Gangwon-do: Eungboksan Mt., 6 May 2004, G. E. Yoo 2102 (KWNU); Hwaaksan Mt., 1 May 1977, W. T. Lee 
7852 (KWNU); Jeombongsan Mt., 21 Jun 2006, S. T. Lee et al. HKI665, 686-7, 707, 905-910 (SKK), 12 May 2007, S. T. Lee et al. s.n. (SKK). Gyeonggi-do: Chukryeongsan Mt., 27 Apr 2007, K. I. Heo et al. HKI00685, 706, 710-1 (SKK); Gwangdeoksan Mt., 17 Apr 2005, S. T. Lee, K. I. Heo HKI00673 (SKK), 27 Apr 2004, C. H. Lee et al. HKI00660 (SKK), 1 May 2005, C. H. Lee, K. I. Heo HKI00658-9, 664, 666-8, 670-2, 679, 691, 693-4, 697-705, 708, 826 (SKK), 28 May 2005, S. T. Lee, K. I. Heo HKI00675-6, 681, 709, 827 (SKK), 5 Jul 2005, K. I. Heo et al. HKI00663, 677 (SKK). Chungcheongbukdo: Minjujisan Mt., 1 Jun 2017, Y. S. Kim et al. IB-00782, IB-00625 (IN). Chungcheongnam-do: Jogyesan Mt., 3 May 1992 , G. T. Sim et al. s.n. (SKK b8732), Y. H. Hyeon et al. s.n. (SKK b8733). Gyeongsangbuk-do: Geumosan Mt., 31 May 2003, W. L. Chen et al. HKI00669, 678, 682-3, 00830 (SKK). Daegu-si: Palgongsan Mt., 1 May 2003, W. L. Chen et al. HKI00674, 824-5 (SKK). Gyeongsangnam-do: Geoje-jayeonhyuyangrim, 25 Apr 2005, C. H. Lee et al. HKI00829, 904 (SKK). Jejudo: Hallasan Mt., 18 Jun 1979, Anonymous s.n. (SNU 74497-8), 20 Jun 2003, W. L. Chen et al. HKI00689-90, 823 (SKK), 2003.7.30, K. I. Heo et al. HKI00661 (SKK), 2004.5.22, S. T. Lee et al. HKI00662, 695-6, 828 (SKK), 8 May 2005, S. T. Lee et al. HKI00684, 688, 692 (SKK), 30 Jul 2005, K. I. Heo et al. s.n. (SKK B200508182094). 